\title{
Geothermal Hydrothermal Direct Heat Use: U.S. Market Size and Market Penetration Estimates
}

\author{
A.H. El Sawy \\ D.J. Entingh
}

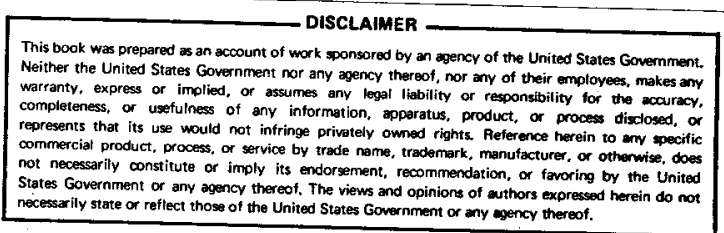

September 1980

MTR-80W81

Sponsor: DOE/DGE

Contract No.: EG-77-C-01-4014

The MITRE Corporation

Metrek Division

1820 Dolley Madison Boulevard.

McLean, Virginia 22102 


\section{DISCLAIMER}

This report was prepared as an account of work sponsored by an agency of the United States Government. Neither the United States Government nor any agency Thereof, nor any of their employees, makes any warranty, express or implied, or assumes any legal liability or responsibility for the accuracy, completeness, or usefulness of any information, apparatus, product, or process disclosed, or represents that its use would not infringe privately owned rights. Reference herein to any specific commercial product, process, or service by trade name, trademark, manufacturer, or otherwise does not necessarily constitute or imply its endorsement, recommendation, or favoring by the United States Government or any agency thereof. The views and opinions of authors expressed herein do not necessarily state or reflect those of the United States Government or any agency thereof. 


\section{DISCLAIMER}

Portions of this document may be illegible in electronic image products. Images are produced from the best available original document. 


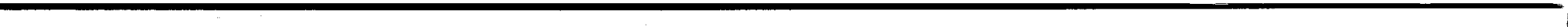


This study estimates the future regional and national market penetration path of hydrothermal geothermal direct heat applications in the United States. A Technology Substitution Model(MARPEN) is developed and used to estimate the energy market shares captured by low-temperature $\left(50^{\circ}-150^{\circ} \mathrm{C}\right)$ hydrothermal geothermal energy systems over the period 1985-2020. The sensitivity of hydrothermal direct heat market shares to various government hydrothermal commercialization policies is examined. Several substantive recommendations to help accelerate commercialization of geothermal direct heat utilization in the United States are indicated and possible additional analyses are discussed. 


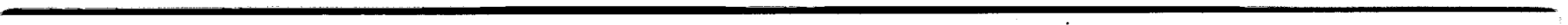


TABLE OF CONTENTS

LIST OF ILLUSTRATIONS

LIST OF TABLES

Page

vii

viil

EXECUTIVE SUMMARY S $\quad$ S-1

1.0 INTRODUCTION $1-1$

1.1 Objectives and Scope of Report $1-5$

2.0 GENERAL APPROACH 2-I

2.1 Overview of the Approach $2-1$

2.2 Elements of the Analysis 2-3

2.3 General Definitions 2-7

3.0 ESTIMATES OF MARKET SIZE 3-1

3.1 Colocated Hydrothermal Baseline Market 3-1

3.1.1 Market Growth Rates 3-14

3.1.2 Baseline Colocated Hydrothermal Market 3-15

to 2020

3.2 Noncolocated Hydrothermal Baseline Market 3-17

4.0 HYDROTHERMAL MARKET SHARES 4-1

4.1 Market Penetration Model 4-1

4.2 Results - Colocated Hydrothermal Markets 4-6

4.2.1 Base Case 4-6

4.2.2 Stimulated Cases 4-7

4.3 Results - Noncolocated Hydrothermal Markets 4-11

4.4 Comparative Impact of Government Support in 4-11

Colocated and Noncolocated Markets

4.5 Sensitivity of Changes in the Propensity to Adopt: 4-13

a New Technology

4.5.1 The U.S. Colocated Market 4-13

4.5.2 The U.S. Noncolocated Market 4-18

4.6 Additional Observations $4-19$

4.6.1 Distribution of Government Stimulation 4-21

4.6.2 Cost Implications 4-25

4.6.3 Sufficiency of Hydrothermal Supply 4-27

5.0 UNCERTAINTIES IN THIS ANALYSIS $\quad 5-1$

5.1 Size of the Resource Base $\quad 5-1$

5.2 Price Escalation of Conventional Fuels $\quad 5-2$

5.3 Unpredicatable Market Sectors 5-2

5.4 Conservation and Waste Heat 5-3 
TABLE OF CONTENTS.

(Concluded)

Page

6.0 UNCERTAINTIES IN THIS ANALYSIS 6-1

6.1 Conclusions 6-1

6.2 Substantive Recommendations 6-3

6.3 Recommendations for Further Analysis 6-4

APPENDIX A REVIEW OF REGIONAL SUPPLY AND DEMAND $A-1$

APPENDIX B BASELINE MARKET DEFINITION $\quad$ B-1

APPENDIX $C$ REVIEW OF MARKET PENETRATION MODELS

APPENDIX D COLOCATED MARKET EXPANSION FACTOR IN $20 \quad$ D-1

YEARS FOR THE PACIFIC AND EASTERN REGIONS IN

THE UNITED STATES

APPENDIX E ESTIMATE OF MARKET PENETRATION RATE PARAMETER E-1

APPENDIX $F$ ESTIMATION OF COST EFFECTIVENESS OF

DIFFERENT LEVELS OF GOVERNMENT BUYS TO

STIMULATE COLOCATED HYDROTHERMAL MARKETS

APPENDIX G COMPARATIVE COST EFFECTIVENESS OF GOVERNMENT G-1

SUPPORT IN COLOCATED VERSUS NONCOLOCATED

MARKETS

APPENDIX H ESTIMATED COST FOR AN INITIAL GOVERNMENT . H-1

BUY OF 0.09 QUADS PER YEAR

REFERENCES

$I-1$ 


\section{LIST OF ILLUSTRATIONS}

Figure

Number

Page

S-1 Hydrothermal Market Penetration. Under Different. S-14 Levels of Government Stimulation To 1985

S-2 Comparative Impact of Same Initial Government S-20 Buy on Colocated Vs. Noncolocated Market. Share Percentages

1-1 Known and Potential Hydrothermal Resources 1-2

1-2 Geographic Boundaries For Study Regions 1-6

3-1 Method for Estimating Initial Hydrothermal 3-2

3-2 Tentative Locations of Market Colocated Low 3-9

Temperature $\left(50^{\circ}-150^{\circ} \mathrm{C}\right)$ Hydrothermal

Resources In The United States

4-1 Hydrothermal Market Penetration Function, 4-5 Takeover Time $=60$ Years

4-2 Effects of Changes in Initfal Government 4-17

Buy and Takeover Time On Hydrothermal.

End Use In Colocated Markets in 2020 
Table

$\underline{\text { Page }}$

Number

S-1 Key Factors Affecting Direct Heat Applicability

S-2 of Hydrothermal Water

S-2 Hydrothermal Baseline Colocated Market-Size

Estimation Factors

S-4

S-3 Baseline Colocated Hydrothermal Markets (1985-2020)

S-6

S-4 Estimation of Non-Colocated Baseline Market

for Hydrothermal Direct Heat Applications

S-8

S-5 U.S. and Regional Noncolocated Hydrothermal

Baseline Market (1985-2020)

S-9

S-6 Base Case Initial Year Hydrothermal Colocated Market Fraction

S-7 Impact of Initial Government Buy on U.S. Colocated Hydrothermal Direct Heat Use, Quads/Year End Use

S-8 Impact of Changes in Takeover Time, $\boldsymbol{r}$, on U.S. Colocated Hydrothermal Market Share $(\mathrm{Q} / \mathrm{Yr})$.

S-9 National and Regional Noncolocated Hydrothermal Direct Heat Market Share With An Initial Government Buy, IGB, Of $0.03 \mathrm{Q} / \mathrm{Yr}$. and $\boldsymbol{\tau}=120$ Years

S-10 Comparative Impact of Government Support In U.S. Colocated Vs. Non-Colocated Markets

1-1 Latest Information On Current and Planned (Up to 1985) Hydrothermal Direct Heat Application in the U.S.

2-1 Main Elements in The Analysis

3-1 Key Factors Affecting Direct Heat Applicability of Hydrothermal Water 
LIST OF TABLES (Continued)

Table

Number

Page

3-8

3-2 Regionally Available Techno-economically

Suitable Hydrothermal Resources For Direct.

Heat Applications

3-3 Regional Colocated Market Population

3-10

3-4 Direct Heat Energy Demand In Resource Colocated

3-11

Markets in Different U.S. Regions

3-5 Resource-Colocated Direct Heat Demand In End-Use

Sectors; Percentage and Quads/Year

3-6 Suitability Index Or Potential of Direct Heat Applications

3-7 Baseline Colocated Markets 1985-2020

3-18

3-8 Estimation of Non-Colocated Baseline Market For Hydrothermal Direct Heat Applications

3-9 U.S. and Reglonal Noncolocated Baseline Market (1985- 3-21 2020) (Queds/Year)

4-1 Base Case Initial Year (1985) Hydrothermal Colocated 4-8 Market Fraction

4-2 Predicted Colocated Hydrothermal Market Shares For : 4-8 The Base Case $\left(s_{c}(t)\right.$, quads/year)

4-3 Impact of Initlal Government Buy On U.S. Colocated Hydrothermal Direct Heat Use (Quads/Year End Use)

4-4 Impact of Inttial Government Buys (IGB), On The Colocated Hydrothermal Market Share (Quads/Yr) In Different Regions In The U.S.

4-5 National and Regional Noncolocated Hydrothermal Direct 4-14 Heat Market Share With An Initial Government Buy, IGB, of $0.01 \mathrm{Q} / \mathrm{Yr}$ in Each Region And $\gamma=120$ Years

4-6 Comparative Impact of Government Support in U.S.: Colocated Vs. Non-colocated Markets 
LIST OF TABLES (Concluded)

Table

Number

Page

4-7 Impact of Changes In Market Penetration Rate

On U.S. Colocated Hydrothermal Market

Share $(Q / Y r)$.

4-8 Impact of Changes In Market Penetration Rate On The U.S. Noncolocated Hydrothermal Market Share (Q/Yr.)

4-9 Impacts Predicted If Initial Government Buys Were Restricted To The West (Quads/Year)

4-10 Comparison of Allocating A Government Buy of 0.03 Quad/Year To Colocated Or Noncolocated Resource Areas (Quads/Year)

4-11 Hydrothermal Supply/Demand Balance

A-1 Sumiary of Direct Heat Activities in the Pacific

$A-4$ Region

C-1 Comparison of Main Features of Common Market Penetration Estimation Methods

D-1 Colocated Market Expansion Factor In 20 Years For The Pacific and Eastern Regions In The United States

\section{D-2 Regional Colocated Market Penetration}

E-1 Effect of Variation In Takeover Time Upon Hydrothermal Direct Use Market Penetration For U.S. (Quads/Year)

F-1 Estimation of Cost Effectiveness of Various Levels of Government Support (IGB) To Stimulate Colocated Hydrothermal Direct Heat Market Share Growth

G-1 Comparative Cost Effectiveness of Government Support G-1 In Colocated Versus Noncolocated Markets 


\section{EXECUTIVE SUMMARY}

\section{INTRODUCTION:}

The federal approach to stimulating geothermal hydrothermal energy resource development has shifted recently to a mission-oriented program aimed at accelerating the commercial utilization of geothermal resources. Successful management of this effort dictates the need for a realistic estimate of the achievable levels of utilization of hydrothermal resources.

This study estimates the regional and national future baseline market and market share of direct (non-electric) utilization of geothermal energy from hydrothermal resources in the United States over the next 40 years. This 40-year period covers the planning horizon of interest to the Department of Energy. Three reglons are analyzed: Pacific, Rocky Mountain Basin and Range, and Eastern.

SCOPE:

Possible direct heat market contributions from Texas and Loulsiana (which are linked to development of geopressured formations), hot dry rock systems, or hydrothermal resources with geofluid temperatures lower than $50^{\circ} \mathrm{C}$ or higher than $150^{\circ} \mathrm{C}$ are not included because these are outside of the main stream of the Federal hydrothermal direct heat program. This study does not quantify the impact of using heat pumps to boost the geofluid temperature to $50^{\circ} \mathrm{C}$ and above.

\section{GENERAL APPROACH:}

Initial analysis work indicated that the growth of hydrothermal direct heat market share would be quite slow, especially in the 1980-2000 perlod, if significant new government initiatives are not undertaken in the near future. Accordingly, the results of the study are presented to emphasize what vartous levels of government (federal plus state) stimulation in the 1981-1985 period could do to accelerate the growth of hydrothermal direct heat installations in the period 1986-2020.

The study was conducted in two distinct phases. First, the baseline market, the direct heat market that could be captured by moderate temperature hydrothermal energy, was estimated for each of the three regions in the period 1985-2020. Second, the rate of market penetration, the rate at which hydrothermal technology can capture portions of the baseline market, was estimated for hydrothermal in each of the same reglons in 1986-2020, based on four different levels of government stimulation in 1981-1985. 
TABLE S-1

KEY FACTORS AFFECTING DIRECT HEAT APPLICABILITY OF HYDROTHERMAL WATER

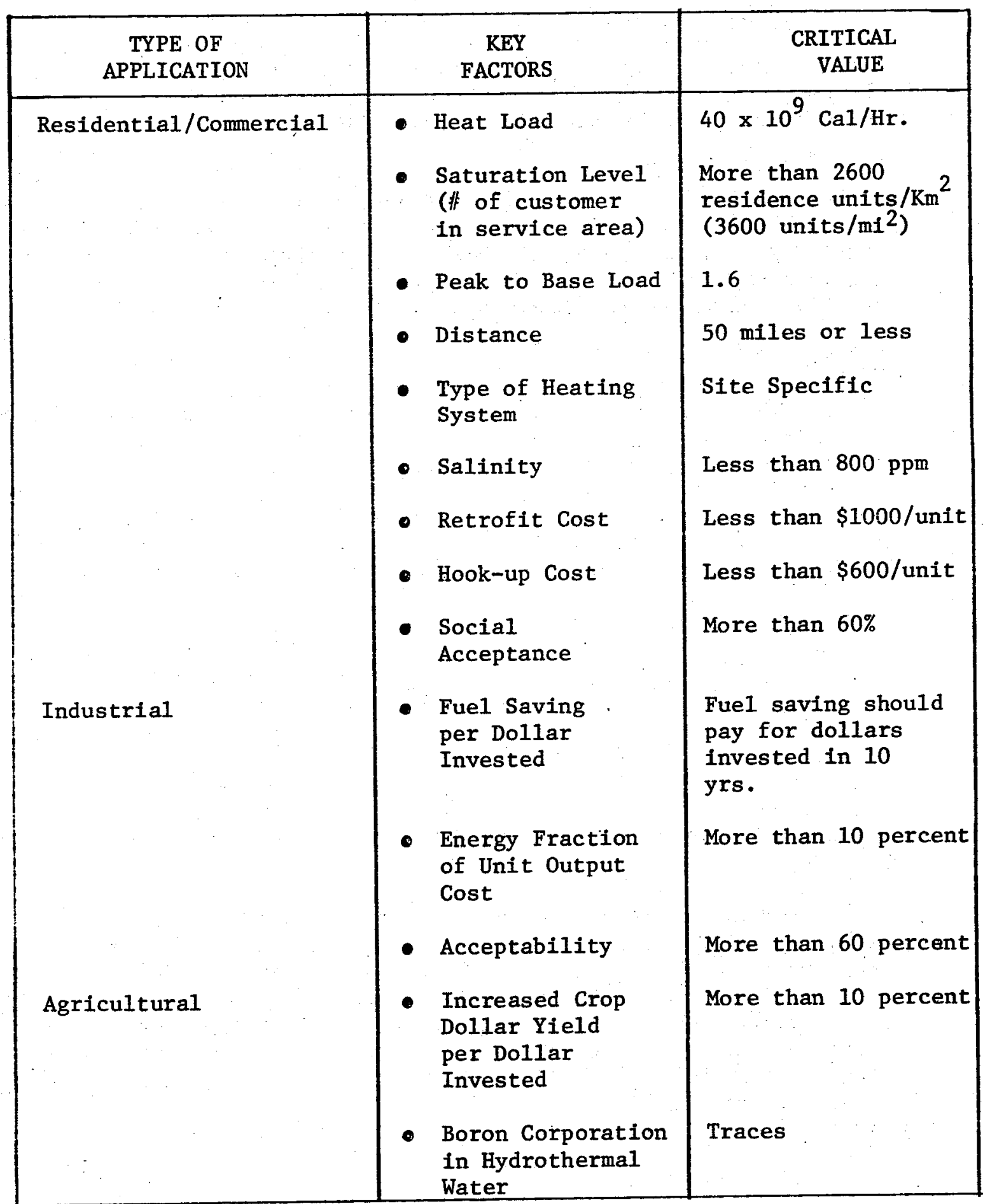


Because of site-specific variations in geothermal energy resources, the question arises for each resource as to whether it is better to transmit the low temperature geothermal fluid to the center of application or to transport the application to the source of geothermal energy. In this study, these two possibilities are treated as two different markets. Thus in each region, one part of the hydrothermal direct heat market share is captured by resources that are colocated (1.e., within a 50-mile distance) with densely populated (i.e.,, 3600 person $/ \mathrm{mi}^{2}$ ) areas. These markets are called colocated markets. The other part of the hydrothermal direct heat market is generated by the relocation of some industries to take advantage of distant hydrothermal resources. These markets are called noncolocated markets. The colocated markets and non-colocated markets are analyzed independently throughout this study.

\section{ESTIMATION OF COLOCATED BASELINE MARKETS}

The first step of this analysis was an extensive review of the geothermal direct heat use literature to evaluate the key general physical, economic, and social factors that make the use of geothermal direct heat practicable. The results of this evaluation are shown in Table S-1. Some of these factors are intrinsic to the hydrothermal resources, while others are intrinsic to population characteristics and energy demand patterns.

The most important factors that allow a hydrothermal resource to be used economically are:

- It is located within 50 miles of a population center of reasonable size. "Reasonable" size varies inversely with the distance between the resource and the population center.

- The density of the customers in the service area must be more than about 2600 residential units per square kilometer. This reflects the reality that the only extensive residential/ commercial market for hydrothermal direct heat must be served by district heating systems in order to be economical.

These criteria assume, as per the scope of this study, that the resource well head temperature falls in the range of $50^{\circ} \mathrm{C}$ to $150^{\circ} \mathrm{C}$.

The second step of the analysis compared the U.S.G.S. Circular 790 lists of hydrothermal resources in this temperature range to a list of cities and towns that meet the population density criterion, 
TABLE S-2

HYDROTHERMAL BASELINE COLOCATED

MARKET-SIZE ESTIMATION FACTORS

(for 1985)

\begin{tabular}{|l|c|c|c|c|c|}
\hline \multirow{2}{*}{ REGION } & \multirow{2}{*}{$\begin{array}{c}\text { RESOLRCE- } \\
\text { COLOCATED } \\
\text { POPULATION } \\
\text { (MIIlions) }\end{array}$} & \multicolumn{4}{|c|}{ RESOURCE-COLOCATED DIRECT HEAT DEMAND } \\
\cline { 3 - 6 } (Quads/Year)
\end{tabular}

\begin{tabular}{|l|c|c|c|c|}
\hline \multicolumn{1}{|c|}{ REGION } & $\begin{array}{c}\text { TOTAL } \\
\text { COLOCATED } \\
\text { DEMAND } \\
(\mathrm{Q} / \mathrm{Yr} \text {. })\end{array}$ & $\begin{array}{c}\text { WEIGHTED } \\
\text { HYDROTHERMAL } \\
\text { SUITABILITY } \\
\text { INDEX }\end{array}$ & $\begin{array}{c}\text { BASELINE } \\
\text { COLOCATED } \\
\text { HYDROTHERMAL } \\
\text { MARKET (Q/YY) }\end{array}$ & $\begin{array}{c}\text { AVERAGE } \\
\text { EXPECTED } \\
\text { MARKET GROWTH } \\
\text { RATE (\%/Yr.) }\end{array}$ \\
\hline Pacific & 0.21. & 0.15 & 0.032 & 5.4 \\
RMB\&R & 0.46 & 0.18 & 0.083 & 3.8 \\
Eastern & 0.90 & 0.16 & 0.153 & 5.6 \\
\hline Total U.S. & 1.63 & 0.17 & 0.27 & 5.1 \\
\hline
\end{tabular}

(1) Excludes Lo:isiana and Texas. 
to identify all instances of resource and market colocation within 50 miles. The population of the resource-colocated markets was then summed for each region. Regional growth rate estimates were prepared, and the colocated population was projected to 1985 .

Energy demand for 1985 in the residential, commercial, and industrial sectors was then estimated, based on the colocated population sizes, the 1975 per capita demand in each market sector, and an estimate of 1975 to 1985 growth in demand per capita. This value was designated as the "Resource-Colocated Direct Heat Demand," which is to be met from all energy sources. The top half of Table $\mathrm{S}-2$ presents the estimates of resource-colocated population and direct heat demand.

The fourth step was to estimate what portion of this total demand could be met by use of hydrothermal resources. This was accomplished by the use of suitability indexes, which estimate the thermodynamic match between resource and end use, technical feasibility of installations, economic attractiveness of hydrothermal energy, and social acceptability. The suitability indexes vary slightly from region to region, mainly because of regional variations in the percentage of the total direct heat demand that is consumed in the industrial sector. In all regions, the social acceptability was assumed to be $50 \%$, which is equivalent to assuming that only about half of all demand that is thermodynamically, technically, and economically well-matched to colocated hydrothermal resources will in the long run be captured by them.

The resource-colocated direct heat demand was then multiplied by the weighted hydrothermal suitability index to derive the "Baseline Colocated Hydrothermal Demand," in quads per year, for each of the three regions. The results are shown in the lower half of Table S-2.

Average expected market growth rates were then estimated, and applied to the baseline colocated hydrothermal demand to project the baseline hydrothermal market out to 2020 (see Table S-3). The market growth rate includes consideration of population growth, per capita demand growth, and a factor related to moderate but continual discovery of new market-colocated hydrothermal resources.

The results (Table $S-2$ and Table $S-3$ ) are surprising in that the Eastern region was found to have the largest resource-colocated demand. While the two western regions have many more high temperature and moderate hydrothermal resources than the Eastern region, the generaliy higher population densities in the east make it much more likely that a given hydrothermal resource will be located close to a population that is dense enough to make even relatively low-temperature hydrothermal fluid usable. 
TABLE S-3

BASELINE COLOCATED HYDROTHERMAL MARKETS (1985-2020)

(Quads/Year)

\begin{tabular}{|l|c|c|c|c|}
\hline \multirow{2}{*}{ YEAR } & \multicolumn{4}{|c|}{ REGION } \\
\cline { 2 - 5 } & PACIFIC & RMB\&R & EASTERN & U.S. $^{*}$ \\
\hline 1985 & 0.032 & 0.083 & 0.153 & 0.27 \\
1990 & 0.045 & 0.098 & 0.207 & 0.35 \\
2000 & 0.070 & 0.141 & 0.369 & 0.58 \\
2010 & 0.110 & 0.200 & 0.660 & 0.97 \\
2020 & 0.203 & 0.310 & 1.017 & 1.53 \\
\hline
\end{tabular}

*Exclusive of Texas and Louisiana 
Overall, the results suggest that the colocated market for hydrothermal direct heat from resources in the range of $50^{\circ} \mathrm{C}$ to $150^{\circ} \mathrm{C}$ will be about 0.27 quads per year in 1985 and grow to about 1.5 quads per year In 2020. The reader should note that this estimate is of the market that could be penetrated by hydrothermal energy systems. Estimates of how much of this market will be captured are made below.

\section{ESTIMATION OF NONCOLOCATED BASELINE MARKET}

The important considerations in the estimation of the noncolocated baseline market are depicted in Table S-4. The estimate of the noncolocated regional market size is based on the energy consumption in six industries that previous studies have identified as having energy needs that are relatively well matched to hydrothermal use. These are food and kindred products, tobacco, textiles, lumber and wood, paper and pulp, and chemicals.

Estimated growth rates for each industry, the industry-specific suitability indexes for hydrothermal use, and the regional distributions of each industry, were taken from previous studies, as documented in the body of this report. The colocated industrial sector suitable demand identified in the analysis of the colocated markets was subtracted from the total suitable industrial demand, resulting in an estimate for the noncolocated hydrothermal baseline market in 1985 of 1.09 quads per year.

To estimate this market to 2020 , as shown in Table S-5, it was assumed that the regionally aggregated noncolocated baseline markets would grow at the weighted average of the recent growth rates for these six industries.

For these noncolocated markets, about three-quarters of the total hydrothermal baseline demand is in the Eastern region.

\section{THE MARKET PENETRATION MODEL}

A market penetration forecasting model, MARPEN, was developed in this study to forecast the market share growth of dirrect use of hydrothermal energy in either the resource colocated or noncolocated markets. This model is based on Blackman's technology substitution modeling' approach, which was evaluated (as described in Appendix $C$ ) to be one of the most appropriate approaches for use in this study.

To apply the MARPEN model it is necessary to estimate four parameters: $T_{0}, F_{0}, T$ and $L$. 
Table S-4

ESTIMATION OF NON-COLOCATED BASELINE MARKET FOR HYDROTHERMAL DIRECT HEAT APPLICATIONS

\begin{tabular}{|c|c|c|c|c|c|c|}
\hline \multirow[t]{2}{*}{$\begin{array}{l}\text { Selected } \\
\text { Industry }\end{array}$} & \multirow{2}{*}{$\begin{array}{l}1985 \\
\text { U. S. Total } \\
\text { Direct Heat } \\
\text { Demand } \\
Q / \mathrm{Yr} \\
\end{array}$} & \multirow[t]{2}{*}{$\begin{array}{l}\text { Suitability } \\
\text { Index }\end{array}$} & \multirow{2}{*}{$\begin{array}{c}1985 \\
\text { U.S. Direct } \\
\text { Heat Demand } \\
\text { Suitable for } \\
\text { Hydrothermal } \\
Q / Y r \\
\end{array}$} & \multicolumn{3}{|c|}{$\begin{array}{l}\text { Regional Distribution of Total } \\
\text { (Colocated \& Non-colocated) } \\
\text { Suitable Demand for Hydro- } \\
\text { thermal Energy Usage }(Q / Y r)\end{array}$} \\
\hline & & & & Pactflc Region & $\begin{array}{r}\text { RMB \&R } \\
\text { Region } \\
\end{array}$ & $\begin{array}{r}\text { Eastern } \\
\text { Region }\end{array}$ \\
\hline Food \& Kindred & 1.17 & 0.36 & 0.42 & 0.16 & 0.08 & 0.18 \\
\hline Tobacco & 0.03 & 0.5 & 0.02 & - & - & 0.02 \\
\hline Textile & 0.39 & 0.39 & 0.15 & 0.01 & - & 0.14 \\
\hline Lumber \& Wood & 0.38 & 0.33 & 0.13 & 0.07 & 0.01 & 0.05 \\
\hline Paper $\&$ Pulp & 1.42 & 0.05 & 0.07 & 0.02 & - & 0.05 \\
\hline Chemicals & 4.04 & 0.10 & 0.40 & 0.03 & - & 0.37 \\
\hline $\begin{array}{l}\text { Total (i.e., } \\
\text { colocated + } \\
\text { Non-colocated) }\end{array}$ & 7.43 & $\begin{array}{l}\text { Weighted } \\
\text { Average }= \\
0.16\end{array}$ & 1.19 & 0.29 & 0.09 & 0.81 \\
\hline \multicolumn{3}{|c|}{$\begin{array}{l}\text { Suitable Industrial } \\
\text { Colocated Demand } Q / Y r\end{array}$} & 0.10 & 0.016 & 0.018 & 0.067 \\
\hline \multicolumn{3}{|c|}{$\begin{array}{l}\text { Noncolocated Baseline } \\
\text { Market Demand } \mathrm{Q} / \mathrm{Yr}\end{array}$} & 1.09 & 0.274 & 0.072 & 0.743 \\
\hline
\end{tabular}


TABLE S-5

U.S. AND REGIONAL NONCOLOCATED HYDROTHERMAL BASELINE MARKET (1985-2020) (Quads/Year)

\begin{tabular}{|c|c|c|c|c|}
\hline \multirow{2}{*}{ YEAR } & \multicolumn{4}{|c|}{ REGION } \\
\cline { 2 - 5 } & PACIFIC & RMB\&R & EASTERN & U.S. $^{*}$ \\
\hline 1985 & 0.27 & 0.07 & 0.74 & 1.09 \\
1990 & 0.30 & 0.08 & 0.82 & 1.20 \\
2000 & 0.37 & 0.09 & 1.00 & 1.47 \\
2010 & 0.45 & 0.11 & 1.22 & 1.79 \\
2020 & 0.55 & 0.12 & 1.50 & 2.18 \\
\hline
\end{tabular}

*Exclusive of Texas and Louisiana. 
TABLE S-6

BASE CASE INITIAL YEAR

HYDROTHERMAL COLOCATED MARKET FRACTION

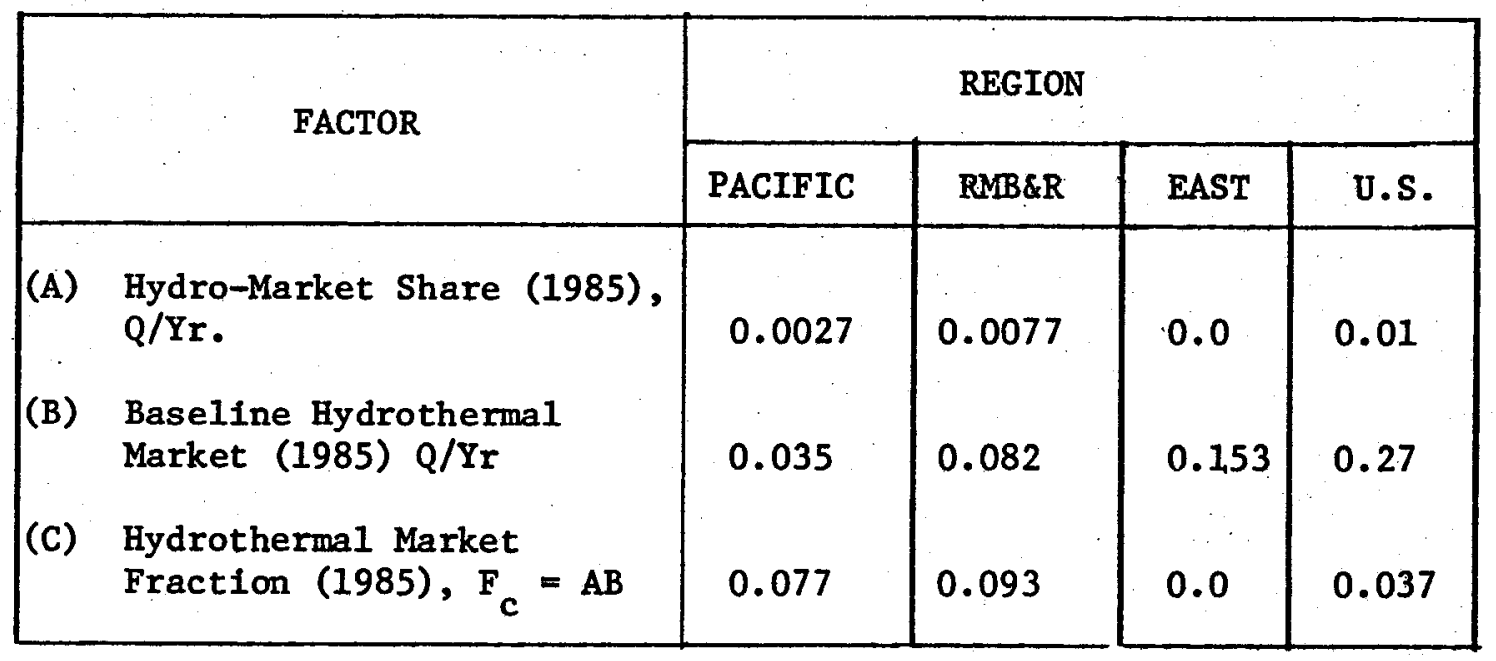


$T_{0}$ is the initial market penetration year when the fractional market Share captured, $F_{0}$, has reached the necessary threshold (i.e., two percent or more) for further self-sustafned market penetration. $T_{0}$ ranges from 1983 to 1986 in the three regions. However, for analytical reasons and purposes described later, the inittal year for this analysis is set at 1985 in all regions.

$F_{0}$, the fractional market share in the initial market penetration year, was estimated by a through review of all information available to MITRE and the Division of Geothermal Energy of current (to May 1980) hydrothermal direct heat installations and announced plans of industry and communities to install hydrothermal direct heat systems in the 1980-1985 period, for each of the three regions. These values, expressed in both quads/year use and as fractions of the calculated hydrothermal baseline market for each region, are shown in Table S-6. These are labelled as the "Base Case" values, because they assume that only the present Federal hydrothermal initiatives will be in place. Later, other stimulated cases are examined.

At present there is essentially no announced private industry interest in noncolocated hydrothermal direct heat utilization. As a result, the model predicts no hydrothermal penetration of the noncolocated markets unless the government initiates significant new activities to stimulate such penetration.

The takeover time; $T$ is the number of years required for the fractional market share, $F(t)$, to grow from 10 percent to 90 percent of the hydrothermal baseline market. For the resource-colocated markets, $\tau$ is assumed to be 60 years, by analogy to the takeover time for market penetration by natural gas in the United States. The detailed reasoning for this assumption is given in Appendix E. For the noncolocated markets, $\tau$ is assumed to be 120 years, on the grounds that the propensity to relocate an industrial firm more then $50 \mathrm{miles}$ to take advantage of the hydrothermal energy will be at best half the. propensity to adopt hydrothermal energy when it is locally available.

$L$ is the maximum fractional market share of the baseline market that could be theoretically captured. In this study $L$ is taken equal to 1.0 because the baseline market is defined here in a way that allows It to be totally captured in the long-run. 
TABLE S-7

IMPACT OF INITIAL GOVERNMENT BUY ON U.S. COLOCATED HYDROTHERMAL DIRECT HEAT USE, QUADS/YEAR END USE

\begin{tabular}{|c|c|c|c|c|c|c|c|}
\hline \multirow[b]{2}{*}{ Year } & \multicolumn{7}{|c|}{ INITIAL GOVERNMENT BUY, IGB. } \\
\hline & $\begin{array}{l}\text { Base Case } \\
I G B=0\end{array}$ & IGE & $\begin{array}{l}\text { Case } 1 \\
=0.01 ? / Y\end{array}$ & IGB & $\begin{array}{l}\text { Case } 2 \\
=0.04 \mathrm{Q} / \mathrm{Y}\end{array}$ & IGB & $\begin{array}{l}\text { Case } 3 \\
=0.09 Q / Y\end{array}$ \\
\hline 1980 & 0.004 & & 0.004 & & 0.004 & & 0.004 \\
\hline 1985 & 0.01 & & 0.02 & & 0.05 & & 0.10 \\
\hline 1990 & 0.02 & & 0.03 & & 0.08 & & 0.16 \\
\hline 2000 & 0.04 & & 0.10 & & 0.22 & & 0.36 \\
\hline 2020 & 0.27 & & 0.66 & & 1.11 & & 1.34 \\
\hline
\end{tabular}




\section{MARKET PENETRATION RESULTS}

The estimated colocated national hydrothermal direct heat market share over the next 40 years is summarized in Table S-7. This table presents various scenarios of initial government support to stimulate future growth of colocated hydrothermal direct heat utilization. In the base case (i.e. business-as-usual condition) there is no government support involved other than that already in place. The remaining three cases shown in Table S-7 represent scenarios in which the government is assumed to support enough additional field demonstration projects or other commercialization efforts to raise the inftial absolute hydrothermal direct heat market share of 0.01 quads/year to $0.02,0.05$, and 0.1 quads per year, respectively, by 1985. This means that the government would induce the installation of an additional $0.01,0.04$, and 0.09 quads/ year of hydrothermal direct heat applications by 1985, respectively for the three cases of additional government stimulation.

Geothermal direct heat installations known to exist by the beginning of 1980 amount to 0.004 quads/year end use. Commercialization projects already sponsored by the U.S. Department of Energy (DOE) are estimated to bring this to 0.010 quads/year by the beginning of 1985 . If no further government impetus were applied, the MARPEN model projects that 0.04 quads/year would be installed by 2000 , and 0.27 quads/year would be installed by 2020 . In this base case scenario, much of the growth in the captured market is due to increased demand for energy and discoveries of new market-colocated resources. The fractional market share captured by hydrothermal direct heat would grow from 3.7 percent in 1985 , to 6.9 percent in 2000 , and to 17.6 percent in 2020 .

Increasingly large additional stimulation of the near term (1985) installed capacity will push the hydrothermal direct use market into accelerated annual rates of substitution of other energy sources by hydrothermal energy. The term "Initial Government Buy" (IGB) is meant here to include any set of actions (e.g., cost-shared demonstrations, financlal incentives, cost-shared drilling) through which the 1985 installation base could be stimulated beyond 0.010 quad/year.

The estimated impacts of three levels of such stimulation are graphed in Figure $\mathrm{S}-1$.

In Case 1, the IGB is set at 0.01 quads/year, a doubling of the 1985 base case value. Under this case 0.10 quads/year would be achieved by 2000 , and 0.66 quads/year by 2020 . The respective fractional market shares are 7.4 percent, 17.2 percent, and 43.0 percent. 


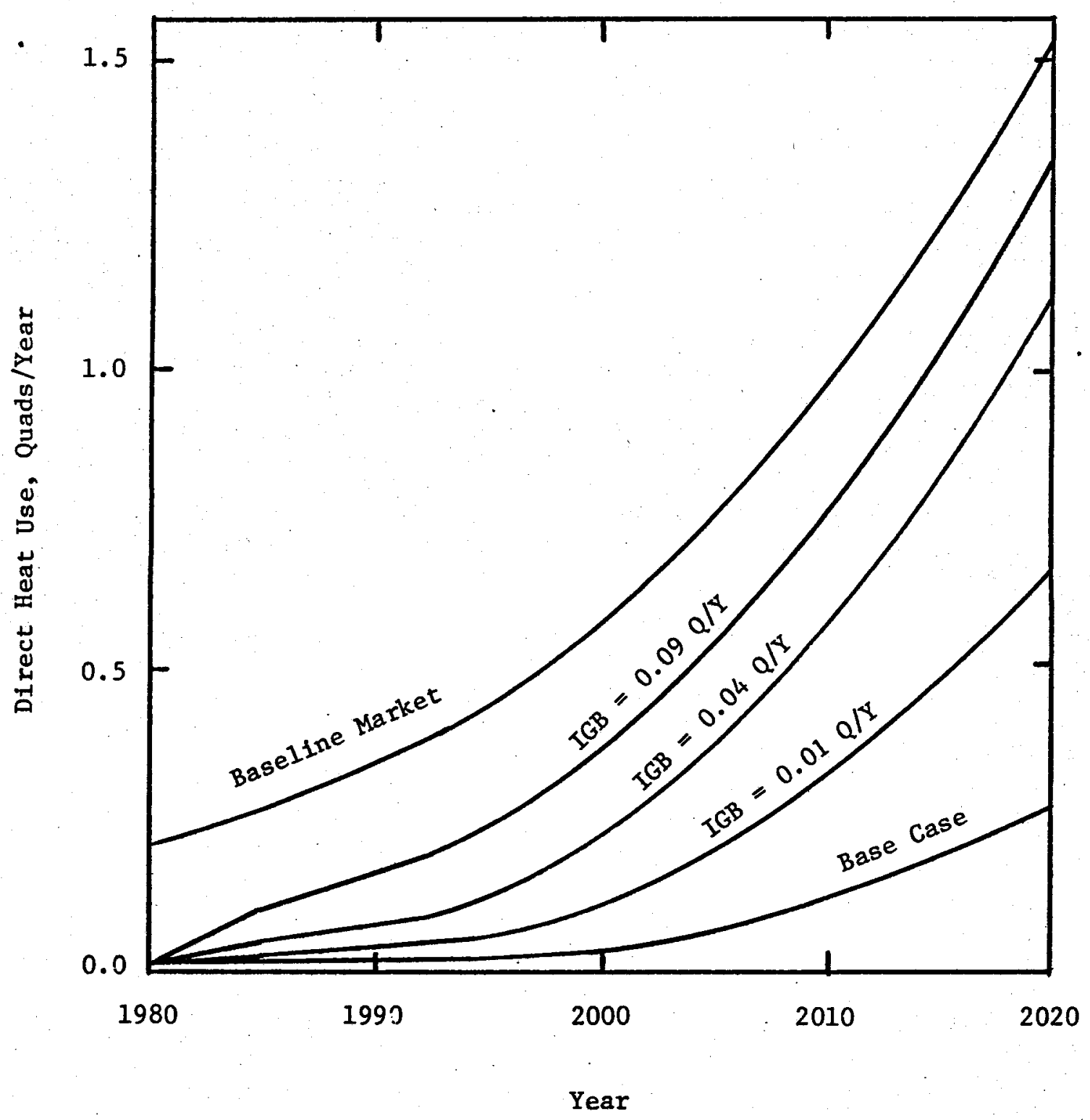

FIGURE S-1

HYDROTHERMAL MARKET PENETRATION UNDER DIFFERENT LEVELS OF GOVERNMENT STIMULATION TO 1985 
Cases 2 and 3 represent substantial increases in the number of installations by 1985. The most noticeable impacts of these cases are seen in the year 2000 , when 38.0 percent and 62.0 percent of the market would be captured. By 2020 , both cases result in large fractional market shares ( 72.5 percent and 87.5 percent, respectively). Thereafter, growth of demand has the greatest continuing impact on continued growth of hydrothermal direct use installations.

The projected Impacts of the three different levels of Initial Government Buy, as shown in Table $\mathrm{S}=7$ and FIgure $\mathrm{S}-1$, are based on the assumption that the IGB would be distributed among the three regions in proportion to the non-penetrated 1985 baseline market in each region. This means that a significant fraction of any IGB would be concentrated in the Eastern region. The reader should be aware that other scenarios of IGB regional distribution are discussed in the text of this report, including a scenarlo where the IGB is restricted to the Pacific and RMB\&R regions.

The above projections of hydrothermal penetration of resourcecolocated markets are based on the assumption that the takeover time, $T$, for hydrothermal will be similar to that exhibited by natural gas, 60 years. It is useful to formulate projections with different takeover times for two reasons:

First, the assumption of 60 years is probably not exactly correct (although we belleve it is reasonable). For this reason, projections based on different takeover times establish reasonable upper and lower bounds on the penetration forecasts.

Second, it is instructive to get a sense of what happens to the forecasts if government inftiatives emphasized actions that might enhance consumer acceptance of hydrothermal energy systems, in the absence of extensive direct subsidies. Such actions might include extensive advertising to generate widespread knowledge of the advantages and avallability of hydrothermal energy, and directing most subsidies to the formation of utility-like district heating systems, in order to minimize end-user involvement with hydrothermal resource and reservoir uncertainties.

Forecasts based on altered takeover times of 45 years and 90 years, compared to the 60 year case, are presented in Table S-8. In Case 1, where the IGB equals 0.01 quads/year, these varlations in takeover time lead to a forecast of hydrothermal usage in 2020 that ranges from 0.40 to 0.95 quads/year. Thus, variations in takeover time have significant effects on the forecasts, and suggest that continued effort be addressed to configure government initiatives in ways that emphasize enhanced consumer acceptance of the technology. 
TABLE S-8

IMPACT OF CHANGES IN TAKEOVER TIME, $\tau$,

ON U.S. COLOCATED HYDROTHERMAL MARKET SHARE (Q/Yr.)

\begin{tabular}{|c|c|c|c|}
\hline Levels of Initial & $\tau=45 \mathrm{yrs}$ & $\tau=60 \mathrm{yrs}$ & $\tau=90 \mathrm{yrs}$. \\
\hline Governiment Days (IGB) & Market Share & Market Share & Market Share \\
\hline $\begin{array}{c}\text { Base Case, IGB }=0 \quad Q / \mathrm{Yr} . \\
1985 \\
1990 \\
2000 \\
2020\end{array}$ & $\begin{array}{l}0.01 \\
0.018 \\
0.06 \\
0.38\end{array}$ & $\begin{array}{l}0.01 \\
0.017 \\
0.044 \\
0.274\end{array}$ & $\begin{array}{l}0.01 \\
0.015 \\
0.034 \\
0.171\end{array}$ \\
\hline 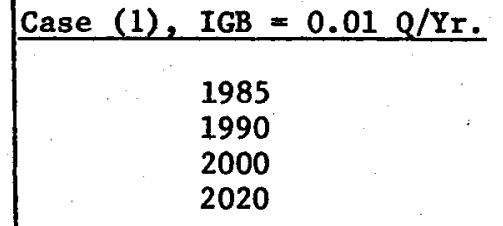 & $\begin{array}{l}0.02 \\
0.038 \\
0.13 \\
0.95\end{array}$ & $\begin{array}{l}0.02 \\
0.03 \\
0.10 \\
0.66\end{array}$ & $\begin{array}{l}0.02 \\
0.03 \\
0.074 \\
0.40\end{array}$ \\
\hline Case (2), IGB $=0.04$ Q./Yr. & $\begin{array}{l}0.05 \\
0.09 \\
0.28 \\
1.31\end{array}$ & $\begin{array}{l}0.05 \\
0.08 \\
0.22 \\
1.11\end{array}$ & $\begin{array}{l}0.05 \\
0.078 \\
0.176 \\
0.817\end{array}$ \\
\hline $\begin{array}{c}\text { Case (3), IGB }=0.09 \mathrm{Q} / \mathrm{Yr} \text {. } \\
1985 \\
1990 \\
2000 \\
2020\end{array}$ & $\begin{array}{l}0.10 \\
0.17 \\
0.41 \\
1.44\end{array}$ & $\begin{array}{l}0 \\
0.10 \\
0.16 \\
0.36 \\
1.34\end{array}$ & $\begin{array}{l}0.10 \\
0.146 \\
0.31 \\
1.15\end{array}$ \\
\hline
\end{tabular}


At present, there is relatively little announced private industry interest in non-colociated hydrothermal direct heat utilization. As a result, the estimated regional and national noncolocated fractional market shares, shown in Table S-9, are based on a scenario in which the government has to support the initial installation by 1985 of sufficient (1.e. at least 2 percent of the 1985 non-colocated baseline market) industrial hydrothermal direct heat applications to induce a future, privately sustalned, market growth. As mentioned above, in the case of resource-noncolocated markets, the takeover time is assumed to be 120 years, double that for the colocated markets.

As shown in Table S-9, even after a government buy of 0.03 quads/year across the three regions, the penetration of the noncolocated markets is projected to be very slow. From the analytical point of view, this is because even relatively large absolute investments can not capture enough of the baseline market to ensure self-sustained rapid growth in this case.

The comparative impact of a given level of government support in stimulating the U.S. hydrothermal direct heat market share growth in the colocated and non-colocated direct heat ut1lization markets is shown in Table S-10 and in F1gure S-2. The assumptions embodied here suggest that government efforts to stimulate the growth of hydrothermal market shares will be most effective if they are directed towards expanding the use of hydrothermal resources that are currently colocated with sizeable markets. Even if the takeover times are identical, any initial government buy is relatively more diluted in the non-colocated. market, resulting in slower growth in both fractional and absolute market shares.

\section{UNCERTAINTIES IN THIS ANALYSIS}

The above estimates of hydrothermal non-electric usage are bounded by several uncertainties, as explained in Section 5.0 .

(1) Size of the Resource Base. The analysis presumes that the market-colocated resource base, and thus the number of resource colocated market centers, w111 grow by about 17 percent between 1980 and 2020. Consideration of U.S.G.S. estimates of the U.S. hydrothermal resources that remain to be discovered suggests that this growth could be as much as but probably no greater than 35 percent. Achieving this upper bround would raise all forecasts of quads/year penetration in the year 2020 by about 17 percent.

(2) Price Escalation of Conventional Fuels. Continued escalation of conventional fuel real prices at more than 10 percent per year during the next 10 years would make the use of hydrothermal resources extremely attractive, and invalidate the conclusions of this study. For example, it has been estimated (27) that each one-dollar rise in the price of natural gas would increase the fractional market share of hydrothermal direct heat applications by 3 percent. 


\section{TABLE S-9}

NATIONAL AND REGIONAL NONCOLOCATED HYDROTHERMAL DIRECT HEAT MARKET SHARE WITH AN INITIAL GOVERNMENT BUY, IGB, OF $0.03 \mathrm{Q} / \mathrm{YR}$. AND $T=120$ YEARS

\begin{tabular}{|c|c|c|c|c|}
\hline Year & $\begin{array}{c}\text { U.S. } \\
\text { Q/Yr. }\end{array}$ & $\begin{array}{c}\text { Pacific Region } \\
\text { Q/Yr. }\end{array}$ & $\begin{array}{c}\text { RMBQR Region } \\
\text { Q/Yr. }\end{array}$ & $\begin{array}{c}\text { Eastern Region } \\
\text { Q/Yr. }\end{array}$ \\
\hline 1985 & 0.03 & 0.01 & 0.01 & 0.01 \\
1990 & 0.04 & 0.013 & 0.013 & 0.014 \\
2000 & 0.068 & 0.022 & 0.022 & 0.024 \\
2020 & 0.20 & 0.07 & 0.05 & 0.08 \\
\hline
\end{tabular}


TABLE S-10

COMPARATIVE IMPACT OF GOVERNMENT SUPPORT IN U.S. COLOCATED VS NON-COLOCATED MARKETS

\begin{tabular}{|c|c|c|c|c|c|c|c|c|}
\hline \multirow[b]{2}{*}{ Year } & \multirow[b]{2}{*}{$\begin{array}{l}\text { Colocated } \\
\text { Baseline. } \\
\text { Market } \\
\text { (Quads/Yr.) }\end{array}$} & \multicolumn{2}{|c|}{$I G B=0.03, \tau-60 \mathrm{Yrs}}$. & \multirow[b]{2}{*}{$\begin{array}{l}\text { Non-colocated } \\
\text { Baseline } \\
\text { Market } \\
\text { (Quads/Yr.) }\end{array}$} & \multicolumn{2}{|c|}{ IGB $=0.03, T=120 \mathrm{Yrs}$} & \multicolumn{2}{|c|}{ IGB $=0.03, \tau=60 \mathrm{Yrs}}$. \\
\hline & & $\begin{array}{c}\text { Fractional } \\
\text { Market } \\
\text { Share }\end{array}$ & $\begin{array}{c}\text { Market } \\
\text { Share } \\
\text { (Quads/Yr.) }\end{array}$ & & $\begin{array}{c}\text { Fractional } \\
\text { Market } \\
\text { Share }\end{array}$ & $\begin{array}{c}\text { Market } \\
\text { Share } \\
\text { (Quads/Yr.) }\end{array}$ & $\begin{array}{c}\text { Fractional } \\
\text { Market } \\
\text { Share }\end{array}$ & $\begin{array}{c}\text { Market } \\
\text { Share } \\
\text { (Quads/Yr.) }\end{array}$ \\
\hline 1985 & 0.27 & 0.11 & 0.03 & 1.089 & 0.028 & 0.03 & 0.038 & 0.03 \\
\hline 1990 & 0.35 & 0.20 & 0.07 & 1.202 & 0.033 & 0.04 & 0.04 & 0.05 \\
\hline 1995 & 0.45 & 0.27 & 0.12 & 1.327 & 0.039 & 0.05 & 0.06 & 0.08 \\
\hline 2000 & 0.58 & 0.33 & 0.19 & 1.466 & 0.047 & 0.07 & 0.08 & 0.12 \\
\hline 2005 & 0.75 & 0.43 & 0.32 & 1.618 & 0.056 & 0.09 & 0.11 & 0.18 \\
\hline 2010 & 0.97 & 0.52 & 0.50 & 1.786 & 0.067 & 0.12 & 0.15 & 0.27 \\
\hline 2015 & 1.26 & 0.61 & 0.77 & 1.973 & 0.079 & 0.16 & 0.20 & 0.39 \\
\hline 2020 & 1.53 & 0.69 & 1.06 & 2.178 & 0.094 & 0.20 & 0.27 & 0.59 \\
\hline
\end{tabular}




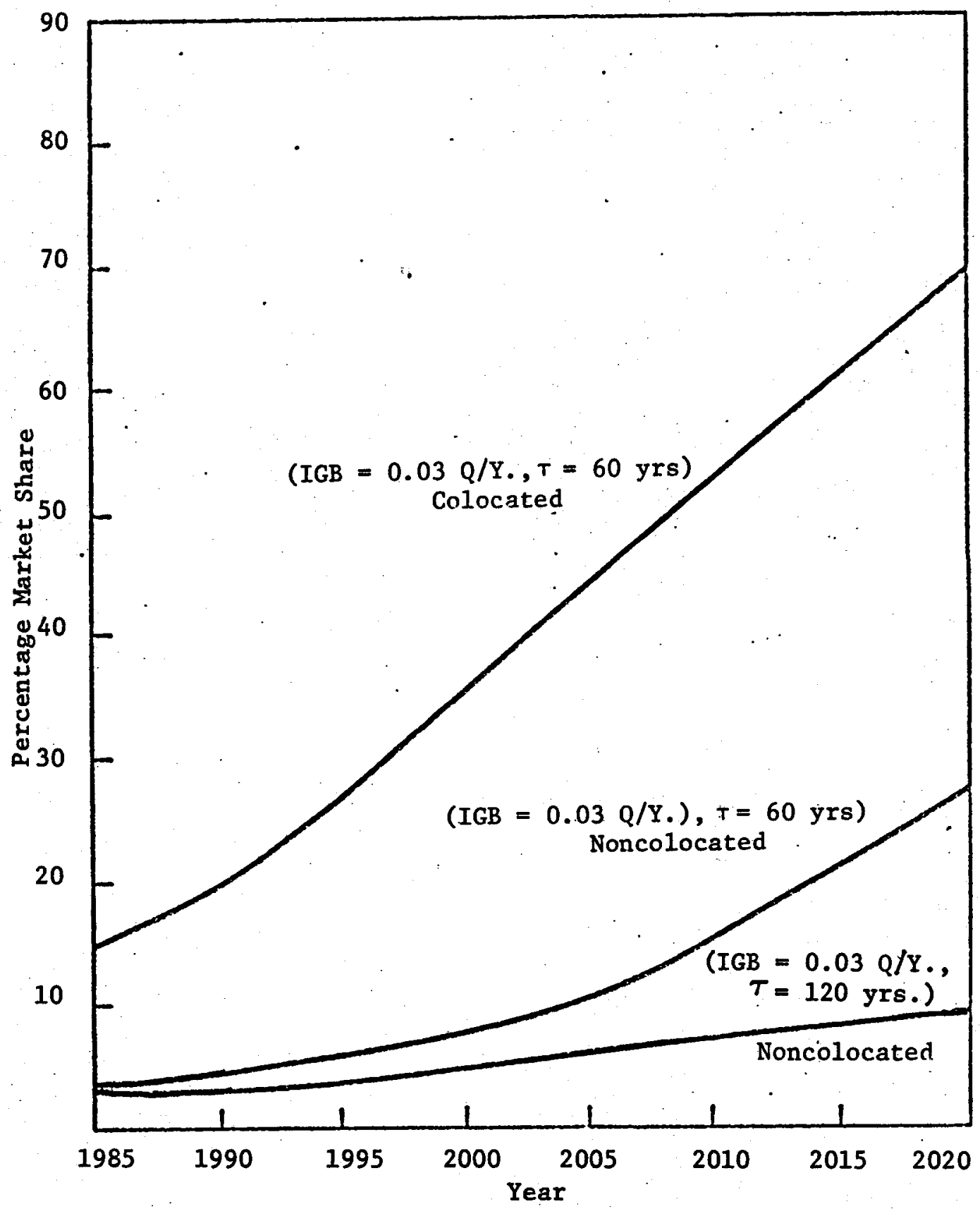

FIGURE S-2

COMPARATIVE IMPACT OF SAME INITIAL GOVERNMENT BUY ON COLOCATED VS. NONCOLOCATED MARKET SHARE PERCENTAGES 
(3) Unpredictable Market Sectors. There are a number of major market sectors where the use of geothermal fluids might be significant but are simply unpredictable. These include enhanced oil recovery, gasohol plants, and space heating needs of the MX missile program. The use of geothermal fluids for gasohol production is especially interesting because this would allow geoheat to contribute to fuel needs in the transportation sector.

(4) Conservation and Waste Heat. Energy conservation efforts and utilization of waste heat from conventional electric plants could result in the present forecasts and estimates being high by perhaps 20 percent to 30 percent in the 2000-2020 period. It should be noted, however, that these efforts would also be subject to technology-substitution dynamics, and require perhaps substantial time to reach significant direct heat market fractions.

\section{CONCLUSIONS}

The overall results suggest the following conclusions.

(1) The baseline colocated market, the market that could be captured by hydrothermal resources located near centers of demand, is 0.27 quads/year in $1985,0.58$ quads/year in 2000 , and 1.53 quads/year in 2020. The baseline noncolocated market, consisting of industries whose heat requirements are matched to hydrothermal resources but are not located near them, is 1.09 quads/year in $1985,1.47$ quads/year in 2000 , and 2.18 quads/year in 2020. For both of these markets, more than half of the baseline market is in the Eastern region.

(2) Current hydrothermal direct heat use is almost nil, and is not sufficlent to induce rapid market penetration. For the Pacific region and RMB\&R region, projects that are now underway should, by about 1985; bring the penetration by hydrothermal energy of the resource-colocated markets into a self-sustained mode. However, without additional stimulation, the estimated penetration of these markets will be only about 0.01 quads/year in 1985, 0.04 quads/year in 2000 , and 0.27 quads/year in 2020 .

For the Eastern region colocated market, and for the noncolocated markets in all regions, the 1985 base case hydrothermal market penetration is essentially nil. The only prediction allowed, given this condition, is that penetration for 2000 and 2020 will be essentially zero, unless significant unpredictable events occur.

(3) New Federal (and/or state) Initiatives in the near-term (1981-1985) could alter this picture. An Initial government byy to install an additional 0.9 quads/year of end-use by the end of 1985 could result in annual end use of 0.36 quads/year in 2000 and 1.34 quads/year in 2020 in the resource-colocated markets. Such an initiative would cost about $\$ 1.7$ billion over the next 5 years, with governments having to furnish perhaps half of the funds. 
(4) The most practicable level of such an initial government buy in the near-term appears to be on the order of an additional installed capacity equivalent to about 0.01 quads/year end use. This would require between $\$ 19$ million and $\$ 26$ million of new government funding for each of 5 years (average government cost share ranging from 50 to 70 percent). This would result in 0.02 quads/year hydrothermal use in $1985,0.10$ quads/year in 2000 , and about 0.66 quads/year in 2020 .

(5) If such a stimulatory action were to be undertaken, it appears that it would be most effective if it is directed toward resource-colocated markets, rather than toward resource non-colocated markets.

(6) The most unexpected finding of the present study is that the market-size analysis (Section 3.0) indicates that the Eastern region has the relatively greatest market potential among the three regions, for both the colocated and the noncolocated markets. The reason for this is that the higher population densities in the East ensure that any geothermal resource has a relatively high probability of being near a market, compared to the probability of resource and market colocation in the West. However, the current hydrothermal penetration of this market is almost nil, suggesting that a large effort would be required to stimulate such use in the near and mid-term.

RECOMMENDATIONS FOR GOVERNMENT ACTIONS

The results and conclusions prompt the following recommendations.

(1) If the Government wishes to ensure a reasonably rapld development of hydrothermal direct heat use, it will have to increase its level of support of these uses in the near term. It should, moreover, emphasize the development of large hydrothermal resource-colocated institutional, commerclal, and industrial applications to accelerate a transition to district heating systems and geothermal industrial complexes.

(2) The Government should support the private sector geothermal commercialization infrastructure that is now just beginning to emerge by accelerating the formation of consortia of geothermal developers, financlers, designers, and builders to help romote regional hydrothermal direct heat applications.

(3) The contribution of the Pacific region to the national hydrothermal direct heat market should be increased by encouraging, to the extent possible, the cascaded utilization of the numerous high temperature (greater than $150^{\circ} \mathrm{C}$ ) geothermal resources in this region.

(4) Hydrothermal resource identification and assessment is a necessary prerequisite for current and future commercialization of geothermal direct heat utilization. Therefore, such an assessment should be an integral part of any Government program designed to promote hydrothermal direct heat applications. 
(5) It might be valuable to establish a new ad hoc group within the Interagency Geothermal Coordinating (IGCC) to explore the commercialization/industrialization of energy use systems that combine the use of hydrothermal resources, ground water heat pumps, waste heat from conventional electric plants, and other sources of waste heat to provide inexpensive heat to district heating systems. The Department of Housing and Urban Development, which joined the IGCC in 1979, would be expected to play an important and perhaps leading role in such a group. A useful initial focus would be engineering/economic assessments of the conditions under which specific mixes of such energy sources would be most feasible.

\section{RECOMMENDATIONS FOR FURTHER ANALYSIS}

Fruitful areas for further analysis might include the following:

(1) Design of a goal-orlented budget for the Government hydrothermal commercialization program based on estimating the cost-effectiveness of various Government actions (e.g., R\&D, fiscal incentives, loan guaranty, marketing and outreach, and other similar actions) in achieving various levels of direct heat market penetration.

(2) Develop a regional analysis model that reflects the socioeconomic acceptability of hydrothermal direct heat applications. Based on regional public opinion surveys, such a model should help improve the accuracy of future forecasts for hydrothermal direct heat market shares in different regions of the United States.

(3) Use the Battelle Pacific Northwest Laboratory's Geocity code, and/or the New Mexico Energy Institute's cost and location models to estimate the cost of delivering geothermal heat from the known hydrothermal resources located within 50 miles of all major. cities and towns in the U.S. Favorable results could then be disseminated to the governments and commercial associations in those locales.

(4) Conduct a fast study of low and moderate temperature needs of all S.I.C. Industries to Identify industry-specific cost factors and advantages of using hydrothermal energy. This should be based on the results of the DGE - sponsored direct use feasibility studies and the voluminous literature generated by the solar energy community in this area of analysis. 
Blank

$5-24$ 


\subsection{INTRODUCTION}

Anticipated depletion of United States oil and natural gas reserves has recently stimulated interest in exploring the potential of new energy technologies such as solar, geothermal and oil shale. The advantages of geothermal energy have been much discussed in the literature. It is renewable and relatively nonpolluting when com pared to coal, nuclear or oil shale. In comparison with solar, geothermal energy has no diurnal and weather dependence and does not require as much land area per unit energy for its development. Furthermore, geothermal energy, in direct heat applications, has the potential of replacing fossil and other conventional energy sources while providing a more appropriate match of energy temperature to work tasks (1) thus allowing more efficient utilization of energy sources.

Although current knowledge does not allow the quantification or help the identification of exact location of recoverable energy for low temperature $\left(1 . e .50^{\circ} \mathrm{C}-150^{\circ} \mathrm{C}\right)$ hydrothermal resources, the USGS Circular 790 (2) has indicated the existence of vast resources of this nature in various regions of the United States. As shown in Figure 1-1, various areas of abnormally high regional heat flow exist in the Rocky Mountain Basin and Range (RMB\&R) Region. An example is the Snake River Plain where a $150^{\circ} \mathrm{C}$ resource potential can be expected. On the Atlantic Coast, various radiogenic heat sources with geofluid temperatures of over $100^{\circ} \mathrm{C}$ can be located. Many moderate and low temperature resources also exist in the Pacific Region. 


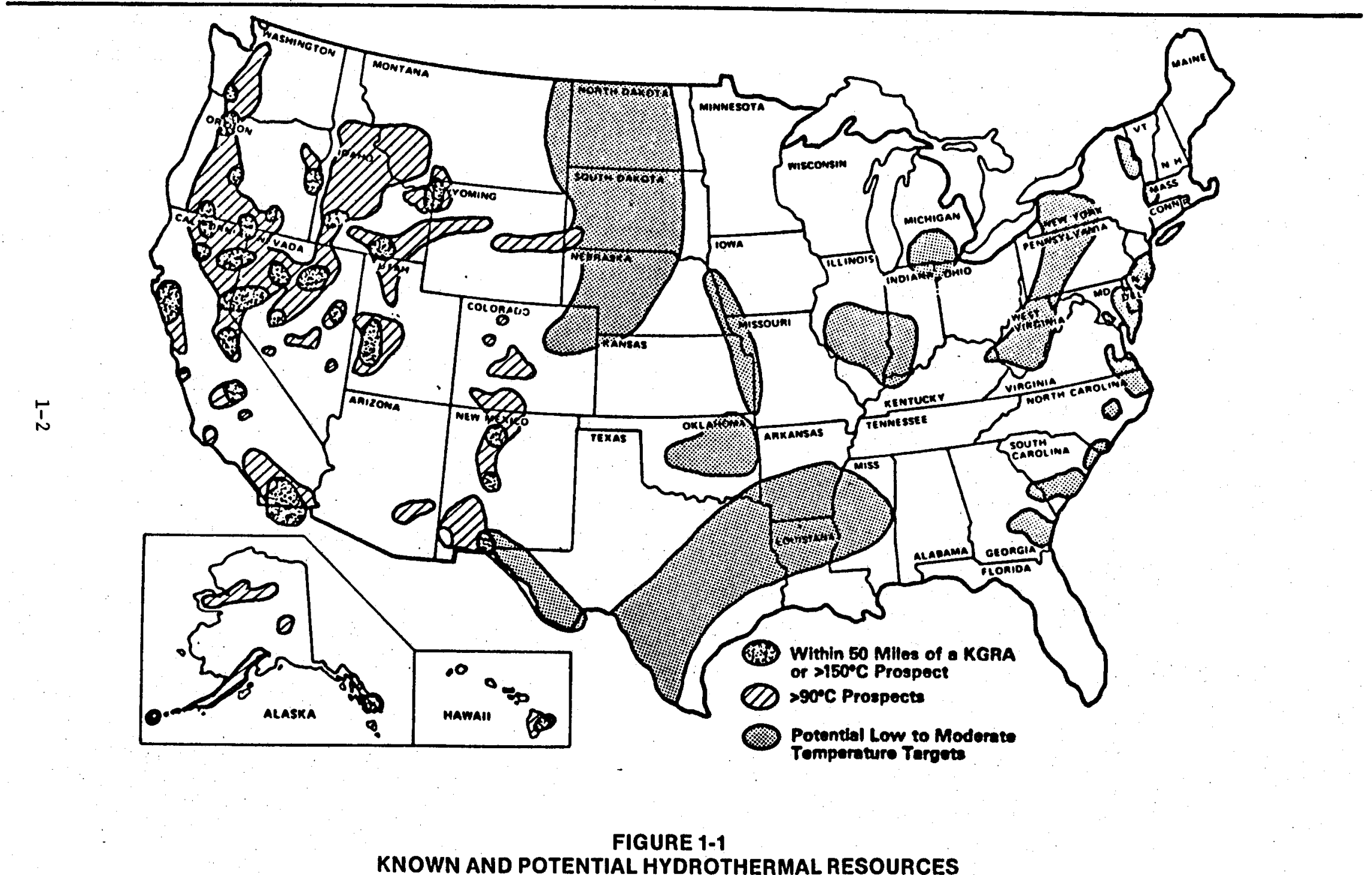

KNOWN AND POTENTIAL HYDROTHERMAL RESOURCES 
At present, direct application of geothermal heat is economically used in many locations (e.g., New Zealand, Iceland, France and Japan) throughout the world. In the United States there are now some examples of successful hydrothermal residential and commercial space heating, and some Industrial applications (e.g., pasteurization of milk) In Klamath Falls, Oregon and Boise, Idaho. Direct heat uses (i.e., residential/commercial and process heat industrial applications) represent 63 percent of the current national energy budgets (3). Sixty percent of these U.S. direct heat energy needs (i.e. 38 percent of the U.S. national energy budget) could be technically supplied by avallable low temperature (1.e., 50-150 $\mathrm{C}$ ) hydrothermal resources. As shown in Table 1-1 the current and planned usage by 1985 of geothermal energy for direct heat application amounts to a total of 0.01 quad/year. These applications are mainly in the ten states of the $R M B \& R$ region and in the state of California in the Pacific region. Increasing this level of application to attain 0.1 quad/year by 1985 would require a tripling of the current sixty wells per year level of geothermal drilling. It seems unlikely that this goal can be met without very strong Federal support.

A knowledge of the potential of hydrothermal energy to penetrate the direct heat utilization market is cruclal if its feasibility as a substitute energy resource is to be evaluated for Federal support purposes. This requires a model that would allow the estimation of the future path of market penetration of geothermal direct heat 
TABLE $1-1$

LATEST INFORMATION ON CURRENT AND PLANNED (UP TO 1985) HYDROTHERMAL DIRECT HEAT APPLICATIONS IN THE U.S. *

\begin{tabular}{|c|c|c|c|c|c|c|c|c|}
\hline \multicolumn{3}{|c|}{$\begin{array}{l}\text { PACIFIC REGION } \\
\left(10^{9} \text { BTU/Yr. }\right)\end{array}$} & \multicolumn{3}{|c|}{$\begin{array}{l}\text { RMB\&R REGION } \\
\left(10^{9} \text { BTU/Yr. }\right)\end{array}$} & \multicolumn{3}{|c|}{$\begin{array}{l}\text { EASTERN REGION } \\
\left(10^{9} \mathrm{BTU} / \mathrm{Yr} \mathrm{r}_{\bullet}\right)\end{array}$} \\
\hline State & Planned & Current & State & Planned & Current & State & Planned & Current \\
\hline $\begin{array}{l}\text { Alaska } \\
\text { California } \\
\text { Oregon } \\
\text { Washington } \\
\text { Hawaii }\end{array}$ & $\begin{array}{r}1523.1 \\
3.7 \\
.2\end{array}$ & $\begin{array}{r}46.5 \\
394.7 \\
71.9 \\
13.5\end{array}$ & $\begin{array}{l}\text { Montana } \\
\text { Idaho } \\
\text { Nevada } \\
\text { Arizona } \\
\text { Utah } \\
\text { New } \\
\text { Mexico } \\
\text { Colorado } \\
\text { Wyoming } \\
\text { North } \\
\text { Dakota } \\
\text { South } \\
\text { Dakota }\end{array}$ & $\begin{array}{r}344.5 \\
1929.5 \\
995 \\
200.5 \\
144.3 \\
2054.9 \\
27.2 \\
301.0 \\
\\
30.7\end{array}$ & $\begin{array}{r}19.0 \\
867.8 \\
186.2 \\
\\
5.8 \\
22.2 \\
13.1 \\
2.7 \\
1.5 \\
11.7\end{array}$ & $\begin{array}{l}\text { Arkansas } \\
\text { Florida } \\
\text { Maryland } \\
\text { Michigan }\end{array}$ & $* *$ & $\begin{array}{l}0.1 \\
0.1\end{array}$ \\
\hline Subtotal & 1527.0 & 526.6 & Subtotal & 6027.6 & 1130.0 & Subtotal & - & 0.2 \\
\hline TOTAL & \multicolumn{2}{|c|}{$2 ; 053.6$} & TOTAL & \multicolumn{2}{|c|}{$7,157.6$} & TOTAL & \multicolumn{2}{|c|}{0.2} \\
\hline
\end{tabular}

* SOURCE: Geoheat Listing of Geothermal Progress Monitor files, MITRE, May 1980.

** Project capacity is still undefined. 
utilization technology based on both price competitiveness and other non-price market factors.

\subsection{Objectives and Scope of Report}

The objectives of this report are: (1) to describe the development of a model for forecasting the market penetration of a geothermal direct heat utilization, and (2) to use this model to estimate the future market share of hydrothermal direct heat technology in the U.S. as well as in the Pacific, RMB\&R, and Eastern Regions of the United States (whose boundaries are defined in Figure 1-2) over a time period extending from 1980 to 2020 .

Estimation of possible direct heat market contributions from the geopressured formations (e.g., In Texas and Loulsiana), hot dry rock. systems, or hydrothermal resources with geofluid temperatures lower than $50^{\circ} \mathrm{C}$ or higher than $150^{\circ} \mathrm{C}$ are outside the scope of this study. Also, this study does not quantify the impact of using heat pumps to boost the geofluid temperature to $50^{\circ} \mathrm{C}$ and above. The current cost of power, electric or otherwise, required to operate a heat pump to upgrade a low-temperature (i.e., less than $50^{\circ} \mathrm{C}$ ) hydrothermal resource is now too expensive to make it economically attractive (4). 


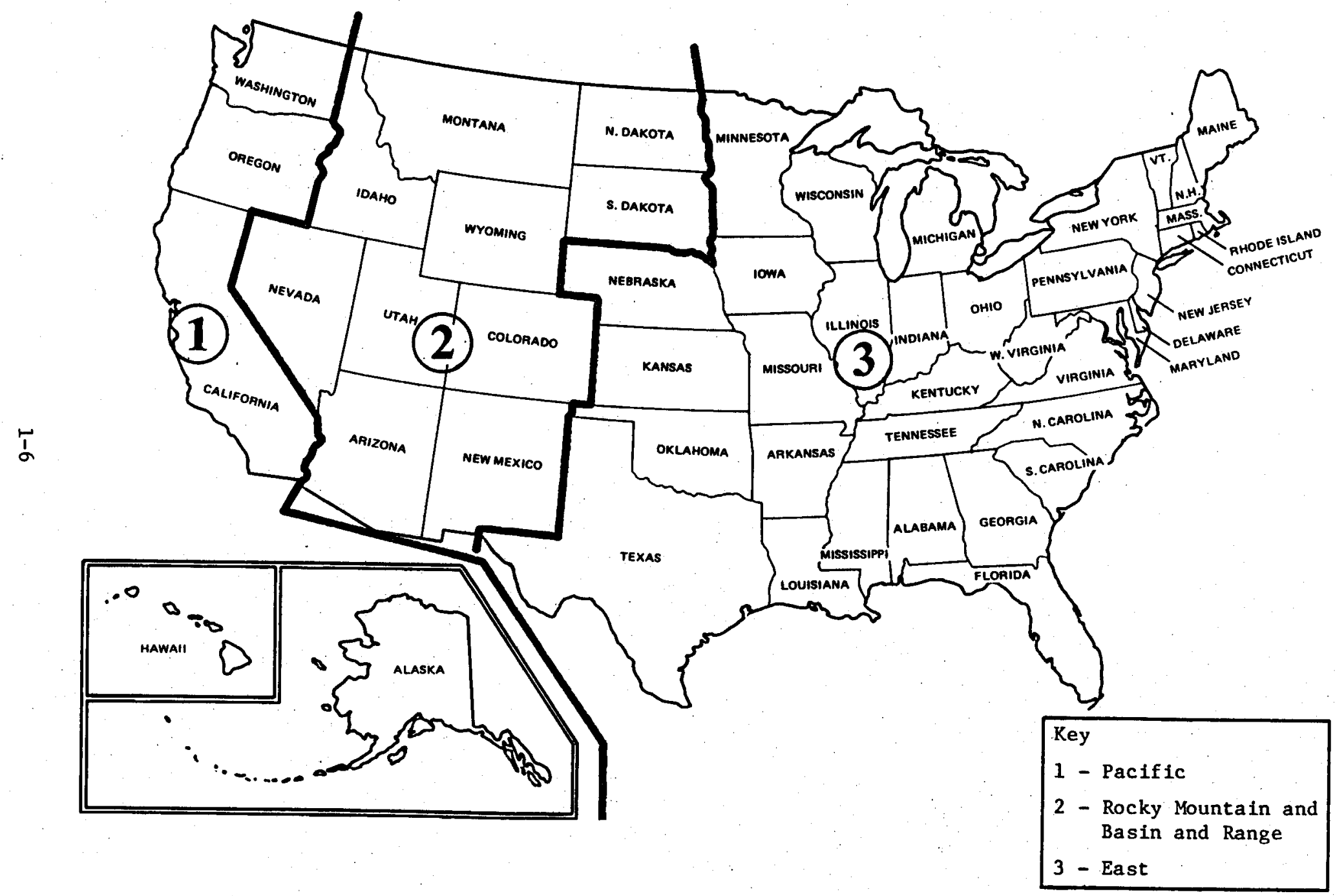

FIGURE 1-2

GEOGRAPHIC BOUNDARIES FOR STUDY REGIONS 


\subsection{GENERAL APPROACH}

\subsection{Overview of the Approach}

The basic requirements of the analysis are to define the size of the market for geothermal hydrothermal direct heat installations in the years 1980-2020 and to estimate the rate at which this market is most likely to be penetrated.

A regional analysis is used for estimating market shares growth for hydrothermal direct heat because:

- Much of the relevant data available from the programs of the Department of Energy (DOE) Is organized into regional subsets.

- Some of the major DOE program activities are organized along regional lines, suggesting that these regions form areas within which geothermal technology will tend to diffuse.

The basic assumption is that, in each region, the main hydrothermal direct heat market share is captured in those densely populated areas in close proximity to techno-economically suitable hydrothermal resources. However, market demand for additional noncolocated hydrothermal direct heat applications could be filled with relocation of some industries that could take advantage of available distant hydrothermal resources to supply all or part of its direct heat process requirement.

No explicit assumption is made about whether the hydrothermal resource to which an industry relocates is colocated or noncolocated with an existing market. However, it seens most likely that most such relocations would be to a colocated resource because this would 
allow the industry to take advantage of existing industrial infrastructure and labor markets.

The market penetration model developed in this study to forecast the market share growth of direct use of hydrothermal energy, in either the resource colocated or noncolocated direct heat markets, involves:

- The estimation of the initial market share of hydrothermal direct heat utilization as a fraction of the maximum direct heat market potential (i.e., baseline market) that could be totally captured in the long run.

- The use of a technology substitution model (B1ackman's mode1) (5) to forecast the year-by-year growth of that initial market share fraction over the next 40 years in each region, as well as in the whole United States.

The initial market captured in the resource colocated markets for direct heat applications is determined by the extent of existing and/or planned hydrothermal direct heat utilization at a time when such utilization becomes large enough to ensure a future selfsustained market growth (6).

During this study, it became apparent that the current rates of hydrothermal direct heat installation, including announced plans for installations to 1985 , seem to be too low to stimulate the identified markets into self-sustained rapid commercialization of this resource. This is especially the case for the colocated hydrothermal markets in the Eastern region and the noncolocated hydrothermal markets in all regions. Therefore, consideration of the potential impact of additional government-stimulated installations was added to the study 
to estimate the extent to which government stimulation might have to be provided to achieve certain levels of hydrothermal direct heat installation by 2000 and 2020 .

\subsection{Elements of the Analysis}

The main elements in this analysis are listed in Table 2-1.

The analysis treats three regions independently. These regions, Pacific (five states), Rocky Mountain Basin and Range (ten states), and Eastern (thirty-three states), conform to the way in which the DGE hydrothermal direct use commercialization program is organized. Louisiana and Texas have been omitted because geothermal direct heat use there is assumed to be coupled to the geopressured geothermal program, a distinct subset of DGE activities.

There appears to be two distinct markets for use of direct heat from hydrothermal resources. The colocated markets are centers of population and industry located within $50 \mathrm{miles}$ of a good hydrothermal resource. The noncolocated markets consist of certain industries that are located more than 50 miles from a good hydrothermal resource but might be able to use hydrothermal energy to economic advantage if they were to relocate. The 50-mlle criterion was issued because this distance is the apparent general 11mit for the economic transmission of geothermal fluids for direct use (see Reference 21).

The sizes of the colocated markets were estimated on the basis of the size of colocated population and energy use per capita. The colocated population size was found by comparing characteristics of 
Element of Approach

Regional Basis

Resource and Market Colocation

Colocated Market Size

Noncolocated Market Size

Market Growth Rates

Market Penetration Rates

Effects of Government Actions

\section{Description}

Three regions selected to conform to organization of DOE hydrothermal commercialization efforts.

Based on 50-mile limit for economic transportation of hydrothermal energy

Based on population density and size of resource-colocated markets, per capita energy use in residential, commercial, and industrial sectors, and suitability match between sector demand and hydrothermal energy characteristics.

Based on annual energy use in six industries that might relocate to use hydrothermal energy.

Based on prediction of trends in regional sectors.

Based on technology substitution kinetics, modeled after market penetration of natural gas use.

Modelled upon kinetic effects of government-stimulated additional installations by end of 1985. 
cities and characteristics of hydrothermal resources within 50 miles of each other to a set of characteristic criteria that is expected to dominate the successful commercialization of hydrothermal energy. These criteria* establish the boundary conditions within which hydrothermal direct use is expected to be economically advantageous in the 1980-1990 time frame and beyond.

The final estimates of the size of the colocated markets take into account the regional energy use per capita in the residential, commercial, and industrial sectors, and the thermodynamic and social suitability for using hydrothermal energy in each sector.

The size of the noncolocated regional markets is based on the current energy consumption in six industries whose energy needs are we11 matched to hydrothermal use. These are food and kindred products, tobacco, textiles, lumber and wood, paper and pulp, and chemicals.

Estimated growth rates for the colocated and noncolocated hydrothermal markets are based on recent regional energy consumption trends and predictions of long-range factors that might alter those trends. The growth rates include consideration of probable rates of discovery of new hydrothermal resources near markets that are currently not resource-colocated.

\footnotetext{
* These criteria are discussed in detall in Appendix B.
} 
The combination of hydrothermal baseline markets and market growth rates provides a moving target of markets that could be captured by hydrothermal energy systems. In this study the rate at which this market is predicted to be captured is based on Blackman's model of technology substitution (5). The behavior of the model as used here is dominated by two parameters: (1) the initial market share captured by the new technology expressed as a fraction of the maximum possible market share, and (2) a takeover time which varies with the characteristics of the new technology.

The takeover time for hydrothermal market penetration is assumed to be 60 years (for the hydrothermal market share to grow from 10 percent to 90 percent of the hydrothermal baseline market). This is the historical takeover time for the market penetration of natural gas, the energy source and delivery system whose infrastructure requirements most closely resemble those of hydrothermal energy. Sensitivity analyses were performed to estimate the effects of varying the assumed takeover time.

The impacts of different initial hydrothermal market shares (in 1985) upon predicted hydrothermal use to 2020 were examined. A base case was studied where the initial market shares at the end of 1985 were assumed to be the regional installations already in place plus announced plans for hydrothermal direct heat installations (both privately funded and cost-shared by DOE). This base case leads to a. low market penetration by 2020 . Additional cases were studied where different levels of government-stimulated installations are achieved 
by the end of 1985. These cases lead to significant market shares for hydrothermal direct use in 2000 and beyond especially in 2020.

\subsection{General Definitions}

The following terms are used in this report to identify different markets with respect to their distribution over space and time, and their suitability for applications of hydrothermal energy. Initial Year - The year in which the fractional market share captured has reached the necessary threshold (i.e., 2 percent or more) for further self sustalned market penetration and, hence, for technology substitution models to be applicable (6). For analytical reasons and purposes described later, the initial year is set at 1985 in all regions. This variable is designated as $\mathrm{T}_{0}$.

Colocated Markets - These are resource-colocated centers of demand or amounts of demand. The colocated markets are within 50 miles of a known or suspected hydrothermal resource. They must also meet certain other criteria to be favorable for hydrothermal direct heat development. Colocated markets of various types are designated by the subscript "C."

Noncolocated Markets - These are certain Industries whose direct heat energy needs are of a nature that is favorable for use of hydrothermal energy, but which are mostly located more than 50 miles from a hydrothermal resource. These resource-noncolocated markets are designated by the subscript "N." 
Direct Heat Demand - The total direct heat market, in quads/ year, in a given region in a given year (exclusive of heat from electricity). Only part of this demand is thermodynamically and socially suitable for application of hydrothermal direct heat. The direct heat demand in any region is designated by $D_{C}(t)$ for colocated markets and $D_{N}(t)$ for noncolocated markets. Baseline Hydrothermal llarket - This is the demand (quads/year)* that is thermodynamically and socially suitable for use of hydrothermal direct heat. In this study the size of this market is calculated in such a manner that all of this market could ultimately be served by hydrothermal energy. The baseline hydrothermal market is designated by $B_{C}(t)$ and $B_{N}(t)$ for colocated and noncolocated markets, respectively.

Hydrothermal Market Share - This is the portion of the baseline hydrothermal market $\left(B_{C}(t)\right.$ or $\left.B_{N}(t)\right)$ that is captured or estimated to be captured by actual use of hydrothermal energy in any specified year. The hydrothermal market share (quads/year) is designated by $S_{C}(t)$ for the colocated market and $s_{N}(t)$ for the noncolocated market.

Hydrothermal Market Fraction - This dimensionless fraction, $F_{C}(t)$ or $F_{N}(t)$, designates the fraction of the baseline hydrothermal market that has been captured or estimated to be captured by the Installation of a hydrothermal energy system. $F(t)$ is simply:

*One quad equals $10^{15}$ BTU. 
$F(t)=S(t) / B(t)$

Initial Hydrothermal Market Share - This market share represents the initial year (1985) hydrothermal installation (quads/year) and is designated by IHS. As such, IHS includes all current installations plus announced plans for such installations in 1980-1985, as known to MITRE as of May 1980 .

Initial Government Buy - An initial government buy is an incremental initial hydrothermal market share (above the IHS) brought into place by the end of 1985 through Federal and/or State stimulatory actions. This buy is designated by "IGB," and is given in units of quads/year.

The detalls of how such incremental market shares are achieved are of no consequence in the model, except that the increments should be regionally distributed in proportion to the known reglonal hydrothermal markets to optimize their cost effectiveness (see section 4.6.1). 
Blank

$2-19$ 


\subsection{ESTIMATES OF MARKET SIZE}

\subsection{Colocated Hydrothermal Baseline Market}

The main factors governing the colocated regional hydrothermal markets are: (1) the geographic boundaries of the region, (2) the hydrothermal resource avallability in that reglon, (3) the potiential of resource colocated markets for direct heat application; and (4) the sut tability Index of the hydrothermal resource for the type of direct heat applications in that region. The sequence for deve1oping these factors is shown in Figure 3-1.

Reglonal Geographic Boundarles. The geographic boundaries for each of the three regions under study (1.e., Pacific, RMB \& $R$, and Eastern) are defined in Figure 1-2. The Pacific region includes five states: California, Washington, Oregon, Hawa11 and Alaska. The RMB \& R region consists of the ten states of Arlzona, Colorado, Idaho, Montana, Nevada, North and South Dakota, Utah and Wyoming. The Eastern region covers all the remaining 35 states of the U.S. except for Texas and Loulsiana. The general energy supply-demand situation is detailed for each region in Appendix A.

As shown by Bloomster's 10 temperature (1.e., $50^{\circ}-150^{\circ} \mathrm{C}$ ) hydrothermal water supply curve (7), the U.S. potentlal hydrothermal heat supply from identifled resources (within the fossil fuel competitive cost range of $\$ 2$ to $\$ 6$ per million Btu) amounts to about 10 quads/ year capacity for 30 years. This supply includes both marketcolocated and market-noncolocated resources. Most of the Identified 


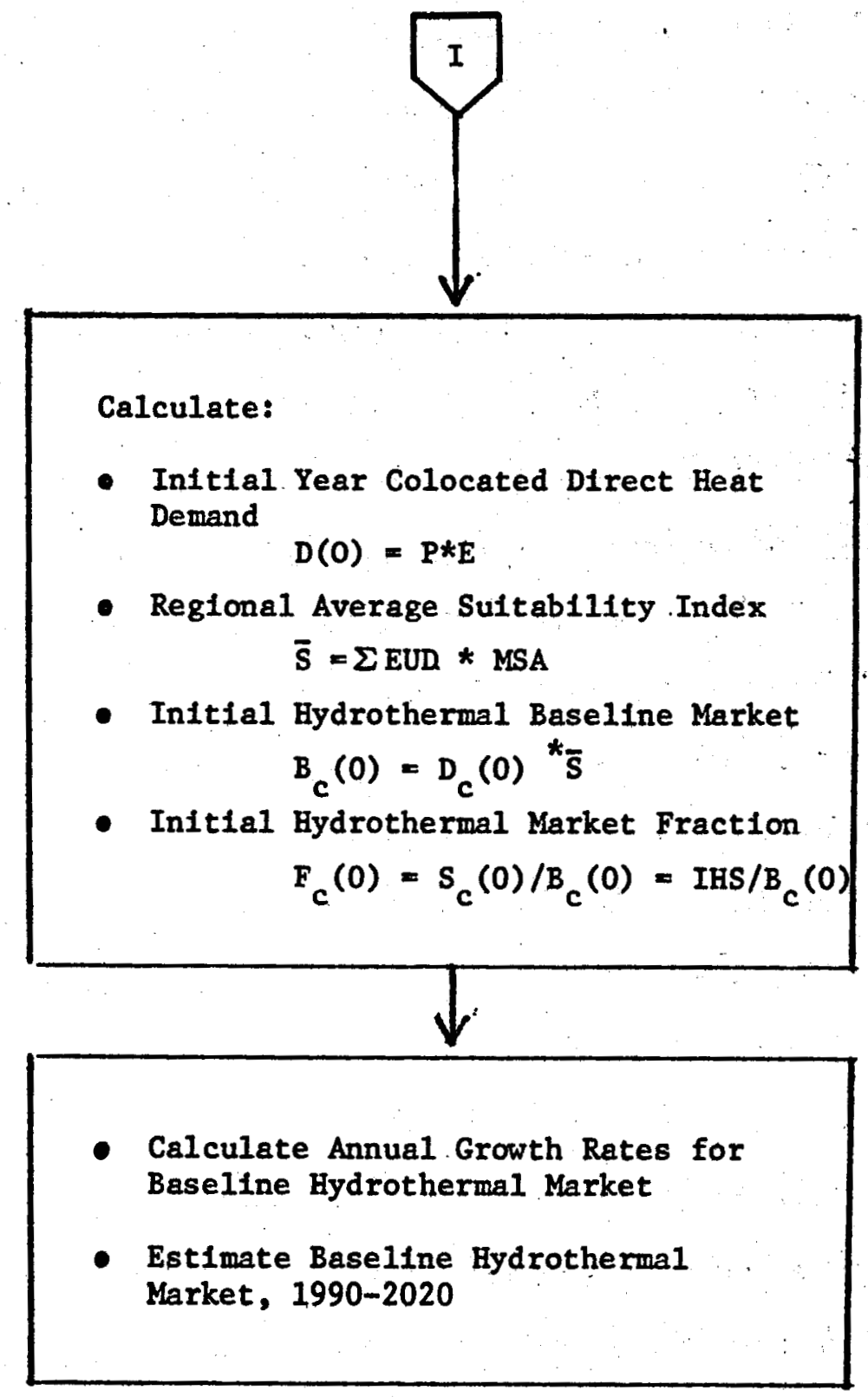

FIGURE 3-1

METHOD FOR ESTIMATING INITIAL HYDROTHERMAL MARKET IN EACH REGION 
Do For

Each Region

$\downarrow$

- Regional Resource Data (RD)

- Regional Colocated Population (P)

- Reglonal Colocated Market Growth Factors (G)

- Regional Per Capita Energy Needs (E)

- Resource Techno Economic Criteria (TEC)

- Initial Penetration Year T

- Reglonal Maximum Sultability Indices (MSA)

- Regional Direct Heat End-Use.

- $\mathrm{L}=.1$

- Intt1al Hydrothermal Share (IHS)

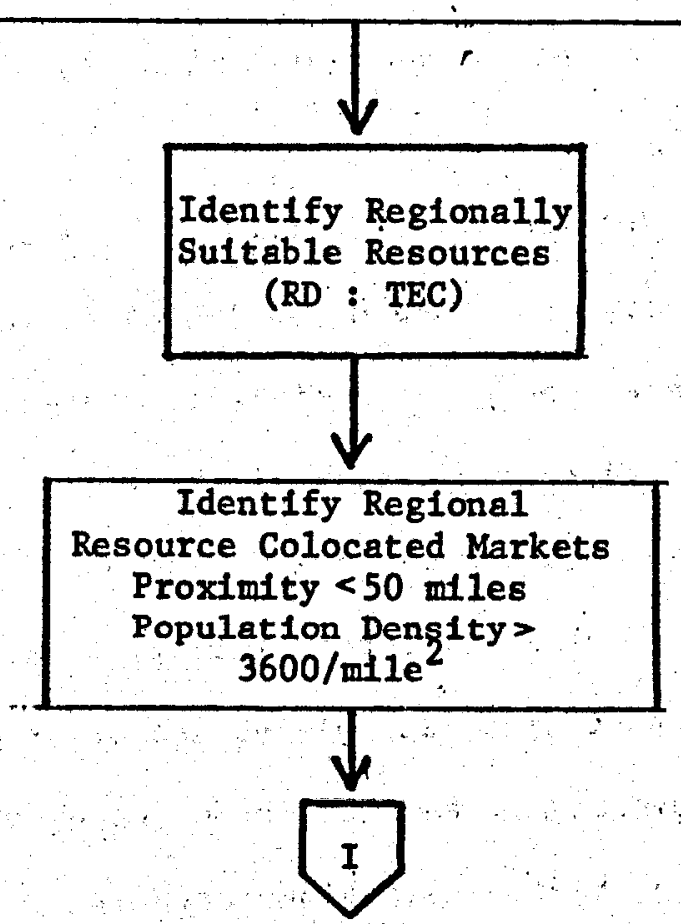

FIGURE 3-1

METHOD FOR ESTIMATING INITIAL HYDROTHERMAL MARKET IN EACH REGION (CONCLUDED) 
supply falls in the Pacific and RMB \& $R$ regions. At least 2 quads/ year of economical hydrothermal resource are known for the Pacific region (8), and at least 3 quads/year for the RMB \& $R$ region (9). The value for the Eastern region is largely uncharacterized. Preliminary analyses indicated that this supply situation seems more than adequate to cover all expected demand for hydrothermal direct heat utilization on elther the regional or national level to at least the year 2000. Thus the market for hydrothermal direct heat applications appears to be, constrained more by the size of hydrothermal-sultable demand rather than by overt lack of hydrotherma1 supply.

Regional Resource Avallability. The large number of hydrothermal resource sites that are of ten listed for each of the U.S. regions and the estimated energy potential associated with such resources present a misleading impression of the true potential for regional geothermal direct heat utilization. Because of the nature of the resource (e.g., salinity, depth, well flow rate), the capital intensiveness of direct heat technology, and other considerations as detailed in Appendix B, many of these resources of fer little if any practical direct heat application potential.

With this in mind, the published data $(2,10)$ for low temperature $\left(50^{\circ}-150^{\circ} \mathrm{C}\right)$ hydrothermal resources reglonally avallable for replacing other existing energy sources (e.g., electric, coal, ofl, natural gas and solar) in direct heat application market was 
TABLE 3-1

KEY FACTORS AFFECTING DIRECT HEAT APPLICABILITY OF HYDROTHERMAL WATER

\begin{tabular}{|c|c|c|}
\hline $\begin{array}{c}\text { TYPE OF } \\
\text { APPLICATION }\end{array}$ & $\begin{array}{c}\text { KEY } \\
\text { FACTORS }\end{array}$ & $\begin{array}{c}\text { CRITICAL } \\
\text { VALUE }\end{array}$ \\
\hline Residential/Commercial & $\begin{array}{l}\text { - Heat Load } \\
\text { - Saturation Level } \\
\text { (\# of customer In } \\
\text { service area) } \\
\text { - Peak to Base } \\
\text { Load } \\
\text { - Distance } \\
\text { - Type of Heating } \\
\text { System } \\
\text { Salinity } \\
\text { - Retrofit Cost } \\
\text { - Hook-up Cost } \\
\text { Social } \\
\text { Acceptance } \\
\text { - Fuel Savings per } \\
\text { Dollar Invested } \\
\text { - Acceptability } \\
\text { Increased Crop } \\
\text { Dollar Y1eld } \\
\text { per Dollar } \\
\text { Invested } \\
\text { Boron Concentra- } \\
\text { thermal Water } \\
\text { - }\end{array}$ & 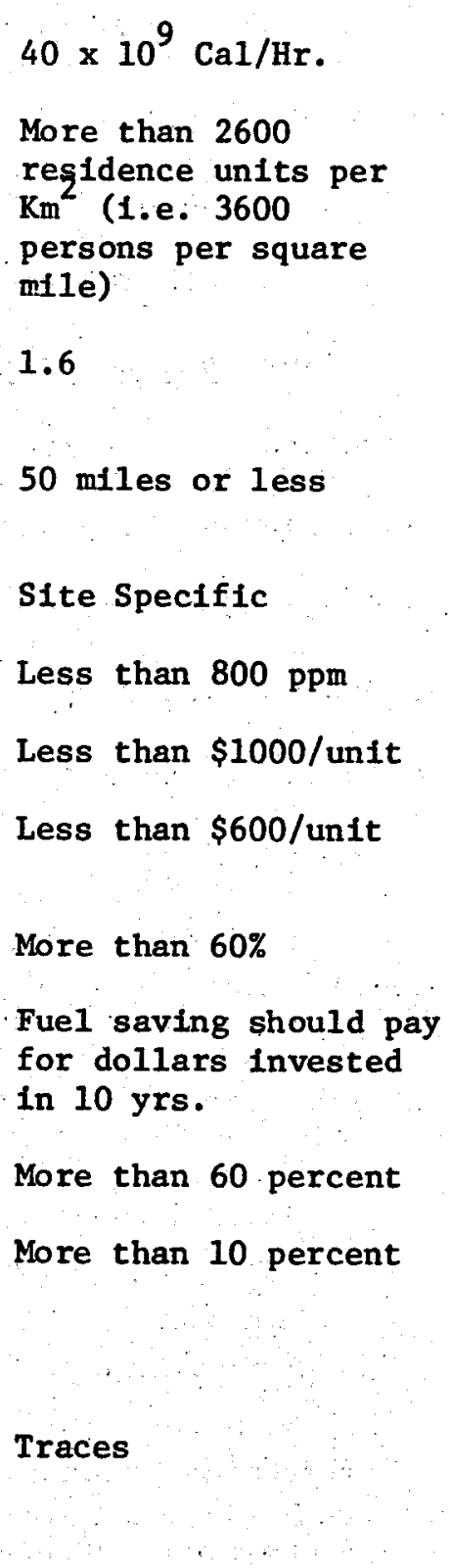 \\
\hline
\end{tabular}


examined. These regional resource data were compared to the set of techno-economic criteria* shown in Table 3-1 to eliminate from further consideration resources which, for one reason or other, could not be considered a feasible supply site for direct heat application. The resources remaining after this selective screening of resource sites are listed in Table 3-2. The locations of these resources are shown in Figure 3-2. These resources represent techno-economically suitable and market-colocated supply sites for direct heat applications in each region.

Regional Colocated Markets. Many otherwise suitable low temperature hydrothermal resources cannot be utilized for direct heat applications because of excessive distance between resource supply and demand sites, or the low population density at the demand center, or both. Users' proximity (i.e., 50 miles or less) to the resource site (11), and a population density of 2,600 persons per square kilometer (12) are the most important factors in the economics of geothermal direct heat utilization.

Regional colocated potential markets for geothermal direct heat utilization were therefore determined by a statewide identification of all potential markets (i.e., cities) that have a population density of over 2,600 persons per square kilometer** and that fall

\footnotetext{
* These criteria are originally identified in Appendix B. **Although this threshold population size does not apply to industrial process heat use, it implicitly indicates an economic energy demand level for residential/commercial and industrial ${ }^{\prime}$ applications.
} 
within 50 miles of the resources listed in Table 3-2. For each region, the state-by-state number of potential users in all identified resource colocated markets with acceptable population densities is indicated in Table 3-3. Following J. Karkhick et al. (12), these population statistics were used to estimate the potential of direct heat energy needs in each resource colocated market by the application of the appropriate per capita energy need multiplier as detalled in Table 3-4, For the Pactfic and Eastern regions, the Initial year resource-colocated direct heat demand $D_{c}(0)$ are thus estimated to be 0.21 and 0.96 quads/year, respectively. For the RMB \& $R$ region, the Initial colocated direct heat demand is estimated to be 0.43 quads/year. This is reasonably close to the EG\&G field study (9) estimate of 0.46 quads/year colocated demand for 1985 . The EG\&G estimate was based on an analysis of colocation of population and industry to known geothermal resources within county borders, and can be viewed as more accurate than that developed here. Therefore the value of 0.46 quads/year was adopted as the $D_{c}$ (1985) for the RMB \& R region.

The percentage distribution of the resource-colocated direct heat demand between residential, commerclal, and industrial sectors for the three regions and the predicted quads/year of regional end-use demand in 1985 (the initlal year for the market penetration rate analysis in Section 4.0 ) are given in Table 3-5. 
TABLE 3-2

REGIONALLY AVAILABLE TECHNO-ECONOMICALLY SUITABLE HYDROTHERMAL RESOURCES

$$
\text { FOR }
$$

DIRECT HEAT APPLICATIONS

\begin{tabular}{|c|c|c|}
\hline PACIFIC REGION RESOURCES & RMB\&R RESOURCES & EASTERN REGION RESOURCES \\
\hline $\begin{array}{l}\text { North End of Tenakee Inlet, AK } \\
\text { Hooniah Hot Springs, AK } \\
\text { Near Fish Bay, AK } \\
\text { Arrowhead Hot Springs, CA } \\
\text { Skaggs Hot Springs, CA } \\
\text { Sespe Hot Springs, CA } \\
\text { Calistoga Hot Springs, CA } \\
\text { Glamis, CA } \\
\text { Glamis East, CA } \\
\text { Dunes, CA } \\
\text { Susanville Area, CA } \\
\text { Honolulu, HI } \\
\text { Puna Area, HI } \\
\text { Klamath, OR } \\
\text { Harney Lake Area, OR } \\
\text { Crane Hot Springs, OR } \\
\text { Riverside Area, OR } \\
\text { Belknap Hot Springs, OR } \\
\text { Foley Hot Springs, OR } \\
\text { Yakima Area, WA }\end{array}$ & $\begin{array}{l}\text { Thermopolis Area, WY } \\
\text { Tucson, AZ } \\
\text { Power Ranches, Inc., AZ } \\
\text { Yuma Area, AZ } \\
\text { Mt. Princeton H.S., Co } \\
\text { Poncha H.S., CO } \\
\text { Waunita H.S., CO } \\
\text { Bolse Area, ID } \\
\text { Moana Area, Reno, NV } \\
\text { Las Vegas, NV } \\
\text { Elko H.S., NV } \\
\text { Cherry Creek Area, NV } \\
\text { Radium Hot Springs, NM } \\
\text { Logan Area, UT } \\
\text { Salt Lake - Provo Area, UT } \\
\text { Bruneau-Grand View, ID } \\
\text { Raft River, ID } \\
\text { ID }\end{array}$ & $\begin{array}{l}\text { Hartford Area, RI } \\
\text { Delmarva Penn. Area, MD } \\
\text { Pensacola Area, FL } \\
\text { Tampa - St. Petersburg, Area, FL } \\
\text { Miami Area, FL } \\
\text { Savannah Area, GA } \\
\text { Terre-Haute Area, IN } \\
\text { Evansville Area, IN } \\
\text { South Bend Area, IN } \\
\text { Indianapolis Area, IN } \\
\text { Kansas City Area, KS } \\
\text { Salisbury Area, MD } \\
\text { Southern New Jersey Coastal } \\
\text { Area, NJ } \\
\text { Trenton Area, PA } \\
\text { Norfolk - Portsmouth Area, VA } \\
\text { Roanoke Area, VA } \\
\text { Richmond Area, VA }\end{array}$ \\
\hline
\end{tabular}




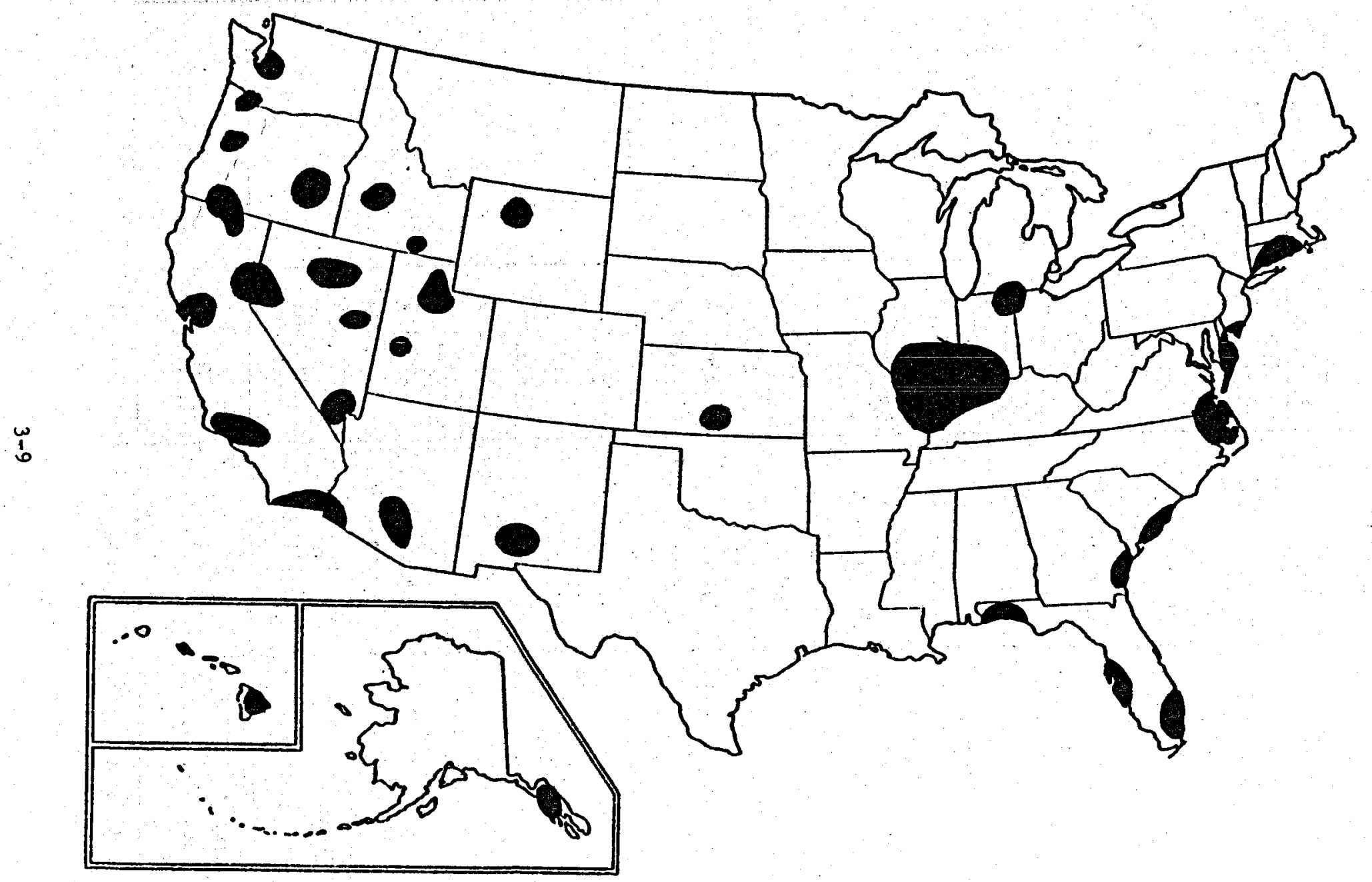

FIGURE 3-2

TENTATIVE LOCATIONS OF MARKET COLOCATED LOW TEMPERATURE $\left(50^{\circ}-150^{\circ} \mathrm{C}\right)$ HYDROTHERMAL RESOURCES IN THE UNITED STATES 
TABLE 3-3

REGIONAL COLOCATED MARKET POPULATION

\begin{tabular}{|c|c|c|c|}
\hline \multirow[t]{2}{*}{ REGION } & \multirow[t]{2}{*}{ STATE } & \multicolumn{2}{|c|}{ ESTIMATED COLOCATED POPULATION } \\
\hline & & 1985 & 2005 (MATURITY DATE) \\
\hline $\begin{array}{l}\text { PACIFIC } \\
\text { RMB\&R } \\
\text { EASTERN }\end{array}$ & $\begin{array}{l}\text { Alaska } \\
\text { California } \\
\text { Hawaii } \\
\text { Oregon } \\
\text { Washington } \\
\text { ** } \\
\text { Arizona } \\
\text { Colorado } \\
\text { Idaho } \\
\text { Montana } \\
\text { Nevada } \\
\text { New Mexico } \\
\text { Utah } \\
\text { Wyoming } \\
\text { ** } \\
\text { Connecticut } \\
\text { Delaware } \\
\text { Florida* } \\
\text { Georgia } \\
\text { Indiana } \\
\text { Kansas } \\
\text { Maryland } \\
\text { New Jersey. } \\
\text { Virginia }\end{array}$ & $\begin{array}{r}5,027,583 \\
274,521 \\
3,358,029 \\
918,775 \\
424,680 \\
51,578 \\
2,142,968 \\
1,257,559 \\
7,548 \\
194,504 \\
23,698 \\
315,918 \\
45,716 \\
294,565 \\
3,450 \\
4,271,854 \\
138,152 \\
119,637 \\
1,675,496 \\
110,348 \\
1,097,181 \\
168,153 \\
16,624 \\
217,658 \\
728,605\end{array}$ & $\begin{array}{l}3,389,227 \\
5,174,204\end{array}$ \\
\hline $\begin{array}{l}\text { Total Colocated } \\
\text { Market Population }\end{array}$ & & $11,442,425$ & $16,338,920$ \\
\hline
\end{tabular}

* Highest population in region

**Lowest population in region 
TABLE 3-4

DIRECT GEAT ENERGY DEMAND

IN RESOURCE COLOCATED MARKETS IN DIFFERENT U.S. REGIONS

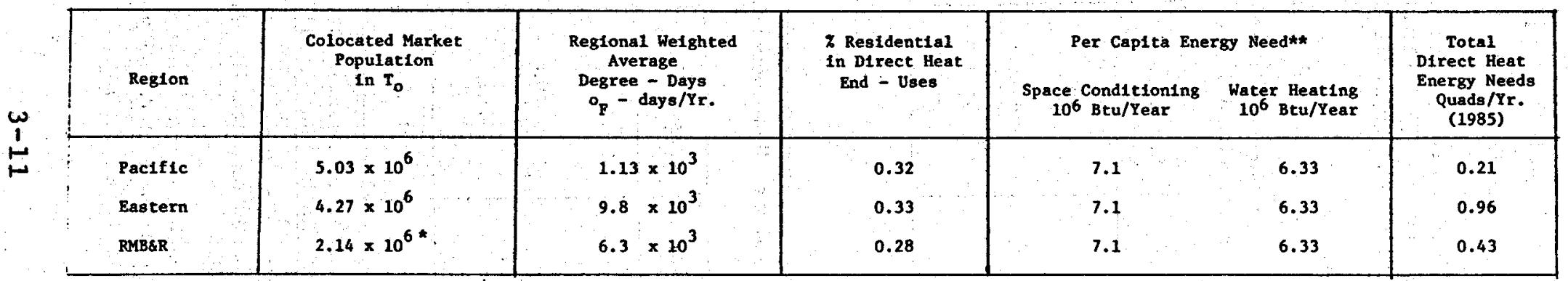

* The RMB\&R colocated market in this study is based on EG\&G fleld study for this region and amounts to 0.46 quad/year which $1 \mathrm{~s}$ not significantly different from the calculated figure of 0.43 quads/year shown above.

** Frank Kretth, Jan P. Kreider, Principles of Solar Engineering (Hemisphere Publishing Corporation, McGraw Hill Book Co., 1978). 
TABLE 3-5

RESOURCE-COLOCATED DIRECT HEAT DEMAND IN END-USE SECTORS;

PERCENTAGE AND QUADS/YEAR

\begin{tabular}{|c|c|c|c|c|}
\hline \multirow{2}{*}{$\begin{array}{c}\text { Region } \\
\text { Residential }\end{array}$} & \multicolumn{4}{|c|}{$\begin{array}{c}\text { Percentage Distribution of Direct } \\
\text { Heat Demand in Sector, Circa 1985 }\end{array}$} \\
\cline { 2 - 5 } & Commercial & Industrial & Total \\
\hline Pacific* & 32 & 16 & 52 & 100 \\
Eas\&R* & 28 & 42 & 30 & 100 \\
\hline
\end{tabular}

\begin{tabular}{|l|c|c|c|c|}
\hline \multirow{2}{*}{ Region } & \multicolumn{3}{|c|}{ Direct Heat Demand, 1985 (Quads/Year) } \\
\cline { 2 - 5 } & Residential & Commercial & Industrial & Total \\
\hline Pacific & 0.068 & 0.034 & 0.107 & 0.21 \\
EMB\&R & 0.129 & 0.193 & 0.138 & 0.46 \\
\hline Total & 0.316 & 0.221 & 0.422 & 0.96 \\
\hline
\end{tabular}

* Distribution Figures are Based on Data In JPL Publication 79-XX, Geothermal Direct Heat Use, Market Potential/Penetration Analysis for Federal Region IX (AZ, $\mathrm{CO}, \mathrm{HA}, \mathrm{NE})$.

** Distribution Figures are Based on Data In EG\&G, Regional Hydrothermal Commercialization P1an RMB\&R.

*** Distribution Figures are Based on Data Published by Aerospace Corporation, Solar Thermal Dispersed Power Program - Total Energy Project, CA., 1978. 


\section{Suitability Index}

Only a portion of the direct heat demand shown in Table 3-5 can be wet by hydrothermal energy systems. In an economically attractive resource colocated market, the extent to which hydrothermal energy can be utilized for a given direct heat application is ultimately controlled by thermodynamic and social considerations, and is expressed in terms of a suitability index. Assuming a fifty percent likelihood of social acceptance, the Reistad (13) sultability index, SI, shown in Table 3-6, represents the fractional demand that could be satisfied by hydrothermal energy in various types of direct heat applications (in the temperature range of $50^{\circ}-150^{\circ} \mathrm{C}$ ) with the highest possible thermodynamic efficiency. Based on this table, and the 1985 regional percentage distribution of varlous types of direct heat applications (14) (e.g., residential, commercial and industrial applications (Table $3-5)$ ), the welghted average sultability indices SI for geothermal heat application in the Paciflc, RMB \& $R$ and Eastern regions are $0.15,0.18$, and 0.16 , respectively. The national welghted average suitability index is similarly estimated to be 0.163.

The hydrothermal baseline market (In any year), $B_{c}(t)$, is the maximum colocated direct heat market share, in absolute energy use units (e.g., quads), which could be satisfied by geothermal energy in that year. As such, the baseline market, represents the upper boundary limit for hydrothermal direct heat market penetration potential in a given year. 
With this in mind, the baseline market $B_{C}(t)$ for hydrothermal direct heat application in any region is calculated as the product of the colocated market demand $D_{c}$ and the weighted average suitability

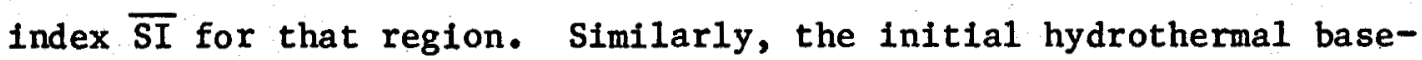
Iine market for the U.S. is the product of the total regional colocated market demand and the national weighted average sultability index.

Accordingly the intial year (1985) baseline hydrothermal markets for the regions are (total for all three end-use sectors):

- Pacific: $0.21 \times 0.15=0.032$ quads/year,

- $R M B \& R: 0.46 \times 0.18=0.083$ quads/year,

- Eastern: $0.96 \times 0.16=0.153$ quads/year, and

- Total U.S.: = 0.268 quads/year; or approximately 0.27 quads/ year

\subsubsection{Market Growth Rates}

It should be noted that the initial colocated market demand will grow with time. In any year following the penetration year $T_{0}$, it is therefore necessary to adjust the initial colocated market demands $D_{c}(0)$ by a growth factor which allows for the expected reglonal growth in $\mathrm{D}_{c}(0)$ due to possible regional new resource discovery, expected regional population growth and future growth in per capita energy demand. The rate of discovery of new market-colocated resources is at about 0.5 percent per year, based on known rates of discovery for the region. Each region's growth is a function of the rate of population growth, the rate of growth of land value, and 
changes in regional wealth, business activity and urbanization (14, 15, 16). Finally, the regional growth in energy demand is deternined by the projected historical trend for direct heat energy demand per capita in the region.

For the $R M B$ \& $R$ region, the colocated market potential growth factor is based on an EG\&G field study. The colocated market potential growth factor for the Pacific and Eastern regions is estimated as shown in Appendix D. The expected growth rates for the baseline colocated hydrothermal market for the Pacific, RMB \& R, and Eastern regions are $4.5,3.3$, and 4.3 percent per year, respectively.

\subsubsection{Baseline Colocated Hydrothermal Market to 2020}

Table 3-7 presents this study's estimate of the baseline colocated hydrothermal market in the period 1985-2020. This is the total resource-colocated direct heat market that could be captured by hydrothermal energy systems to 2020 , provided there are no great structural changes in the U.S. energy economy.

The present analysis is structured such that all of the market depicted in Table 3-7 could ultimately be captured by hydrothermal energy systems without abnormal relocation of industry or population.

Estimates of the additional hydrothermal market that might be available if certain industries were to relocate are made in Section 3.2. Estimates of the rates at which these markets might be captured are given in Section 4.0 . 
TABLE 3-6

SUITABILITY INDEX

OR

POTENTIAL OF DIRECT HEAT APPLICATIONS

\begin{tabular}{|l|c|}
\hline TYPE OF APPLICATION & $\begin{array}{c}\text { MAXIMUM FRACTIONAL } \\
\text { DEMAND SUITABLE } \\
\text { FOR HYDROTHERMAL ENERGY } \\
\text { (SUITABILITY INDEX) }\end{array}$ \\
\hline Space Heating & 0.35 \\
Water Heating & 0.16 \\
Refrigeration & 0.24 \\
Air Conditioning & 0.09 \\
Process Heating & 0.09 \\
Other (e.g. Agricultural Uses) & 0.11 \\
\hline
\end{tabular}

- Average Suitability Index for Residential/Commercial $=0.22$

- Average Suitability Index for Industrial Usage $=0.09$ 


\subsection{Noncolocated Hydrothermal Baseline llarket}

According to Lindal (17) and others, the main criteria that governs the decision of industry to relocate so as to take advantage of a new energy resource are:

(1) The cost of energy per unit cost of product (i.e., the energy intensiveness of industry) must exceed ten percent;

(2) The cost of fuel saved by shifting to the new energy source must be enough to pay for the necessary equipment retrofit in less than ten years.

On the basis of these criteria, six industries, namely food and kindred products, tobacco, textiles, lumber and wood, paper and pulp, and chemicals have been identifled as those using significant amounts of hot process water or low pressure steam in the temperature range of $50^{\circ}-150^{\circ} \mathrm{C}$ per ton of output and could therefore be considered as the most promising potential users for hydrothermal water in this temperature range.

For better logistics, labor availability, marketing outlets, and other economic advantages, some of the foregoing industries are already located in regions that are also endowed with hot hydrothermal water of sultable temperature for these industries. It is therefore conceivable that some of these industries would be willing to relocate within these regions to take advantage of such reglonally avallable hydrothermal resources to f1ll some of their industrial process heat requirements. Based on published statistics (14), the estimated low temperature $\left(1 . e,, 50^{\circ}-150^{\circ} \mathrm{C}\right.$ ) heat consumption for these industries in the U.S. by 1985 is 7.42 quads/year. Because of 
TABLE 3-7

BASELINE COLOCATED MARKETS 1985-2020

(Quads/Year)

\begin{tabular}{|c|c|c|c|c|}
\hline \multirow{2}{*}{ Year } & \multicolumn{4}{|c|}{ REGION } \\
\cline { 2 - 5 } & Pacific & RMB\&R & Eastern & U.S.* \\
\hline 1985 & 0.032 & 0.083 & 0.153 & 0.27 \\
1990 & 0.045 & 0.98 & 0.207 & 0.35 \\
1995 & 0.058 & 0.119 & 0.273 & 0.45 \\
2000 & 0.070 & 0.141 & 0.369 & 0.58 \\
2005 & 0.080 & 0.160 & 0.510 & 0.75 \\
2010 & 0.110 & 0.200 & 0.660 & 0.97 \\
2015 & 0.148 & 0.250 & 0.862 & 1.26 \\
2020 & 0.203 & 0.310 & 1.017 & 1.53 \\
\hline
\end{tabular}

*Exclusive of Texas and Louisiana 
techno-economic and thermodynamic limitations, only 16 percent of this low temperature industrial process neat requirement (i.e., $7.42 \times 0.16$ or 1.19 quads/year) could most likely be satisfied by hydrothermal energy. of these 1.19 quads/year, however, an estimated 0.10 quads/year are already accounted for in resource-colocated markets. Therefore, the 1985 noncolocated baseline market is only 1.09 quads/year. The initial regional distribution of this baseline market is. shown in Table 3-9. It is assumed that over the next 40 years the initial (1.e., 1985) reglonal noncolocated hydrothermal d1rect heat baseline market will grow at the weighted average rate of industrial growth for the specific mix of industries* in each region.

The estimated growth of the U.S. noncolocated hydrothermal baseline market and its distribution across the various regions (i.e., Paclfic, RMB \& $R$ and Eastern regions) is shown in Table 3-9. By comparing Tables $3-7$ and $3-9$, it can be seen that the size of the U.S. noncolocated baseline market 1s, for $1985-2005$, more than twice as large as that of the U.S. colocated basellne market. In 1985 , the size of the noncolocated baseline market in the Pacific region alone is the same as the total U.S. colocated baseline market in that year.

\footnotetext{
*Industries suitable for hydrothernal direct heat application.
} 
TABLE 3-8

ESTIMATION OF NON-COLOCATED BASELINE MARKET

FOR HYDROTHERMAL DIRECT HEAT APPLICATIONS

\begin{tabular}{|c|c|c|c|c|c|c|}
\hline $\begin{array}{l}\text { Selected } \\
\text { Industry }\end{array}$ & $\begin{array}{c}1985 \\
\text { U.S.* Total } \\
\text { Direct Heat }\end{array}$ & $\begin{array}{l}\text { Suitability } \\
\text { Index }\end{array}$ & $\begin{array}{l}1985 \\
\text { U.S. Direct } \\
\text { Heat Demand } \\
\text { Suitable for }\end{array}$ & $\begin{array}{l}\text { Reglonal Distr } \\
\text { (Colocated } \\
\text { Suitable Den } \\
\text { thermal Ener }\end{array}$ & $\begin{array}{l}\text { bution } \\
\text { Non-colc } \\
\text { nd for } \\
\text { y Usage }\end{array}$ & $\begin{array}{l}\text { Total } \\
\text { cated) } \\
y \text { dro- } \\
(Q / Y r) \\
\end{array}$ \\
\hline & $\begin{array}{c}\text { Demand } \\
\mathrm{Q} / \mathrm{Yr}\end{array}$ & & $\begin{array}{c}\text { Hydrothermal } \\
\mathrm{Q} / \mathrm{Yr}\end{array}$ & Pacific Region & $\begin{array}{l}\text { RMB\&R } \\
\text { Region } \\
\end{array}$ & $\begin{array}{l}\text { Eastern } \\
\text { Region }\end{array}$ \\
\hline Food \& Kindred & 1.17 & 0.36 & 0.42 & 0.16 & 0.08 & 0.18 \\
\hline Tobacco & 0.03 & 0.50 & 0.02 & - & - & 0.02 \\
\hline Textile & 0.39 & 0.39 & 0.15 & 0.01 & & 0.14 \\
\hline & 0.38 & 0.33 & 0.13 & 0.07 & 0.01 & 0.05 \\
\hline Paper \& Pulp & 1.42 & 0.05 & 0.07 & 0.02 & - & 0.05 \\
\hline Chemicals & 4.04 & 0.10 & 0.40 & & & 0.37 \\
\hline $\begin{array}{l}\text { Total (1.e., } \\
\text { Colocated }+ \\
\text { Non-colocated) }\end{array}$ & 7.43 & $\begin{array}{c}\text { Average }= \\
0.16\end{array}$ & 1.19 & 0.29 & 0.09 & 0.81 \\
\hline \multicolumn{3}{|c|}{$\begin{array}{l}\text { Suitable Industrial } \\
\text { Colocated Demand } Q / Y r\end{array}$} & 0.101 & 0.016 & 0.018 & 0.067 \\
\hline \multicolumn{3}{|c|}{$\begin{array}{l}\text { Non-colocated Baseline Market } \\
\text { Demand } Q / Y r\end{array}$} & 1.089 & 0.274 & 0.072 & 0.743 \\
\hline
\end{tabular}

* Based on 1972 Census of Manufacturers, Vol. 1 - Subject and Special statistics, Issued August, 1976 (U.S. Department of Commerce, Bureau of the Census). 
TABLE 3-9

U.S. AND REGIONAL NONCOLOCATED BASELINE MARKET (1985-2020) (Quads/Year)

\begin{tabular}{|c|c|c|c|c|}
\hline \multirow{2}{*}{ Year } & \multirow{2}{*}{$\begin{array}{c}\text { U.S. Baseline } \\
\text { Market }\end{array}$} & \multicolumn{3}{|c|}{ Regional Baseline Market } \\
\cline { 3 - 5 } & Pacific & RMB\&R & Eastern \\
\hline 1985 & 1.09 & 0.27 & 0.07 & 0.74 \\
1990 & 1.20 & 0.30 & 0.08 & 0.82 \\
1995 & 1.33 & 0.33 & 0.09 & 0.91 \\
2000 & 1.47 & 0.37 & 0.09 & 1.00 \\
2005 & 1.62 & 0.41 & 0.10 & 1.11 \\
2010 & 1.79 & 0.45 & 0.11 & 1.23 \\
2015 & 1.97 & 0.50 & 0.12 & 1.35 \\
2020 & 2.18 & 0.55 & 0.12 & 1.50 \\
\hline
\end{tabular}


Blank

$3-22$

0 


\subsection{HYDROTHERMAL MARKET SHARES}

\subsection{Market Penetration Model}

The basic approaches (1.e., regression, simulation and analytic) that are currently used to estimate the future installation (i.e., market penetration) of new energy technologies are reviewed in Appendix c. The main features of these approaches are summarized in Table C-1.

Inspection of Table c-1 indicates that the "diffuston" or "technology substitution" model is the most approprlate approach now available for the estimation of future market shares of hydrothermal direct heat utilization. The technology substitution model is the only simple approach that is based on both price competitiveness and other non price market factors (e.g., environmental impact, perceived security of supply, ease of maintenance, and other premium attributes of competing energy sources and technologies). Technology substitution models have also been shown by Cassel (18) to adequately represent the investment decision process for low temperature hydrothermal applications. Furthermore, the technology substitution model is flexible, and is conceptually and analytically simple.

A number of new technology substitution models have been developed in recent years to forecast market shares. The most widely used of these models were developed by Blackman (5), Fisher and Pry (19), and Floyd (20) respectively.

The basic assumptions of any substitution model are: 
(1) As indicated by historical evidence, market acceptance and use of a new technology, product, or fuel does not occur immediately upon introduction, but grows slowly following an S-shaped curve, with 3 distinct phases: demonstration, rapid or widespread acceptance, and maturity phase.

(2) Distinct phases of market penetration reflect the interaction of several consumer related factors (8): degree of awareness concerning the existence and performance of the new product or technology, uncertainty about the benefits of these products or technology, consumer desire to wait for product or technology to become cheaper and better, and recent consumer investment in a competing product.

(3) If a substitution has progressed as far as 2 percent of the total consumption, it will proceed to completion (6).

(4) The rate of growth of fractional substitution of a new technology for an existing technology is proportional to the product of the currently attained fractional market share and the remaining fraction of the existing technology left to be substituted (21).

The selection of the most appropriate model for a particular forecast depends on many factors including the context of the forecast, the assumptions underlying each model, and the extent and availability of the required input data for each model.

The Fisher and Pry model gives an overestimated fractional market shares forecast, while Floyd's model is known to give an underestimated prediction (20). Experience with Blackman's model, however, seems to result in more accurate predictions (21). As a result, Blackman's substitution model was selected here to forecast the market share of geothermal direct heat utilization technologies. Blackman's model is represented by the equation (from reference 22): 


$$
F(t)=\frac{L}{1+\left(\frac{L}{F\left(t_{0}\right)}-1\right) * e^{-\alpha\left(t-T_{0}\right)}}
$$

where,

$F(t)=$ the fraction of the market captured by the new technology in any year $t$ following the initlal market penetration year $\mathrm{T}_{\mathrm{O}}$; $L=$ the maximum fractional market share that could be captured in the long-run by the new technology (1.e., market saturation level); $F\left(t_{0}\right)=$ the captured market fraction at time $t_{0}$ (1.e., initial market fraction; also designated here by $\mathrm{F}_{0}$ ); and $\alpha=$ a rate constant that is proportional to the propensity of an adopter of the technology to adopt the technology in the early years of the technology substitution process.

Equation 4-1 gives the fractional market share. The absolute market share, $S(t)$, in quads/year is given by:

$$
S(t)=F(t) * B(t)
$$

where:

$B(t)$ Is the baseline hydrothermal market (either colocated or noncolocated) as defined in Section 3.0 .

The effects of various values of $\alpha$, the market penetration rate constant, are most easily understood in terms of a related parameter, the takeover time, $T$. $T$ is the number of years required for the fractIonal market share $F(t)$ to grow from 0.10 to 0.90 . The derived relationsh1p between $\alpha$ and $\tau$ is:

$$
T=4.3944 / \alpha
$$


Referring to equations $4-1$ and $4-3$, the parameters that specify

the model are $L, \tau, T_{O}$, and $F_{O}$. These parameters must be esti-

mated to apply the model.

(1) Maximum Fractional Market Share, L. As adapted for use in this study, the maximum fractional market share, $\mathrm{L}$, has been set equal to 1.00 to reflect the condition that the baseline hydrothermal market has been defined and quantified in a way that allows the entire market to be captured, given a sufficiently long time.

(2) Takeover Time, $\tau$. For the resource-colocated markets $T$ is estimated to be 60 years, by analogy to the takeover time for market penetration by natural gas in the United States. The detailed reasoning for this assumption is given in Appendix E. For the noncolocated markets $T$ is estimated to be 120 years, on the grounds that the propensity to relocate an industrial firm by more than 50 miles to take advantage of hydrothermal energy will be at best half of the propensity to adopt hydrothermal energy when it is locally available.

The general behavior of the Blackman function with $L=1$ and $\tau=60$ years is shown in Figure 4-1. There the function is graphed over a 100-year interval with $F(50)=0.50$. With this value for $\tau$, the market fraction doubles every 10 years until $F(t)$ reaches about 15 percent $(0.15)$. Then the rapid or widespread acceptance phenomenan takes over until $F(t)$ reaches about 85 percent. During the last phase, the rate again slows down as total penetration is approached asymptotically.

(3) Initial Penetration Year, $T_{0}$. This can be set at any year for which the market fraction exceeds two percent (6). Below this fractional value, there is no guarantee that technology substitution will proceed to completion. From data on current and near-term planned hydrothermal direct heat installations (23), $T_{0}$ for the Pacific region colocated market appears to be 1983, while $T_{0}$ for the RIB\&R colocated market is about 1986. Since current installations and plans for such are essentially nil for the Eastern colocated market and for the noncolocated markets in all three regions, no "empirical" $\mathrm{T}_{\mathrm{o}}$ can be estinated or set. 


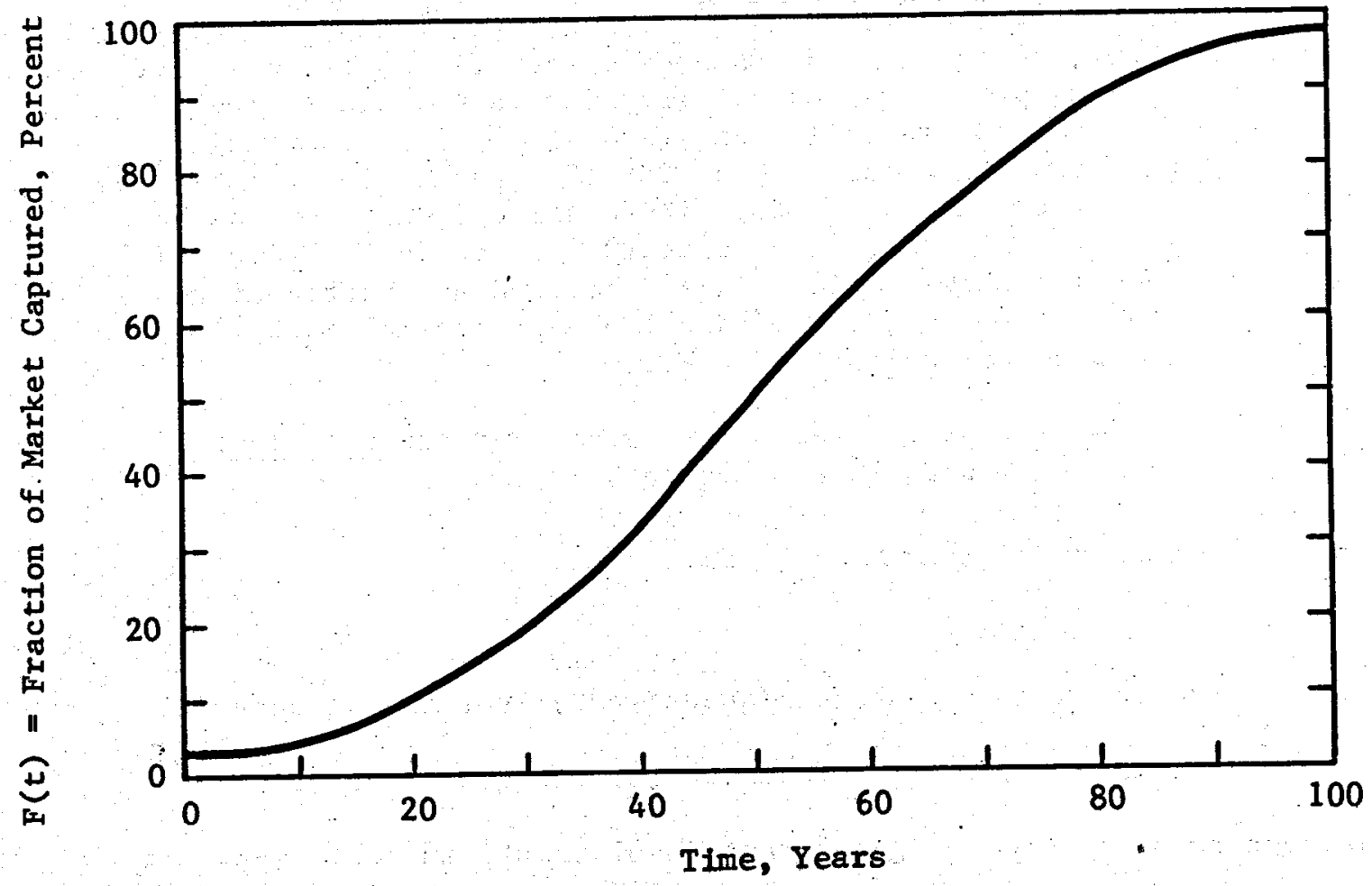

FIGURE 4-1

HYDROTHERMAL MARKET PENETRATION FUNCTION,

TAKEOVER TIME $=60$ YEARS

4-5 
Accordingly, for these latter four cases, no market penetration of any significance can be expected for hydrothermal direct heat during the next 10 to 20 years unless significant new initiatives are begun almost immediately.

To place anlaysis of all markets on an equal footing with respect to possible new government (federal or state) initiatives, we have set $T_{0}=1985$ for all penetration analyses.

(4) Initial Market Fraction, $F_{0}$. This is the fractional market penetration achieved by the end of the initial year (here, 1985). In the Base Case scenarlo analyzed below, $\mathrm{F}_{\mathrm{o}}$ consists of the market fraction calculated to result from current installations (end of 1979) in each region plus installations in the 1980-1985 period for which plans have been announced (23). These values, expressed as absolute market shares (quads/year), are shown in Table 1-1. They are shown in Table 4-1 expressed as fractional market shares (absolute share/baseline hydrothermal market) for the regional colocated markets.

The Base Case Initial market share for the noncolocated markets is zero in a11 regions.

\subsection{Results - Colocated Hydrothermal Markets}

\subsubsection{Base Case}

The predicted market shares (quads/year); for the colocated hydrothermal markets, $S_{c}(t)$, are shown for the Base Case (i.e. business as usual with no government involvement) in Table 4-2. If no additional government actions other than those announced by the spring of 1980 occur, the predicted total U.S. annual hydrothermal energy use by these markets is 0.044 quads/year in 2000 and 0.274 quads/year in 2020.

These numbers differ significantly from those of other forecasts (24, 25) for two major reasons. Previous forecasts have elther ignored detalled estimates of the colocation of potential users with 
hydrothermal resources, detalled estimates of thermodynamic suitability of matching hydrothermal supplies to end use, or have assumed rapid exponential growth of market fractions. When all of these factors are considered, it appears that hydrothermal direct heat will make its greatest contribution to U.S. energy needs in the post-2000 era.

Further inspection of Table 4-2 indicates that more than 60 percent of the base case market share is in the RIB\&R region. The Eastern region market is not penetrated at all up to the year 2020 because expected market penetration by 1985 in that region is almost ni1.

\subsubsection{Stimulated Cases}

These cases represent an accelerated direct heat market development scenarios in which the government(s) is assumed to stimulate a self-sustained hydrothermal direct heat market growth by supporting a buy of $0.01,0.04$, and 0.09 quads per year by 1985 . The 1mpact of these initial government buys, IGB, on the entire U.S. direct heat market over the next 35 years is shown in Table 4-3. As shown in this table, an initial government purchase of 0.01 quads/year of hydrothermal direct heat applications by 1985 will stimulate enough self-sustained growth of hydrothermal direct heat ut1lization to capture 0.66 quads/year in the year 2020. By increasing the initial government purchase four times (i.e. to 0.04 quads/year) the hydrothermal direct heat market share will grow to 1.1 quads/year by the 
TABLE 4-1

BASE CASE INITIAL YEAR (1985)

HYDROTHERMAL COLOCATED MARKET FRACTION

\begin{tabular}{|c|c|c|c|c|}
\hline \multirow{2}{*}{ FACTOR } & \multicolumn{4}{|c|}{ REGION } \\
\hline & Pacific & RMB\& $\mathbf{R}$ & East & U.S. \\
\hline $\begin{array}{l}\text { Hydro-Market Share, } S_{c} \text { (1985), } \\
\text { q/yr }\end{array}$ & 0.0027 & 0.0077 & 0.0 & 0.01 \\
\hline $\begin{array}{l}\text { Baseline Hydrothermal } \\
\text { Market } B_{c}(1985), q / y r . \\
\text { Hydrothermal Market } \\
\text { Fraction } F_{c}(1985), \\
\text { dimensionless }\end{array}$ & 0.035 & 0.082 & 0.153 & 0.27 \\
\hline
\end{tabular}

TABLE $4-2$

PREDICTED COLOCATED HYDROTHERMAL MARKET

SHARES FOR THE BASE CASE

$\left(S_{c}(t)\right.$, quads/year)

\begin{tabular}{|c|c|c|c|c|}
\hline \multirow{2}{*}{ YEAR } & \multicolumn{4}{|c|}{ REGION } \\
\cline { 2 - 5 } & PACIFIC & RMB\&R & EASTERN & TOTAL \\
\hline 1985 & 0.0027 & 0.007 & 0.000 & 0.010 \\
1990 & 0.0048 & 0.0120 & 0.000 & 0.017 \\
2000 & 0.0140 & 0.030 & 0.000 & 0.044 \\
\hline
\end{tabular}


year 2020. Further increase of the initial governnent purchase to 0.09 quads per year (Case 3 in Table 4-3) will stimulate the hydrothermal direct heat utilization to such an extent that it will, by the year 2020, capture 1.34 Quads per year and almost totally saturate the direct-heat baseline market.

The effectiveness of increasing the initial government support to stimulate more growth in the hydrothermal direct heat market share diminishes as this market share grows progressively to capture the whole baseline market. An inttial government purchase of 0.01 quads of hydrothermal direct heat applications in 1985, seems (see Appendix F) to be the most cost-effective level of government support for comercialization of hydrothermal direct heat utilization.

The regional estimates for the expected hydrothermal direct heat market share over the next 40 years are shown in Table 4-4 under various assumptions of inftial government support to stimulate the diffusion of hydrothermal direct heat utilization in each of the Pacific, RMB\&R and Eastern regions respectively. Inspection of Table 4-4 indicates that:

In all regions the captured hydrothermal direct heat market share increases with increased level of government support. However, the Initial government support has the highest impact on hydrothermal direct heat market shares in the Eastern region and has the least effect in the RMB\&R region due to a larger baseline market potential in the Eastern region. 
TABLE 4-3

IMPACT OF INITIAL GOVERNMENT BUY ON U.S.

COLOCATED HYDROTHERMAL DIRECT HEAT USE

(quads/year end use)

\begin{tabular}{|l|l|l|l|l|}
\hline \multirow{2}{*}{ Year } & \multicolumn{4}{|c|}{ INITIAL GOVERINENT BUY } \\
\cline { 2 - 5 } & $\begin{array}{l}\text { Base Case } \\
\text { IGB }=0\end{array}$ & $\begin{array}{l}\text { Case 1 } \\
\text { IGB }= \\
0.01 Q / Y r .\end{array}$ & $\begin{array}{l}\text { Case 2 } \\
\text { IGB }= \\
0.01 Q / Y r .\end{array}$ & $\begin{array}{l}\text { Case } 3 \\
\text { IGB }= \\
0.09 Q / Y r .\end{array}$ \\
\hline 1980 & 0.004 & 0.004 & 0.004 & 0.004 \\
1985 & 0.01 & 0.02 & 0.05 & 0.10 \\
1990 & 0.02 & 0.03 & 0.08 & 0.16 \\
2000 & 0.04 & 0.10 & 0.22 & 0.36 \\
2020 & 0.27 & 0.66 & 1.11 & 1.34 \\
\hline
\end{tabular}


In all regions, the effectiveness of government support in stimulating more growth of hydrothermal direct heat market share drops sharply after the total initial government purchase of hydrothermal direct heat applications across all regions has reached 0.04 quads per year, because the markets start to near saturation.

\subsection{Results - Noncolocated Hydrothermal llarkets}

The estimated national and regional noncolocated hydrothermal direct heat market shares are summarized in Table 4-5 under the assumption that the government would stimulate future self-sustained growth of this non-colocated market by supporting the purchase of 0.01 quads of hydrothermal Industrial applications in each region by 1985. Examination of Table 4-5 shows that:

(1) At the national level, the captured hydrothermal direct heat market share in 2020 is about 0.2 quads. This market share represents 9.4 percent of the non-colocated baseline market.

(2) The non-colocated market share growth of hydrothermal direct heat applications is almost the same in different regions. This is so because the differences in baseline market size between the different regions are compensated for by differences in the initial fractional share in each region. Thus, while the Eastern region has the largest size of initial baseline market among all the regions, it also has the lowest inftial fractional share of all the reglons.

\subsection{Comparative Impact of Government Support in Colocated and Non- colocated Markets}

As shown in Table 4-6, the effectiveness of Initlal government support in stimulating the hydrothermal direct heat market share growth in the noncolocated market is much lower than in the colocated market. Thus, for the same level of initial government support (i.e. 
TABLE $\quad 4-4$

IMPACT OF INITIAL GOVERNMENT BUYS (IGB) ON THE COLOCATED HYDROTHERMAI MARKET SHARE (QUADS/YR) IN DIFFERENT REGIONS IN THE U.S.

\begin{tabular}{|c|c|c|c|c|}
\hline Size of Initial Buy & $\begin{array}{c}\text { Pacific Region } \\
\text { Q/Yr. }\end{array}$ & $\begin{array}{c}\text { RMB\&R Region } \\
\text { Q/Yr. }\end{array}$ & $\begin{array}{c}\text { Eastern Region } \\
\mathrm{Q} / \mathrm{Yr} \text {. }\end{array}$ & $\begin{array}{c}\text { Total (U.S.) } \\
\text { Q/Yr. }\end{array}$ \\
\hline Case 1, IGB $=0.01 \mathrm{Q} / \mathrm{YII}$. & & & & \\
\hline 1985 & 0.004 & 0.009 & 0.006 & 0.019 \\
\hline 1990 & 0.007 & 0.017 & 0.010 & 0.034 \\
\hline 2000 & 0.021 & 0.041 & 0.038 & 0.100 \\
\hline 2020 & 0.129 & 0.198 & 0.336 & 0.663 \\
\hline Case 2, IGB $=0.04 \mathrm{Q} / \mathrm{Yr}$. & & & & \\
\hline 1985 & 0.009 & 0.016 & 0.023 & 0.048 \\
\hline 1990 & 0.014 & 0.028 & 0.041 & 0.083 \\
\hline 2000 & 0.034 & 0.063 & 0.127 & 0.224 \\
\hline $2020^{\circ}$ & 0.164 & 0.242 & 0.705 & 1.111 \\
\hline Case (3), IGB $=0.09 \mathrm{Q} / \mathrm{Yr}$. & & & & \\
\hline 1985 & 0.016 & 0.030 & 0.051 & 0.097 \\
\hline 1990 & 0.025 & 0.045 & 0.087 & 0.157 \\
\hline 2000 & 0.050 & 0.090 & 0.221 & 0.361 \\
\hline 2020 & 0.185 & 0.276 & 0.881 & 1.342 \\
\hline
\end{tabular}


an Initial government buy of 0.03 quads) Table 4-6 indicates that the U.S. colocated hydrothermal direct heat market share is expected to grow to reach 1.06 quads in 2020 , as compared to a U.S. noncolocated market share of 0.20 quads in the same year.

\subsection{Sensitivity of Changes in the Propensity to Adopt a New Tech- nology}

\subsubsection{The U.S. Colocated Market}

Since $\alpha$ is a measure of the propensity for adopting a new technology in a given market, a change in $\alpha$ and hence in $\tau$ could conceivably lead to a change in the future market share growth. With this in mind, the estimated U.S. colocated hydrothermal direct heat market share is shown in Table 4-7 for different values of $\alpha$, at different levels of initial government support. Examination of this table Indicates that:

(1) An increase in $T$ or equivalently, a reduction in the average market penetration rate, $\alpha$, does indeed lead to a reduction in the market share captured in any year regardless of the initial level of government support.

(2) The impact of an increase in $\tau$ (or equivalently a reduction in the average market penetration rate, $\alpha$ on the yearly market shares is drastically reduced as the initial government buy becomes greater than 0.01 quad/year. For example, if in Case (1) 1.e. IGB $=0.01$ quads per year $T$ is increased to 90 years instead of 60 years, the market shares in the year 2020 w111 be reduced by 40 percent. In comparison a $\tau$ of 90 years will only result in a 14 percent reduction in market share if the inftial government buy is increased to 0.09 quads per year (Case 3 ).

The implications of this can be seen more easily from Figure 4-2, which graphs the year 2020 results from Table $4-7$. If the 
TABLE 4-5

NATIONAL AND REGIONAL NONCOLOCATED HYDROTHERMAL DIRECT HEAT MARKET SHARE WITH AN INITIAL GOVERNMENT BUY, IGB, OF 0.01 Q/YR IN EACH REGION AND $\tau=120$ YEARS

\begin{tabular}{|c|c|c|c|c|}
\hline Year & $\begin{array}{c}\text { U.S. } \\
\text { Q/Yr. }\end{array}$ & $\begin{array}{c}\text { Pacific Region } \\
\text { Q/Yr. }\end{array}$ & $\begin{array}{c}\text { RMB\&R Region } \\
\text { Q/Yr. }\end{array}$ & $\begin{array}{c}\text { Eastern Region } \\
\text { Q/Yr. }\end{array}$ \\
\hline \multirow{2}{*}{1985} & 0.03 & 0.01 & 0.01 & 0.01 \\
1990 & 0.04 & 0.013 & 0.013 & 0.014 \\
2000 & 0.068 & 0.022 & 0.022 & 0.024 \\
2020 & 0.20 & 0.07 & 0.05 & 0.08 \\
\hline
\end{tabular}



TABLE $4-7$

IMPACT OF CHANGES IN MARKET PENETRATION RATE

ON U.S. COLOCATED HYDROTHERMAL MARKET SHARE (Q/Yr.)

\begin{tabular}{|c|c|c|c|}
\hline & $\tau=60 \mathrm{yrs}, \alpha=0.1173$ & $T=90$ yrs, $\alpha=0.049$ & $\mathrm{~T}=45 \mathrm{yrs}, \alpha=0.097$ \\
\hline $\begin{array}{l}\text { Levels of Initial } \\
\text { Government Buys (IGB) }\end{array}$ & $\begin{array}{c}\text { Market Share } \\
\left(Q / \mathrm{Y}_{r} .\right)\end{array}$ & $\begin{array}{c}\text { Market Share } \\
(Q / \mathrm{Yr} .)\end{array}$ & $\begin{array}{c}\text { Market Share } \\
(\mathrm{Q} / \mathrm{Yr} .) \\
\end{array}$ \\
\hline 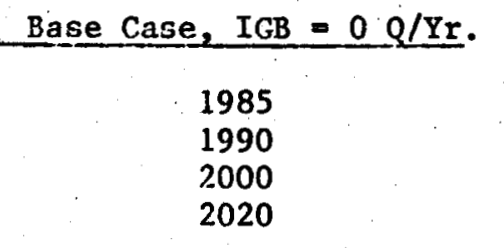 & $\begin{array}{l}0.01 \\
0.018 \\
0.06 \\
0.38\end{array}$ & $\begin{array}{l}0.01 \\
0.015 \\
0.034 \\
0.171\end{array}$ & $\begin{array}{l}0.01 \\
0.017 \\
0.044 \\
0.274\end{array}$ \\
\hline $\begin{array}{c}\text { Case (1), IGB }=0.01 \text { Q/Yr. } \\
1985 \\
1990 \\
2000 \\
2020\end{array}$ & $\begin{array}{l}0.02 \\
0.038 \\
0.13 \\
0.95\end{array}$ & $\begin{array}{l}0.02 \\
0.03 \\
0.074 \\
0.40\end{array}$ & $\begin{array}{l}0.02 \\
0.03 \\
0.10 \\
0.66\end{array}$ \\
\hline $\begin{array}{c}\text { Case (2), IGB }=0.04 \text { Q/Yr. } \\
1985 \\
1990 \\
2000 \\
2020\end{array}$ & $\begin{array}{l}0.05 \\
0.09 \\
0.28 \\
1.31\end{array}$ & $\begin{array}{l}0.05 \\
0.078 \\
0.176 \\
0.817\end{array}$ & $\begin{array}{l}0.05 \\
0.08 \\
0.22 \\
1.11\end{array}$ \\
\hline $\begin{array}{c}\text { Case }(3), \text { IGB }=0.09 \mathrm{Q} / \mathrm{Yr}_{\mathrm{r}} \text {. } \\
1985 \\
1990 \\
2000 \\
2020\end{array}$ & $\begin{array}{l}0.10 \\
0.17 \\
0.11 \\
1.44\end{array}$ & $\begin{array}{l}0.10 \\
0.146 \\
0.31 \\
1.15\end{array}$ & $\begin{array}{l}0.10 \\
0.16 \\
0.36 \\
1.34\end{array}$ \\
\hline
\end{tabular}




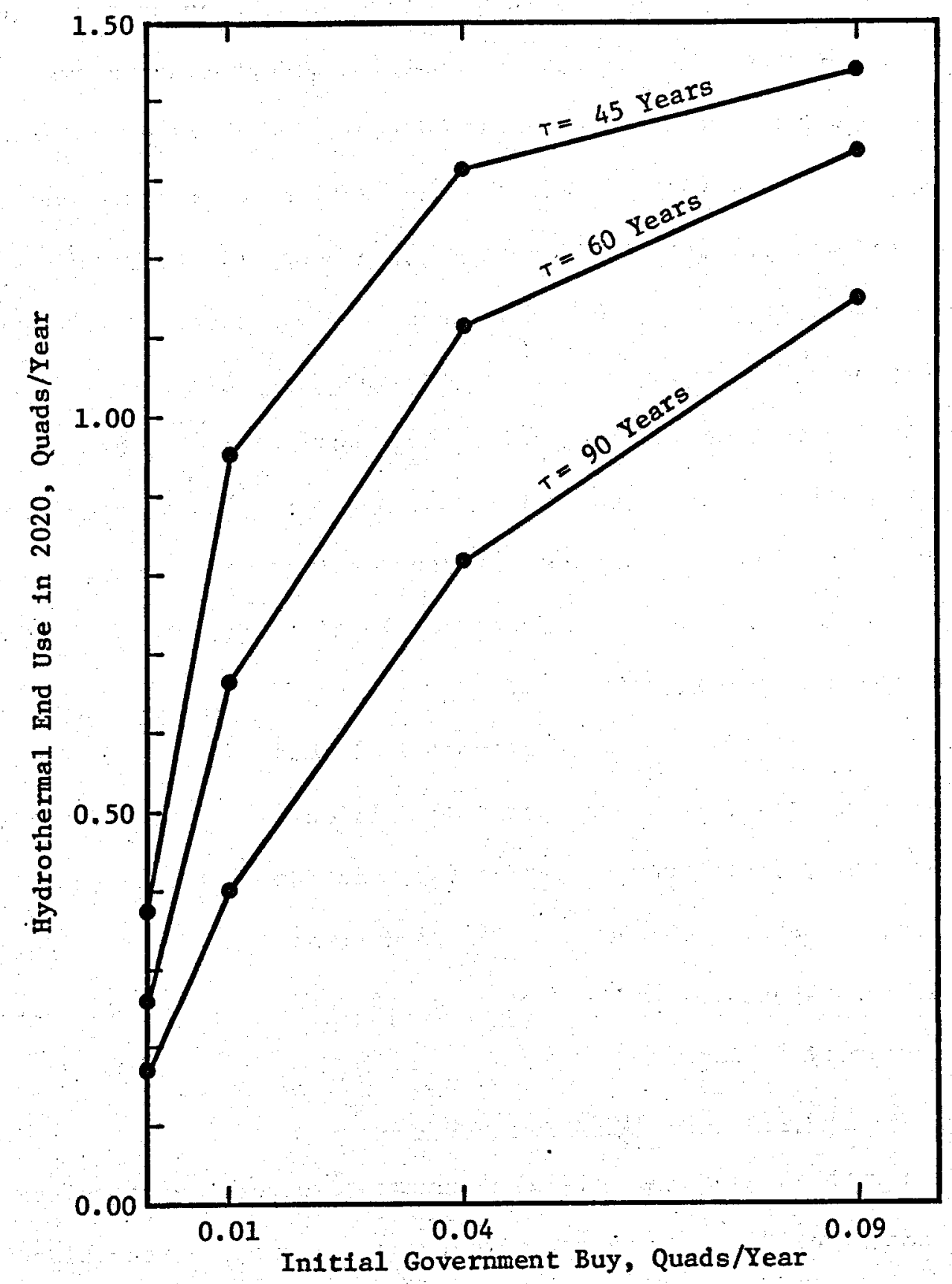

FIGURE 4-2

EFFECTS OF CHANGES IN INITIAL GOVERNMENT BUY AND TAKEOVER TIME ON HYDROTHERMAL

END USE IN COLOCATED MARKETS IN 2020

4-17 
Initial government buy is held in the range of 0.01 quads/year, then efforts to increase the natural propensity to adopt hydrothermal energy (reducing $\boldsymbol{T}$ from the expected 60 years toward 45 years) has a relatively marked effect. The government actions that could have such an effect include: (a) Continued technology R\&D to reduce the costs of hydrothermal systems, and especially the costs of reservoir confirmation, (b) Expanded outreach and publicity efforts, (c) Additional efforts toward establishing large consortla of users for district heating systems and geothermal energy industrial complexes, and toward brokering connections between suppliers and users, and (d) Continued effort to reduce State and local institutional barriers to hydrothermal commercialization.

Since the costs of each additional 0.01 quad per year of initial government buy are on the order of $\$ 184$ Million, or about $\$ 37$ Million per year over a 5-year buying period (See Section 6.2), it seems likely that something on the order of $\$ 3$ Million to $\$ 5$ Mililon per year might be spent most effectively in efforts to enhance the general propensity to buy.

\subsubsection{The U.S. Noncolocated Market}

Even with an adequate Initial government support to stimulate future noncolocated hydrothermal market share growth, a reduction in the propensity of Industry to relocate to take advantage of technoeconomically sultable hydrothermal resources could reduce the noncolocated hydrothermal market share significantly. This situation is 
shown in Table 4-8, which summarizes the estimated U.S. noncolocated hydrothermal direct heat market shares under various levels of initial government support and for different values of the average market penetration rate. Inspection of Table 4-8 shows that a 100 percent increase in the value of $\alpha$ (i.e. 50 percent decrease in $T$ ) increases the corresponding noncolocated hydrothermal direct heat market share in the year 2020 by about 150 to 200 percent, which is a greater effect than that gained by doubling the initial government buy.

This indicates that the noncolocated market share growth is more affected by the propensity of industry to relocate than it is to the level of the initial government buy. This suggests that demonstration efforts targeted toward relocation of Industries to hydrothermal resources might have limited effectiveness unless the intrinsic advantages to such relocation are very high.

\subsection{Additional Observations}

The foregoing analysis suggests that without continuing government stimulation the U.S. hydrothermal direct heat market growth, whether colocated or noncolocated, will be very slow. This raises a number of related issues concerning the regional distribution of the government stimulation, the cost implications of such stimulation, and the sufficiency of hydrothermal supply. These issues are addressed below. 
TAB LE $4-8$

IMPACT OF CHANGES IN MARKET PENETRATION RATE ON THE

U. S. NONCOLOCATED HYDROTHERMAL MARKET SHARE (Q/Yr.)

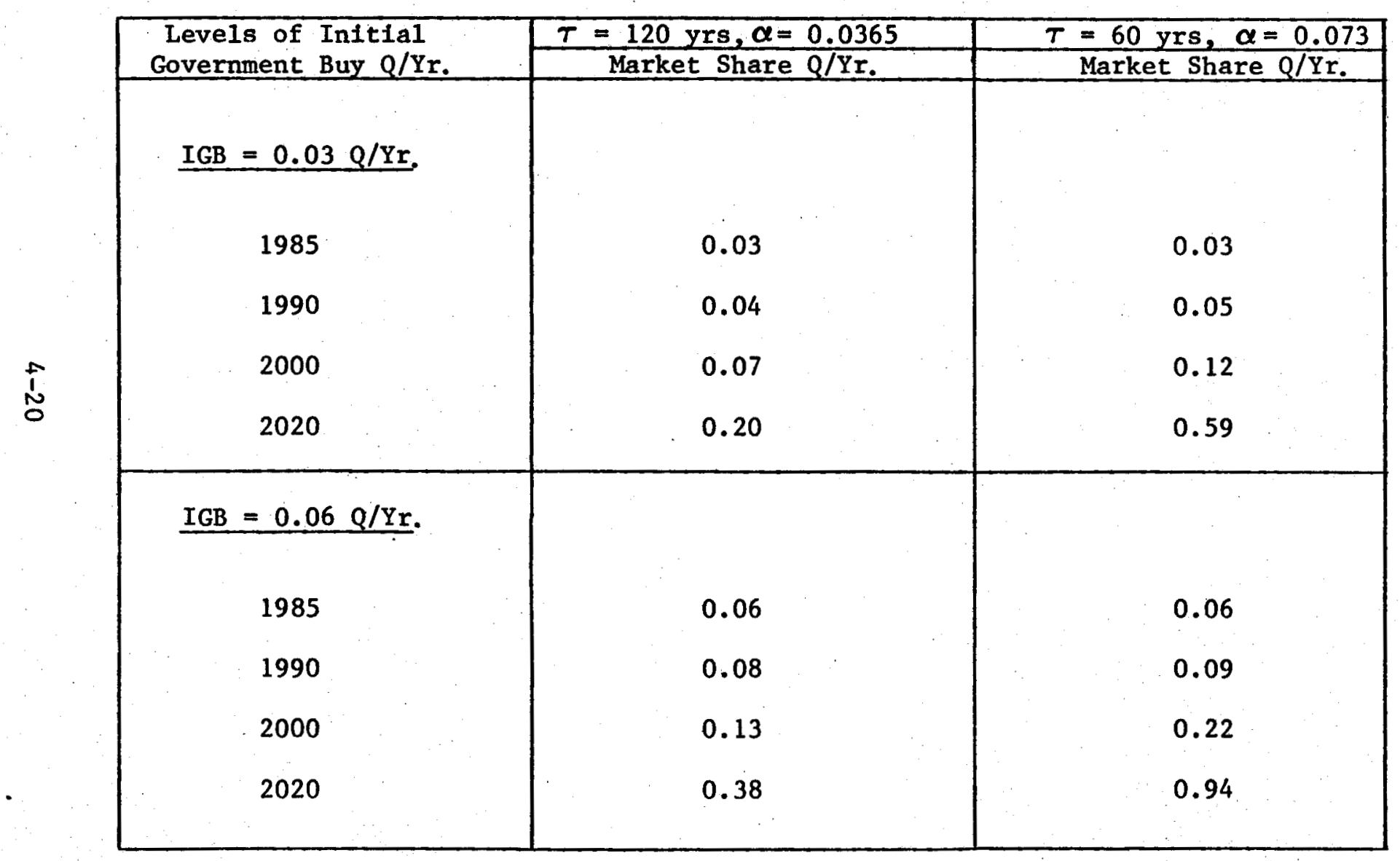




\subsubsection{Distribution of Government Stimulation}

(1) Distribution of Government Buys in Regional Colocated

As shown in Appendix F, the most cost effective initial government buy to stimulate self-sustained growth of the colocated hydrothermal direct heat market share is 0.01 quads per year. Equal dollar distribution of this buy among the three regions (1.e., Pacific, RMB\&R and Eastern regions) will tend to favor more market share growth in the Pacific and RMB\&R regions.

To guarantee an equal fractional market share growth in all three regions, the initial fractional market share $\left(\mathrm{F}_{0}\right)$ in all regions must be the same. However, if the initial government buy is regionally distributed to achieve this result (i.e., equal $F_{0}$ in all regions) the initial government buy in the RMB\&R would be zero because $F_{0}$ for a 0.01 quad/year buy by 1985 would exceed the $F_{0}$ expected there in the Base Case. Such distribution of the initial government buy would appear to be generally inequitable to the RMB\&R region.

The most logical distribution rule is to make the initial government buy in each region proportional to its baseline market. On this basis, the inftial government buy will be distributed such that 12 percent will be in the Pacific region, 31 percent will go to the RMB\&R region and the rest (1.e., 57 percent) will be in the Eastern region. The impact of such a distribution of the Initial government buy on the regional hydrothermal market share growth was 
shown in Table 4-4. For an IGB of 0.01 quads/year, the U.S. total market share will grow to 0.10 quads/year in 2000 and 0.66 quads/year in 2020 .

The incremental effect of buying the additional 0.01 quads/year capacity (over the Base Case, as shown in Table 4-3) is equal to $0.1-0.044^{*}-0.01=0.046$ quads/year. This is equivalent to the government buying about 17 .percent of the expected market share gain in the year 2000. The incremental boost by 2020 from the same additional buy of 0.01 quads/year is similarly estimated to be 0.38 quads/year. This is equivalent to the government buying only 2.6 percent of the expected year 2020 gain and thus represents a significant leverage for government investment.

To date, hydrothermal energy use for direct heat applications has not been developed in the Eastern region. This has been due to a number of factors, especially that the useful resource is generally tound at much greater depths than in the West. It is possible that hydrothermal use in the Eastern region simply will not be developed to any great degree, at least not before 2000 .

If that is assumed to be the case, then it is important to consider what is likely to happen if Initial Government Buys are distributed across only the Pacific and RMB\&R regions. Again assuming that buys are distributed between the regions in proportion to their baseline markets in 1985, $30 \%$ of each buy would go to the Pacific region

\footnotetext{
*0.044 quads/year is the estimated market share in the year 2000 under business-as-usual conditions ( $1 . e .$, base case in Table 4-3).
} 
TABLE 4-9

IMPACTS PREDICTED IF INITIAL GOVERNMENT

BUYS WERE RESTRICTED TO THE WEST

(quads/year)

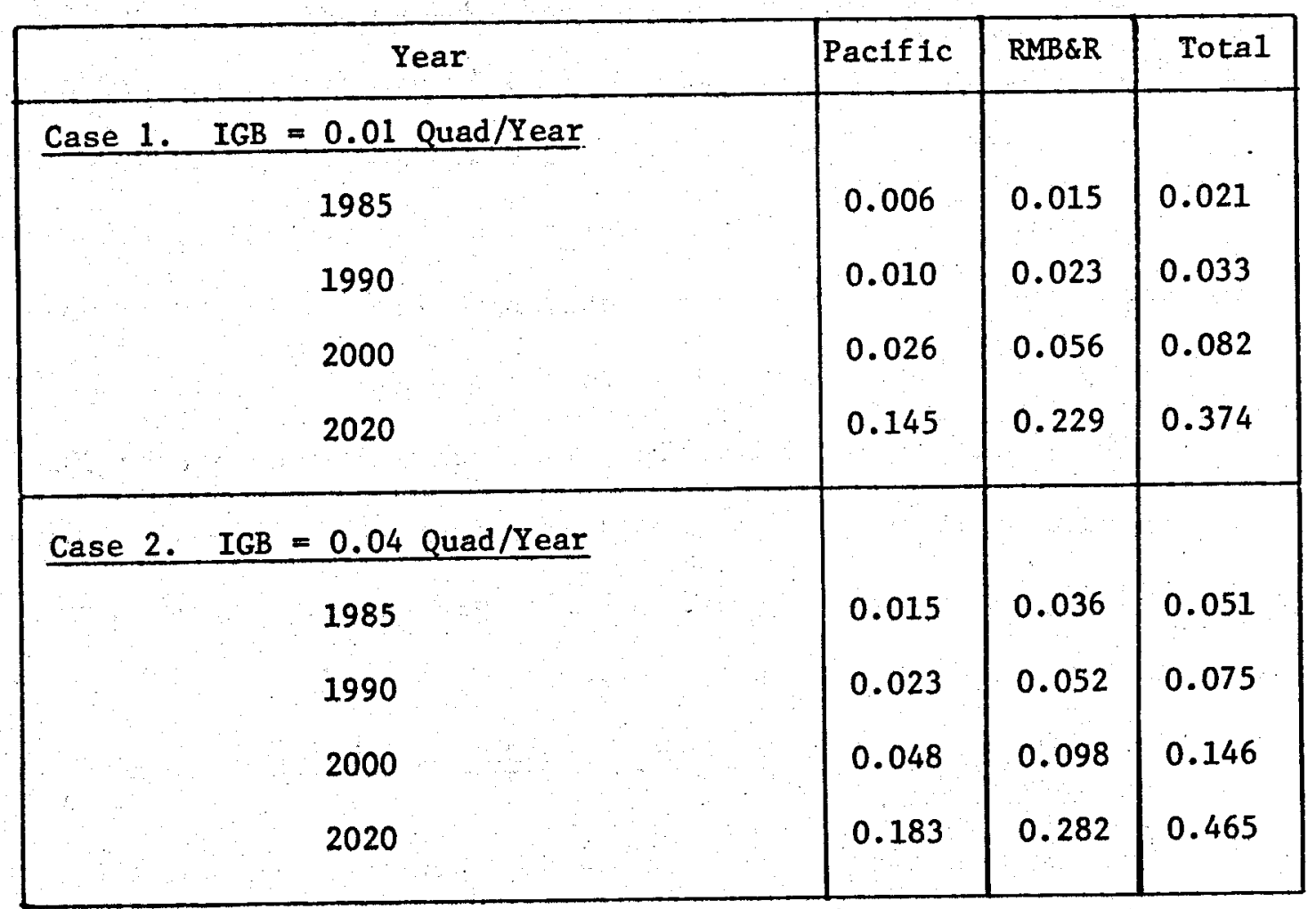


and $70 \%$ would go to the RMB\&R region. Only buys of 0.01 and 0.04 quad/year capacity are considered here, because a buy of 0.09 quad/ year would simply flood these markets in a counterproductive way. The results of these buys are shown in Table 4-9. For an IGB of 0.01 quads/year, the end use would total 0.082 quads/year in 2000 and 0.37 quads/year in 2020. For an IGB of 0.04 quads/year, the end use would total 0.146 quads/year in 2000 and 0.465 quads/year in 2020.

The incremental effect by 2000 of buying the additional $0.040-$ $0.010=0.030$ quads/year capacity is equal to $0.146-0.082-0.030=0.034$ quads per year. This is equivalent to the government buying about half of the expected year 2000 gain. The incremental effect by 2020 from the same additional buy of 0.030 quads $/$ year $=0.465-0.374-0.030=$ 0.06 quads/year. Neither the 2000 or 2020 gain appears to offer much leverage for the Government's investment.

(2) Allocation of Government Buys Between Colocated and Noncolocated Markets

No explicit estimates are made in this study of how fast the noncolocated market might be penetrated in the Base Case. As discussed in Section 3.0, the present installations and plans for Installations at non-colocated markets appear to be well below the threshold values at which technology diffusion dynamics or analytical models of those dynamics apply.

The only useful comparison that can be made is of the (estimated) relative effectiveness of allocating a given level of government 
buy of demonstrations to either market colocated or noncolocated sites. This comparison is shown for an $I G B=0.03 \mathrm{quad} /$ year in Table 4-10.

The results indicate that if $\tau$ is the same for the two situations, then additional buys have double the effect in quads captured when they are spent at colocated as compared to noncolocated resources. We believe that $\tau$ would be greater for the non-colocated case, but it is beyond the scope of this study to estimate the degree of difference in an analytically detailed manner.

\subsubsection{Cost Implications}

As already indicated, the current pace of hydrothermal direct heat utilization seems unlikely to help achieve the 1985 goal (26) of 0.1 quad/year for direct heat uses (26) without an initial government buy of 0.09 quads per year by 1985 . This buy would require drilling about 144 successful wells each delivering $1.3 \times 10^{11} \mathrm{BTU} /$ year and the start up of 36 plants each with an installed capacity of 0.0005 quads per year, for each of the next 5 years. The estimated cost for such an endeavour is 1.66 billion dollars over five years and about 331 million dollars per year in 1980 dollars (see Appendix F). This level of spending is roughiy double the total DGE budget of $\$ 153$ million for 1981 and does not seem to be feasible. Even if this level of funding (1.e., 331 million dollar per year) is partly absorbed through loan guarantees, and active private sector participation, the remaining government yearly outlays would be at least 150 million dollars mostly for resource and reservoir confirmation. 
TABLE $\quad 4-10$

COMPARISON OF ALLOCATING A GOVERNMENT BUY OF 0.03 QUAD/YEAR TO COLOCATED OR NONCOLOCATED RESOURCE AREAS (Quads/Year)

\begin{tabular}{|c|c|c|}
\hline Year & $\begin{array}{c}\text { U.S. Colocated } \\
\text { Market Share }(Q / Y r .) \\
\text { U.S. }\end{array}$ & $\begin{array}{c}\text { Noncolocated } \\
\text { Market Share }(Q / Y r) \\
\text { U.S. }\end{array}$ \\
\hline 1985 & 0.03 & 0.03 \\
1990 & 0.07 & 0.05 \\
2000 & 0.19 & 0.12 \\
2020 & 1.06 & 0.59 \\
\hline
\end{tabular}


A less ambitious, but perhaps more feasible and cost effective goal is for the government to restrict its initial buy to 0.01 quads per year by 1985. This would cost the government between $\$ 19$ million and $\$ 26$ million per year in 1981 through 1985 (with the Federal cost share ranging from 50 percent to 70 percent). This level of initial government buy is expected to stimulate the hydrothermal direct heat market share to reach 0.1 quads/year by the year 2000 .

\subsubsection{Sufficiency of Hydrothermal Supply}

At this point, it is necessary to examine the sufficiency of hydrothermal resource supply to meet the colocated and noncolocated hydrothermal direct heat market demand stimulated by an assumed initial government buy of 0.01 quads per year. This situation is examined in Table 4-11 which indicates the regional hydrothermal supply/demand balance over the period of 1985 to 2000 . The estimated market demand in both colocated and noncolocated hydrothermal direct heat markets is based on the results in this section. The estimated supply, however, is based on the available wellhead energy, in quads per year, as Indicated in the U.S.G.S Circular 790 for each of the identified colocated techno-economically suitable resources in each region (Table $3-2$ ).

Inspection of Table 4-11 1ndlcates that there will be enough supply to cover all expected demand for hydrothermal direct heat utilization up to the year 2000. To meet the hydrothermal direct 
TABLE $4-11$

HYDROTHERMAL SUPPLY/DEMAND BALANCE

\begin{tabular}{|c|c|c|c|c|c|c|c|}
\hline \multirow{2}{*}{ Region } & \multicolumn{2}{|c|}{ Colocated Demand } & \multicolumn{2}{|c|}{ Noncolocated Demand } & \multicolumn{2}{|c|}{$\begin{array}{c}\text { Total Colocated and } \\
\text { Noncolocated Demand } \\
(\mathrm{Q} / \mathrm{Yr})\end{array}$} & \multirow{2}{*}{$\begin{array}{c}\text { Known Colocated } \\
\begin{array}{c}\text { Suftable Supply } \\
\text { (Q/Yr.) }\end{array} \\
1985\end{array}$} \\
\hline & 1985 & 2000 & 1985 & 2000 & 1985 & 2000 & \\
\hline Pacific & 0.0042 & 0.021 & 0.01 & 0.022 & 0.014 & 0.043 & 0.15 \\
\hline RMB\&R & 0.01 & 0.041 & 0.01 & 0.022 & 0.02 & 0.063 & 0.12 \\
\hline Eastern & 0.0058 & $0.03 \mathrm{~S}$ & 0.01 & 0.024 & 0.016 & 0.062 & 0.10 \\
\hline
\end{tabular}


heat market demand stimulated by an initial government buy of 0.04 quads per year or more will require the discovery and identification of more market-colocated resources in each region. 
Blank

$4-30$ 


\subsection{UNCERTAINTIES IN THIS ANALYSIS}

It should be noted that the estimates of hydrothermal direct heat usage given in this paper are bounded by a number of uncertainties. The implications of some of the known sources of uncertainty are described here.

\subsection{Size of the Resource Base}

The above estimates of the year 2020 resource-colocated baseline market include the assumption that the market-colocated resource base, and thus the number of resource-colocated market centers will grow by about 17 percent between 1980 and 2020. (see Appendix D.). This estimate could be low. An active program in hydrothermal resource assessment and identification could result in new discoverfes and extend the resource base to the boundaries of existing cities or active business centers. It is estimated that such an extended resource base could increase the colocated market size, hence the absolute market share, by no more than 35 percent by the year 2020 . This assumes that the unidentified hydrothermal resources are about 5 times the size of known resources (from U.S.G.S. Circular 790), and that about 7.5 percent of newly identified resources will be colocated with major markets (same proportion as estimated here for currently known resources).

Achieving this 35 percent upper bound would raise all forecasts of quads/year use in 2020 by about 17 percent. 


\subsection{Price Escalation of Conventional Fuels}

An increase in conventional fuel prices will concelvably

increase the relative economic attractiveness of hydrothermal direct heat application. It has been shown (27) for example, that on the average each dollar rise in natural gas price increases the economic attractiveness, hence the fractional market share, of hydrothermal direct heat applications by 3 percent.

Continued escalation of conventional fuel real prices at more than 10 percent per year during the next 10 years would make the use of hydrothermal resources extremely attractive, and invalidate the conclusions of this study. However, it appears to us that the physical conditions at the currently known resource-colocated hydrothermal markets are restrictive enough that the ultimate utilization in those markets (as listed in Table 3-2) will not exceed about 1.5 quads/year in 2020, regardless of relative prices. Price-related acceleration of market share fraction growth could occur in all markets around the year 2000, but the effective boost would be temporary for the resource-colocated markets. The largest ultimate effect of long term differential energy price escalations would be in the stimulation of the use of hydrothermal resources that are not market-colocated.

\subsection{Unpredictable Market Sectors}

There are a number of major market sectors where the use of geothermal fluids for direct heat applications might be significant but are simply unpredictable. These include use for enhanced ofl 
recovery (where the geoheat enhances the effects of flooding), gasohol plants (where geoheat could displace either biomass or fossil fuel for heat needed to support both fermentation and distillation), and space heating needs associated with the possible installations of the MX missile system near geothermal reservolrs in western states. There is no simple way to predict the probable impacts of these developments upon the use of geothermal heat. Honetheless these potential hydrothermal applications could make useful contributions to the U.S. energy ecomomy because they could contribute to energy supply for the transportation sector or for national defense requirements.

The direct utilization of hydrothermal energy could also receive a big boost as a result of increased utilization of low temperature geofluids for enhanced oil recovery. The colocation of oil fields with low and moderate temperature hydrothermal resources especially in the western U.S., may help make the utilization of these resources technoeconomically attractive.

\subsection{Conservation and Waste Heat}

Steam electric generating plants produce waste heat in amounts exceeding the total U.S. space and water heating demands (12). In addition, the geographical distribution of these plants is favorable for hot water transmission to all but a few urban areas in the United States (12). At present, the cost of a unit of waste heat is one third the cost of a unit of fuel oil. The costs of waste heat for 
uranium, coal and oil fired plants are therefore estimated (12) at $\$ 0.13, \$ 0.32$ and $\$ 0.64$ per million Btu respectively. Increased interest in such abundant and cheap sources of waste heat energy may thus constitute a serious challenge to the future growth of hydrothermal direct heat applications unless the hydrothermal energy can be produced at a competitive price (i.e. at a cost that is significantly lower than $1 / 3$ the cost of conventional fuel).

General energy-conservation efforts to reduce heat losses from structures and improve the efficiency of process-related heat use could also tend to reduce the absolute (quad/year) use of hydrothermal heat estimated here for 2000 and 2020 .

We estinate that the combination of conservation efforts and utilization of waste heat from conventional electric plants could result in the current forecasts and estimates being high by perhaps 20 to 30 percent in the $2000-2020$ period. However, these occurrences would be subject to technology-substitution dynamics and require perhaps substantial time to reach significant direct heat market fractions. 


\subsection{CONCLUSIONS AND RECOMLENDATIONS}

\subsection{Conclusions}

The overall results of this analysis suggest the following conclusions.

(1) The baseline colocated market, the market that could be captured by hydrothermal resources located near centers of demand, is 0.27 quads/year in $1985,0.58$ quads/year in 2000 , and 1.53 quads/year in 2020. The baseline noncolocated market, consisting of industries whose heat requirements are matched to hydrothermal resources but are not located near them, is 1.09 quads/year in 1985, 1.47 quads/year in 2000 , and 2.18 quads/year in 2020. For both of these markets, more than half of the baseline market is in the Eastern region.

(2) Current hydrothermal direct heat use is almost nil, and not sufficient to induce rapid market penetration. For the Pacific region and $R M B \& R$ region, projects that are now underway should, by about 1985, bring penetration by hydrothermal energy of the resourcecolocated markets into a self-sustained mode. However, without additional stimulation, the estimated penetration of these markets will be only about 0.01 quads/year in 1985, 0.04 quads/year in 2000 , and 0.27 quads/year in 2020 .

For the Eastern region colocated market, and for the noncolocated markets in all regions, the 1985 base case hydrothermal market penetration is essentially nil. The only prediction allowed, given this condition, is that penetration for 2000 and 2020 will be essentially zero, unless significant unpredicatable events occur. 
(3) New Federal (and/or State) initiatives in the near-term (1981-1985) could alter this picture. An initial government buy to install an additional 0.09 quads/year of end-use by the end of 1985 could result in annual end use of 0.36 quads/year in 2000 and 1.34 quads/year in 2020 in the resource-colocated markets. Such an initiative would cost about $\$ 1.7$ billion over the next 5 years, with federal and state governments having to furnish perhaps half of the funds.

(4) The most practicable level of such an initial government buy in the near-term appears to be on the order of an additional installed capacity equivalent to about 0.01 quads/year end use. This would require between $\$ 19$ million and $\$ 26$ million of new government funding for each of 5 years (average government cost share ranging from 50 to 70 percent). This would result in 0.02 quads/year hydrothermal use in 1985, 0.10 quads/year in 2000, and about 0.66 quads/ year in 2020.

(5) If such a stimulatory action were to be undertaken, it appears that it would be most effective if it is directed toward resource-colocated markets, rather than toward resource non-colocated markets.

(6) The most surprising finding of the present study is that the market-size analysis (Section 3.0) indicates that the Eastern region has the relatively greatest market potential among the three regions, for both the colocated and the noncolocated markets. The 
reason for this is that the higher population density in the East ensures that any geothermal resource has a relatively high probability of being near a market, compared to the probability of resource and market colocation in the West. However, the current hydrothermal penetration of this market is almost nil, suggesting that a large effort would be required to stimulate such use in the near and mid-term.

\subsection{Substantive Recommendations}

The results and conclusions prompt the following recommendations.

(1) If the government wishes to ensure a reasonably rapid development of hydrothermal direct heat use, it will have to increase its level of support of these uses in the near term. It should, moreover, emphasize the development of large hydrothermal resourcecolocated institutional, commercial, and Industrial applications to accelerate a transition to district heating systems and geothermal Industrial complexes.

(2) The Government should support the private sector geothermal commercialization infrastructure that is now just beginning to emerge by accelerating the formation of consortia of geothermal developers, financiers, designers, and builders to help promote regional hydrothermal direct heat applications.

(3) The contribution of the Pacific region to the national hydrothermal direct heat market should be increased by encouraging, 
to the extent possible, the cascaded utilization of the nunerous high temperature geothermal resources in this region.

(4). Hydrothermal resource identification and assessment is a necessary prerequisite for current and future commercialization of geothermal direct heat utilization. Therefore, such an assessment should be an integral part of any Government program designed to promote hydrothermal direct heat applications.

(5) It might be valuable to establish a new ad hoc group within the Interagency Geothermal Coordinating Council (IGCC) to explore the commercialization/industrialization of energy use systems that combine the use of hydrothermal resources, ground water heat pumps, waste heat from conventional electric plants, and other sources of waste heat to provide inexpensive heat to district heating systems. The Department of Housing and Urban Development, which joined the IGCC In 1979, would be expected to play an important and perhaps leading role in such a group. A useful initial focus would be engineering/economic assessments of the conditions under which specific mixes of such energy sources would be most feasible.

\subsection{Recommendations for Further Analysis}

Fruitful areas for further analysis might include the following:

(1) Design of a goal-oriented budget for the Government

hydrothermal commercialization program based on estimating the costeffectiveness of various Government actions (e.g., R\&D, fiscal incentives, loan guarantee, marketing and outreach and other similar 
actions) in achieving various levels of direct heat market penetration.

(2) Develop a regional regression model that reflects the socioeconomic acceptability of hydrothermal direct heat applications based on regional public opinion surveys. Such model would help Improve the accuracy of future forecasts for hydrothermal direct heat market shares in different regions of the United States.

(3) Use the Battelle Pacific Northwest Laboratorles Geocity code, and/or the New Mexico Energy Institute's cost models to estimate the cost of delivering geothermal heat from the known hydrothermal resources located within 50 miles of all major cities and towns in the U.S. Favorable results could then be disseminated to the governments and commercial associations in those locales.

(4) Conduct a fast study of the low and moderate temperature needs of all S.I.C. Industries to identify industry specific cost factors and advantages of using hydrothermal energy. This should be based on the results of the DGE-sponsored direct use feasibility studies and the voluminous literature generated by the solar-energy community in this area of analysis. 


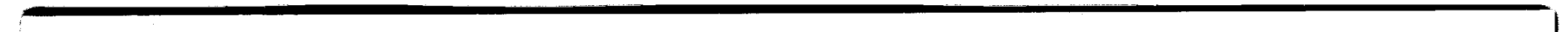

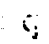

APPENDIX A

REVIEW OF REGIONAL SUPPLY AND DEMAND 
APPENDIX A

REVIEW OF REGIONAL ENERGY SUPPLY AND DEIIAND

To make a reasonable estimate of the achievable levels of geothermal direct heat utilization, the regional energy supply and demand situation in each of the three national hydrothermal regions (Pacific, Rocky Mountain Basin and Range, and Eastern) must be analyzed (Figure 2-2).

\section{A.1 The Pacific Region}

The market for direct heat use of geothermal energy in the Pacific region appears to be constrained by demand rather than by the resource. The extensive geothermal resources of the region are 10cated primarily in remote, mountainous, or desert areas and are of ten within national and state parks and forests. Most of these resources are far from demand centers. However, the market penetration of geothermal energy is expected to Increase slowly over time as it gains consumer acceptance.

The statewise situation is as follows:

(1) California. In California the market for direct-heat use of geothermal water is approximately 0.083 quads in 1980 (regardless of location), increasing to 0.143 quads in 2020 (8) Most of the demand for residential direct heat is concentrated in the populous San Diego, Sonoma, Napa and Lake Counties, However, those counties with the largest Industrial and commercial demand, San Diego, Ventura, and Riverside, have low temperature water (1.e., lower than $90^{\circ} \mathrm{C}$ ) rather 
than the more readily exploitable medium temperature resource (i.e., higher than $90^{\circ} \mathrm{C}$ ). Other counties (e.g., Inyo, Mono, Lassen and Siskiyou) are rural and rely heavily on liquified petroleum gas (LPG) for heating and cooking purposes. Agricultural use of geothermal energy represents only 3 percent ( $1 . e \cdot, 3.8 \times 10^{12} \mathrm{Btu}$ ) of the total direct heat market in 2020. About 60 percent of this market is concentrated in Kern, San Bernardino and Monterey Counties. (8)

(2) Hawail. Over 90 percent of Hawail's energy needs are supplied by foreign imports of fossil fuels. As a result, the state goverment and business are aggressively seeking local alternative energy sources to reduce their dependence on foreign supplies.

Based on potential resources and need, Hawail is a prime candidate for direct applications of hydrothermal fluids in industrial and food processing. However, the state's limited industrial activity, its climatic conditions, and its 1sland formations are major limiting factors to the commercialization of direct application. Also, high exploration and development costs and the cost of transmission and other necessary infrastructure costs combined with retrofit and backup system costs will prevent geothermal from belng dramatically cheaper, if at all, than other (imported) energy sources.

(3) Washington. To date the only uses of geothermal waters (in Yakima) have been in irrigation of agriculture lands and for warm water needs at a car wash facility. The dominance of agriculture in 
the area could provide markets for geothermal energy in greenhouses, grain drying, sugar processing, soil warming and food processing.

At present the U.S. Park Service is looking into the feasibility of updating the large geothermal heated swimming pool, and overnight accommodation facilities in Sol Duc Hot Spring Area. Other geothermal spring areas in Washington Mt. Adams, Indian Heaven, Kennedy Hot Spring and Baker. KGRA's have no expressed interest, to date, in geothermal development. Mt. Saint Helens is now a major potential source of heat, but there is no way to predict how this volcano might prove useful.

(4) Oregon. Oregon has more than 170 hot springs situated primarily from the Cascades east across the state. In Klamath Falls, homes have been heated with geothermal fluids for 45 years. The most important need is for resource assessment. The two important factors inhibiting more utilization of resources in Oregon are lack of access to federal land and the high cost and risks of geothermal exploration and development.

(5) Alaska. Most of the hydrothermal resources in Alaska are situated in remote, mostly inaccessible areas. The resource temperature, however, is sultable for salmon hatcherles, greenhouses, and soil warming.

Table A-I shows a summary of the direct heat applications being carried out in the Pacific region. This 11st of activities is not a comprehensive 1 ist but does indicate the main developments in direct 
TABLE A-1

SUMMARY OF DIRECT HEAT ACTIVITIES

IN THE PACIFIC REGION

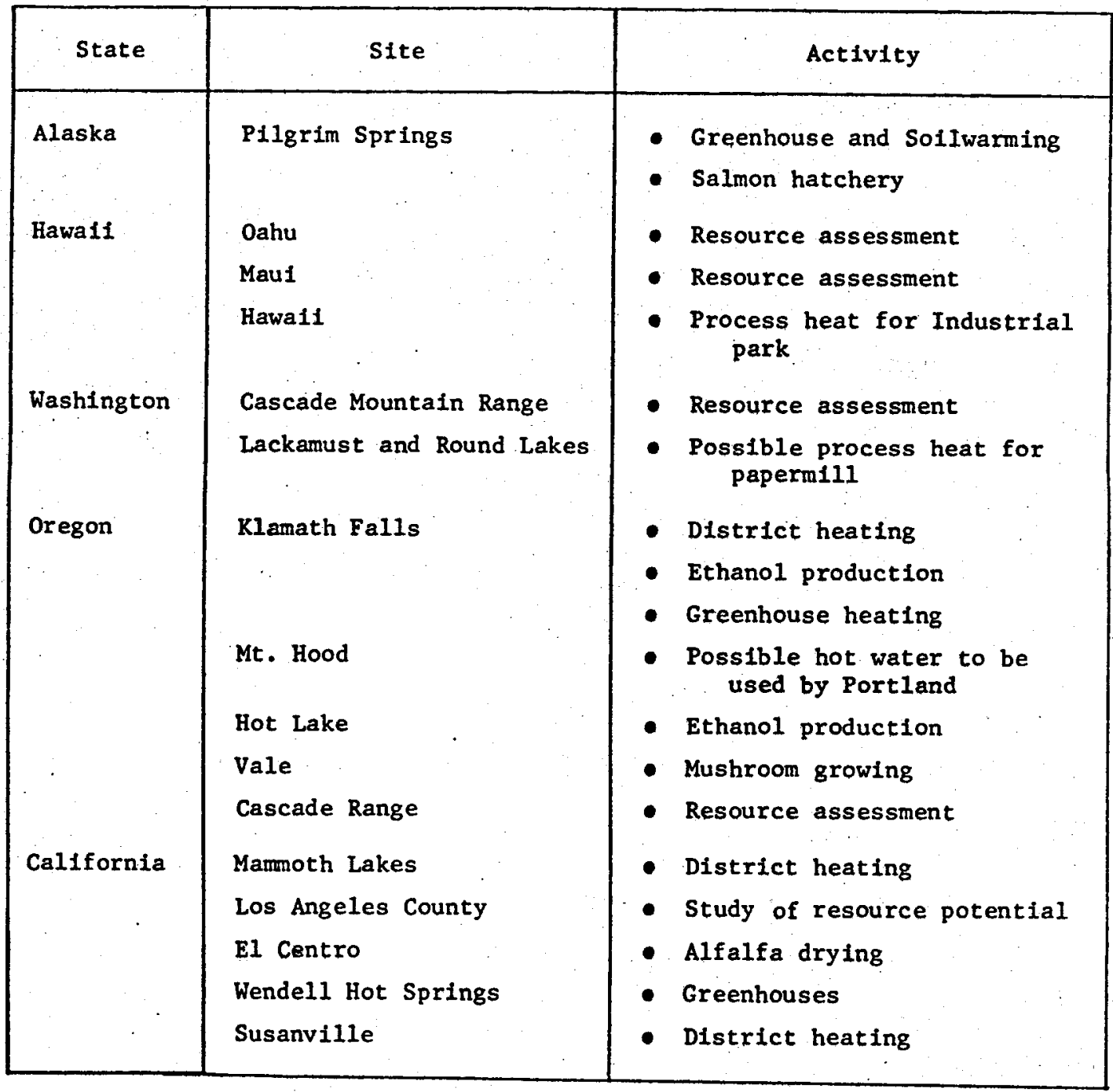


heat uses. Oregon seems to be much further down the road than other Pacific states toward developing its low temperature resources. The other four states in the region are more involved in resource assessment with limited developments for direct heat usage. However, accelerated development of proven resources should be expected as geothermal energy increases its price advantage over fossil tuels. A.2 The Rocky Mountain Basin and Range Region (RMB\&R Region)

The Rocky Mountain Basin and Range Region consists of 10 states: Arizona,-Colorado, Idaho, liontana, Nevada, New Mexico, North Dakota, South Dakota, Utah and Wyoming. This region is a net energy exporter. (24) The industrial sector is the leading consumer of energy in the region. Natural gas is the primary energy source for industry and accounts for about 45 percent of the energy use. 0il supplies approximately 33 percent of the industrial needs. Coal is used primarily for electric power generation.

Major industrial consumers in the region use low to Intermediate-heat energy sources for at least a part of their energy needs. These industries include food and kindred products, wood and lumber products, and stone, clay and glass products.

The population centers vary greatly in size, latitude and altitude. These are the factors that have a direct bearing on the amount of energy required for space conditioning in the residential and commercial sectors. As a result, the percentage of energy that these 
sectors consume for space conditioning and for water heating varies in the range of 50 to 95 percent.

The specific energy supply demand situation in each state of the RMB\&R region is discussed below.

(1) Arizona. One of the most significant factors in Arizona's energy supply/demand pattern is the large portion (67 percent) of the net energy that Arizona now imports. (24)

Industries making food and kindred products, lumber and wood products, chemical and allied products, and stone, clay and glass products account for about 25 percent of the industrial energy consumption. Due to the wide range of climates in Arizona, air conditioning is as necessary as space heating and accounts for about 50 percent of the residential and commercial sector's energy needs.

(2) Colorado. If uranium exports were not considered, Colorado would be a net importer of energy (16 percent of use).

The industrial sector is the second largest energy consumer in Colorado. 011 and natural gas supply about 80 percent of industrial needs. The food industry is the largest industrial consumer accounting for about 30 percent of the industrial total. Other industries that can use low-to-intermediate temperature energy account for about another 20 percent. Residential and commercial sectors combined account for a large portion of Colorado's natural gas consumption. Approximately 70 percent of the residential consumption is for space conditioning. 
(3) Idaho. The most significant energy factor in Idaho is that the state 1mports 66 percent of its energy needs. Natural gas is the primary industrial energy source supplying 40 percent of the industrial energy needs in Idaho. $0 i 1$ is the major source of energy for the residential and commercial sectors supplying about 40 percent of those energy needs.

The industrial sector is the largest energy user in Idaho. The food and kindred products and wood and lumber product industries account for approximately 45 percent of this industrial energy consumption of which a large portion could be satisfied by low- to intermediate temperature sources of energy. (24)

Residential space heating ( 80 percent) and water heating ( 10 percent) account for approximately 90 percent of the residential energy consumption, and the commercial sector probably consumes energy according to a similar pattern.

The energy demand in Idaho is expected to double by 2010 , with an initial drop in projected demand due to possible near-term curtallments in natural gas supplies and the conservation efforts that would follow.

(4) Montana. Montana is a net exporter of energy. However, about 40 percent of llontana's natural gas is imported. This gas is the first energy source in the residential sector and the second energy source used by industry. The stone, clay and glass-products industry represent about 15 percent of industrial total energy needs 
and food and kindred products consumes 8 percent. The residential and commercial sectors account for approximately one-third of Montana's energy consumption, with 80 percent of that energy being required for space conditioning.

(5) Nevada. This state imports almost all of its present energy supply. The other significant feature of Nevada is the large distances between population centers making transportation the largest energy consuming sector in Nevada. The very small industrial sector of Nevada, compared to other states, is the second largest energy consumer using primarily natural gas (about 45 percent) and oil (approximately 35 percent), with electricity and a very small amount of coal making up the remainder. The stone, clay and glass products industry accounts for approximately 40 percent of the energy used by Nevada's industry.

Nevada's residential consumption of energy exceeds the national average by a factor of about 3 due to the prevalling climatic conditions in this state. About 95 percent of the gas sold for residential purposes in the northern counties is used for space heating. In the southern counties, however, a substantial amount of the natural gas is used for absorption alr conditioning.

(6) New Mexico. The state of New Mexico is a net exporter of energy. New Mexico's industrial sector is relatively small, but it is the largest energy-using sector in the state accounting for approximately 35 percent of the total state energy consumption. 
Approximately 30 percent of the industrial energy consumption in the state of New Mexico goes to the food and kindred products industry, the wood and lumber industry, and the stone, clay and glass industry. The residential and commercial sectors combined are responsible for approximately 25 percent of the state's energy consumption, with space conditioning accounting for half this amount of energy.

(7) North Dakota. This state is also a net exporter of energy. Transportation is the largest energy consuming sector, accounting for 32 percent of the total energy consumption with the remaining 68 percent equally divided between the other sectors (1.e., Industrial, residential, commercial and electric sectors). Over half of the Industrial energy consumption (1.e., 9 percent) goes to the state's food and kindred-products industry.

011 is the major energy source for the residential and commerclal sectors supplying over half the energy needed by each sector. Due to its predominantly cold weather, North Dakota requires 2 to 2.5 times the space heating energy per volume as the national average. (8) South Dakota. The only sizable energy source in South Dakota is hydroelectric which is mostly exported to surrounding states. The percentage energy used for industrial purposes is the smallest (representing only 7 percent) of the states in the region. However, over three-fourths of this energy is used by industries requiring mostly low to intemediate temperature energy (e.g., food and lumber industries). Transportation is by far the largest user 
of energy ( 39 percent). The next largest use of energy is for residential and commercial purposes accounting, respectively, for 23 and 17 percent of the total energy need of South Dakota.

(9) Utah. This state is a net energy exporter. The industrial sector is the largest energy consumer, with oil, coal and natural gas being used in about equal proportion to supply the required energy need. The primary industrial use of energy is by the primary metal sector ( 50 percent). However, a significant amount of the remainder ( 25 percent) is used by industries that can use low to intermediate heat energy sources.

Utah's residential and commercial sectors use natural gas as the primary energy source, with a large portion of energy consumed being used for space conditioning.

(10) Wyoming. Wyoming is the region's leading exporter of energy. The industrial sector is the largest energy consumer, with petroleum and oil products industries consuming about 65 percent of the energy used by Wyoming Industries. However, approximately 15 percent of the remaining use is by industries.that can use low to intermediate heat energy sources.

The residential and commercial sectors use primarily oll and natural gas with 70 to 80 percent of these sources being consuned to provide for space conditioning energy requirements. 


\section{A. 3 The Eastern Region}

The Eastern Region of the United States includes 33 states. A review $(10)$ of the statewide energy supply/denand situation and other pertinent data related to the potential application of direct hydrothermal heat in the eastern U.S. region indicates that the prime candidate for direct heat application appears to be the areas along the Southern New Jersey Coast, the Delmarva Peninsula, and around Norfolk, Virginia, Wilmington, North Carolina, Charleston, South Carolina, and Savannah, Georgia. 

APPEIDIX B

BASELINE MARKET DEFINITION

The baseline market for geothermal direct heat utilization is limited by the following five basic considerations:

(1) Geographical Boundaries of Regions. The three regions analyzed in this study are described in section 3 in the body of the report.

(2) Resource Availability. The maximum potential of hydrothermal energy avallable for replacing other existing energy sources (e.g., coal, oil, natural gas, solar) in direct heat application market is limited by a number of techno-economic criteria as detailed below.

- Well Head Temperature. Based on thermodynamic and heat transfer consideration, the most suitable temperature range for non-electric hydrothermal applications is $50^{\circ} \mathrm{C}$ to $150^{\circ} \mathrm{C}$, where $50^{\circ} \mathrm{C}$ represents the minimum temperature for greenhouse heating, and $150^{\circ} \mathrm{C}$ represents the 1imit above which it may become more attractive to use the hot water in a binary-cycle system for the generation of electricity. As shown by Relstad, (13) the resource temperature is the most important factor in determining the type of application for which the resource is most technically and economically suitable.

- We11 Depth. The exploitation of hot waters for non-electric uses in the range of $50^{\circ} \mathrm{C}$ to $150^{\circ} \mathrm{C}$ has an economic-feasibility limit. This limft depends on the depth of the reservolr containing these 
waters. Faca (28) has fixed this limit at 1.5 to $2 \mathrm{kn}$ (i.e., 1500 to 2000 meters or about 4950 to 6500 feet) beyond which the drilling costs rise exponentially and become conparatively higher than the value of the geothermal extractable energy.

- Subsurface Environment. Three subsurface characteristics, unique to each hot water geothermal reservoir, Influence the cost of direct heat extracted from such reservoir. These characteristics are the temperature gradient, the hydrostatic pressure gradient, and the reservoir rock properties (e.g., effective permeability).

To a great extent the temperature gradient controls the heat flow rate and, hence, the cost of unit energy output from a given geothermal we11. For increasing depth the available fluid energy (and hence the corresponding fluid temperature) must increase at least an amount equivalent to the pumping energy required to maintain a single phase flow which is necessary for low enthalpy non-electric uses. The required temperature gradient $\Delta^{T}$ (i.e., increase in temperature per unit increase in depth) is given by the equation:

$T_{f}-\Delta T=T_{0}+0.0024 h$

where,

$\mathrm{T}_{\mathrm{f}}$ is the geofluid temperature ${ }^{\circ} \mathrm{C}$;

To is the ambient temperature ${ }^{\circ} \mathrm{C}$; and

$\mathrm{h}$ is the depth in $\mathrm{km}$.

As estimated by equation (1) this temperature gradient is typically $2.4^{\circ} \mathrm{C} / \mathrm{km}$, and the normal thermal gradient (i.e., $24^{\circ} \mathrm{C} / \mathrm{km}$ ) in 
most resource areas more than meets this requirement. However, up to ten times as much energy is consumed to produce the pump energy as is actually delivered to the fluid. In that case, the required increase in temperature with depth (i.e., temperature gradient) would be $24^{\circ} \mathrm{C} / \mathrm{km}$. To be economical, therefore, the temperature gradient of the geothermal resource must be slightly higher than the normal gradient of $24^{\circ} \mathrm{C} / \mathrm{km}$.

Other things being equal, an increase of the reservoir pressure gradient increases the bottom-hole flowing pressure. This reduces the amount of energy required to lift and transport the geofluid from the bottom of the well bore to the heat utilization point. This reduction causes a corresponding reduction in the required capacity of the submersible pump capacity and, hence, reduces the thermal unit cost to the end user. Artesian outflow from a hot water aquifer is, therefore, desirable.

The reservoir rock properties also control the geothermal well flow rate. For typical geothermal direct heat applications (e.g., district heating) a well flow rate of at least $470 \mathrm{gallon} / \mathrm{min}$ at $50^{\circ} \mathrm{C}$ is necessary before the economic value of geothermal heat extracted can pay for the costs of geofluid heat extraction and transportation to the end user.(29) To maintain this high well flow rate (i.e., $470 \mathrm{gal} / \mathrm{min}$ ), the transmissivity (1.e., aquifer thickness $\mathrm{x}$ permeability) of the water-bearing formation must exceed 1000 millidarcy meter. Such transmissivity will ensure a maintained recovery of at 
least $12 \times 10^{9} \mathrm{cal} / \mathrm{hr}$ (1.e., $47 \times 10^{6} \mathrm{Btu} / \mathrm{hr}$ ) per well, (29) at a brine temperature of $100^{\circ} \mathrm{C}$.

(3) Colocated Mlarkets. 'Users' proximity to the resource is an important factor to the economics of geothermal direct heat utilization due to the large size of the fluid transmission expense. It has been shown (27) that the distance over which geothermal fluid must be transported strongly influences the rate of return on investment in a geothermal direct heat application system. For example, at a distance of 5, 15 and 25 miles, the rate of return falls from 12.75 to 10.0 to -0.25 percent at a resource temperature of $120^{\circ} \mathrm{C}$. As a result, only those markets that are situated within 15 miles from the geothermal resource are generally suitable for economic geothermal direct heat applications. For heavily populated markets (i.e., more than $3600 / \mathrm{mi}^{2}$ ), however, a 50 mile distance is still suitable. The size of the resource colocated market should be greater than 50 million Btu/hr(29) to take advantage of the economics of scale if the distance is 50 miles.

(4) Environmental and Institutional Constraints. Both environmental and institutional constraints are major factors in sizing up the geothermal direct heat market. Stringent environmental regulations such as exist in the U.S.A. can limit the extent of geothermal direct heat applicability. For example, the economically attractive single-pipe systems that use geothermal water and dump to a drain will usually not be permitted in the United States. 
Institutional constraints can also limit the widespread usage of geothermal direct heat. In certain states, for example, district heating systems have difficulty forming because they are not recognized as a public utility.

(5) Applicability of Geothermal Heat. The extent of applicability of geothermal heat differs with the type of application, whether residentlal/commercial, industrial or agricultural. For each type of application many factors influence the extent to which geothermal energy may be used as follows:

(A) Residential/Commercial Applications

of all the energy needs for residential/commercial establishments, space and water heating, and drying require relatively low temperature levels $\left(40-90^{\circ} \mathrm{C}\right)$ and are therefore very suitable and most promising end uses for geothermal energy. Practically any geothermal source with a geofluid temperature above $40^{\circ} \mathrm{C}$ can be utilized directly or indirectly for space heating and other low temperature residential/commercial usage. However, the economy of geothermal heating systems relative to individual fuel fired or electrically powered systems is dependent on the following considerations:

- Transportation and Distribution Costs. The direct application of low temperature geothemal energy involves capital intensive distribution systems, and significant costs are incurred as the thermal energy is transported to the user site. Thus, it is important to know not only the overall size of the potential market, but also its 
spatial configuration. This spatial configuration determines the housing densities (i.e., the number of houses) per unit area and is fixed by the housing type in this area. In any direct heating system, costs rise as housing densities decline. Thus, in the U.S.A., a single family housing pattern which allows only 7 households per $400^{\prime}$ by $200^{\prime}$ block does not provide a dense enough heating requirement to economically permit district heating. Meanwhile, 15 households per block is considered economically marginal, and 40 family units per block is economically attractive for direct heating.

The percentage of participant households (1.e., customers) within a service area (i.e., saturation level) is another crucial factor in determining the distribution cost for a direct heating system. To indicate the impact of some household not participating in the system, the length of the system is multiplied by the reciprocal of the saturation level. For example, a system with a total length of 2 miles and 100 percent saturation would be equivalent to 2.5 miles with an 80 percent saturation, and to $20 \mathrm{miles}$ at 10 percent saturation. Of course, for housing types of differing densities, the saturation level changes in relative importance, but remains very significant for all types. The lowest econonical saturation level is sixty percent.(11)

For a system of a given length, the impact of changes in the unit cost of installed pipe is a function of heat market density and the market saturation 1evel. At lower saturation levels, changes in 
pipe costs would have a greater impact. However, even large changes in the cost per mile of an installed insulated pipe (e.g., from $\$ 250,000$ per mile to $\$ 450,000$ per mile) raises average unit energy cost only about $\$ 1.5$ per million Btu's when the neighborhood is one of townhouses ( 30 households per block) and market saturation level is 80 percent. (11)

- Heating Load Characteristics. The yearly energy consumption of a given space heating system depends primarily on the yearly average inside-outside temperature differential expressed in degree-days per year. Higher numbers of degree-days per year and higher conventional fuel prices tend to make geothermal direct heat systems more economically appealing. The colder climates raise the level of space heating energy demand per household so that the same number of Btu's can be sold to fewer residents and thus through a shorter and less costly distribution system.

The ratio between the maximum (1.e., peak) and the average temperature-differential gives a measure of the yearly load factor which determines the extent to which fuel-fired peak-load booster plants will be needed for an overall economic operation. A yearly factor of 1.6 is marginally economical.

- Retrofit Market Condition. Since many potential applications are for existing cities, the case of converting to a geothermal direct heat system ( $1 . e .$, retrofitting) is an important consideration. The three types of building heating systems most easily adaptable to 
geothermal hot water are (1) baseboard convectors, (2) forced air over hot water colls, and (3) radiant heating panels. Conversion of a baseboard convector heating system generally requires only hookup of the geothermally heated fluid to bypass the existing boiler. To modify a forced air systen, a new heating coll would be installed in the ductwork downstream from the furnace. A somewhat larger fan may be necessary to increase the heat transfer across the coil. The original fosstl fuel furnaces could be left in place for use as a booster or backup system if needed. Radiant heat panels can easily be adapted by using the geothermal fluid in the existing radiators provided no corrosion or scaling problems are expected. Otherwise, it would be necessary to replace existing radiators by an expensive binary-fluid surface heat exchanger system in which scaling and corrosion are controlled.

In general, the cost of retrofitting and the quality of geothermal brine (whether corrosive or scale forming) would determine the economic attractiveness of a change over from an existing conventional heating system to a geothermal direct heat system. The economic limit of geothermal retrofit cost is here fixed at $\$ 1000$ per residential unit, based on the opportunity cost of easily adaptable heating alternatives (e.g., alr-tight wood stove).

The quality of geothermal brine is dependent on the reservoir condition (1.e., temperature, pressure, and rock properties and composition) where the geofluld is generated. Normally, the salinity 
of the geothermal brine expressed in parts per million ( $\mathrm{ppm}$ ) is used to judge its quality. The salinity of a good quality brine should not exceed $800 \mathrm{ppm}$. (30)

- Investment Requirement. The required investment is determined primarily by the type of geothermal direct heat system that fits the specific local conditions of the site under consideration. Three basic types of geothermal direct heat systems are available as follows:

System I. Production and Direct Use of Geothermal Fluid. This is the simplest type (and hence the least expensive) in which the geothermal fluids are removed from the reservoir and piped directly to the user. The two basic requirements of this system are (1) sufficlent fluid productivity from the wells and (2) exceptionally high water (brine) quality to avoid corrosion and/scaling.

System II. Production of Geothermal Fluid Through Heat Exchanger. This system is necessary for handing poor quality geothermal brines. The complexity of this system and its associated economics of scale will probably make it economical only for large district heating projects and not for smaller, individual uses or "mini-districts."

System III. Downhole Heat Exchange With No Fluid Production. In this system a clean working fluid (city water) is pumped down one. pipe and returns up the other pipe after extracting heat from the we11. Such a system is specifically advantageous in low permeability 
reservoirs which cannot supply adequate fluid production rates under systems I or II. Due to the inherent low efficieincy of System III, however, it will probably have its most economical application limited to small individual uses or for "mini-district" heating of a small area of users (as is the case in Klamath Falls, Oregon).

In all cases the economic attractiveness of a geothermal direct heat system will decrease with increasing investment per participant home (i.e., customers) in the system. It could be shown that the investment must be less than about $\$ 3$ million for geothermal direct heat to compete with natural gas heating at $\$ 2$ per million Btu's. For a fixed charge rate of 20 percent and 1000 households on the system this amount of investment fixes the economical cost per home (1.e., hook-up cost) at $\$ 600$.

(b) Industrial Applications

Industry requires energy in a wide variety of forms: electrical energy, direct heat and process steam. Geothermal energy sources have the potential to contribute to these industrial needs. However, the number of industrial applications presently using geothermal energy is relatively small. The two critical factors affecting the geothermal direct heat industrial applications, in particular, are:

- Geothermal Fuel Saving. The idea here is to trade off the fuel savings that would result from a geothermal direct heat industrial application against the necessary investment that would be required for such an application. For any geothermal direct heat 
application to be economically attractive, the dollars of fuel savings per dollar invested in such application should be large enough to pay out for the invested capital in less than 10 years. The annual geothermal fuel saving $S(\$ / y r)$ is estimated by the equation:

$$
S=\frac{C}{h_{g}}\left(a \frac{h_{g}}{h_{f}}-b\right)
$$

where,

$C=$ geothermal plant net output in Btu/yr

$h_{f}=$ thermal efficiency for fossil fuel

$h_{g}=$ thermal efficiency for geothermal hot water

$a=$ cost of fossil fue $1\left(\$ / 10^{6}\right.$ Btu $)$

b $=$ cost of geothermal hot water $\left(\$ / 10^{6} \mathrm{Btu}\right)$

- Energy-Cost Intensiveness. This factor represents the cost of energy requirement as a fraction of the unit output cost of an industrial process. As such, the energy-cost intensiveness factor indicates the significance of the cost of energy to the unit production cost of the industry involved. As indicated by B. Lindal, (17) energy cost becomes a major consideration in direct heat industrial application when it exceeds 10 percent of the unit production costs. Geothermal direct heat application may thus be attractive only for those industries with an energy-cost intensiveness of 10 percent or more (e.g., food processing industries).

(C) Agricultural Applications

This application refers to the use of geothermal warm waters to establish and naintain optimal temperature conditions for plant and 
animal cultivation. The four main agricultural applications of geothermal fluids are greenhouses, soil warming and irrigation, animal husbandry, and aquaculture. The use of geothermal waters in greenhouses is more common in higher latitudes (i.e., Iceland) with low level of sunshine and short growing seasons. The key factor affecting the application of geothermal fluid for direct soil heating operations in greenhouses or outdoors is the purity of water (i.e., low salinity) and no traces of such poisonous chemical elements as boron.

The application of geothermal waters in animal husbandry, although not as extensive as for greenhouses operations, is more diverse in that the geofluid, is used not only for heating, but also for cleaning, sanitizing, and drying of animal shelters and wastes. Poultry, swine and cattle respond to an optimal thermal environment with increased production, growth rate and feeding efficiency. (29) Therefore, the deciding factor for geothermal direct heat application in husbandry is how close the geofluid temperature is to the predetermined optimal thermal environment required for the animal species 1nvolved. Geofluid temperature match to optimal thermal environment is also a prerequisite condition for geothermal direct heat application in cultivating aquatic species (1.e., Aquaculture) under controlled environmental conditions.

For most agricultural applications the most desirable temperature differential between the geofluid temperature $T_{s}$ and the 
surrounding atmospheric temperature is $17.5^{\circ} \mathrm{C} .(31)$ This temperature differential will result in an increased production yield of 10 to 35 percent depending on the specific application in hand. A summary of the foregoing key factors that govern the various geothernal direct heat (1.e., non-electric) uses and their determined critical values for different types of applications was given in Table 3-1. 


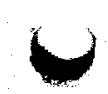

APPENDIX C

REVIEW OF MARKET PENETRATION MODELS 


\section{APPENDIX C}

REVIEW OF MARKET PENETRATION MODELS

over the years, several different market penetration algorithms (models) have been used to predict or explain the growth of new markets. In general all market penetration models fall into three classes, all of which may be manual or computerized: regression, simulation and analytic models.

\section{C.1 Regression Models}

Regression market penetration models are least square polynomial fit of historical data that are intended to project the future trend of a given market. An example of such model is the $\operatorname{scott}(32)$ model which relates the future probability of purchase of a new technology to its expected installation cost, the monthly fuel saving, the financing terms (i.e., debt to equity ratio), and the available tax incentives. The main advantage of such models is its intuitive simplicity and its emphasis on the decision makers attitude towards a new technology. However, the regression model is conceptually unsultable for new technologies, usually with very limited or no historical data.

\section{C.2 Simulation Mode1s}

Simulation models are dynamic models that show how a decision model output will change with time. These models attempt to describe market penetration as a function of the many dynamic economic, market, and other forces that impact upon it. To this end, these

$$
\mathrm{C}-1
$$


simulation models are based on information feedback within closed systems. As originally described by J. Forrester(33) this approach requires: (1) the identification of information feedback loops in a decision model, (2) determination of decision points and decision rules in each loop, (3) the identification of state and rate variables of the decision model and (4) the state-rate relationship. The dynamic simulation model has several advantages: (1) it explicitly allows for temporal variations in decision parameter values, (2) it is highly flexible (i.e., it can include any number of relevant technological, behavioral, institutional, market and financial decision factors), and (3) it allows for possible interdependence and interaction of various decision factors. However, the data requirement for such models are extensive and of ten times unava11able. The most important new energy technology market simulation models are the General Electric, Arthur D. Little, Intertechnology Corporation and the PRC System Sciences models.(32) All these models specifically address solar energy system market penetration problems.

\section{C.3 Analytic Models}

Analytic models are able to describe the market penetration process as a function of a few key quantifiable variables. Five basic approaches (models) are currently used to determine the future demand (i.e., market penetration) on new energy technologies. 
These models are respectively based on fixed demand, partial equilibrium elasticity, energy-economy interaction, probabilistic and diffusion concepts.

\section{C.3.1 Fixed Demand Models}

In fixed-demand models, the Gross National Product (i.e., GNP) growth rate and other time trends are the only factors affecting demand and the objective is to minimize the cost of energy supply.

\section{3.2 Partial Equilibrium Models}

Partial equilibrium models allow for energy supply and demand to be balanced through an equilibrium price, which equalizes the consumer propensity to pay against the producers incremental costs to produce more energy to satisfy an existing consumer demand. In such models, therefore, price elasticity fixes the market share of a new energy source (and/or technology) based on their relative cost competitiveness. If the GNP and energy prices are the only independent variables involved, the corresponding partial equilibrium price elasticity could be represented by the equation:(34)

$$
\text { Energy Demand }=\left(\begin{array}{c}
\% \text { Change in } \\
\text { GNP }
\end{array}\right) \text { minus }\left(\begin{array}{c}
\text { Price } \\
\text { Elasticity } \\
\zeta
\end{array}\right)\left(\begin{array}{c}
\% \text { Change } \\
1 \text { En Energy } \\
\text { Price }
\end{array}\right)
$$

where the price elasticity $\xi$ is the percent reduction in demand for each one percent increase in energy price.

Typically, a partial-equilibrium model would consist of an economic demand component, a series of special purpose supply components, and an integrating component. Because such models include a 
step function to approximate the resource supply curve, conventional optimization techniques cannot be applied directly to solve for an equilibrium price. Instead, an iterative procedure is employed, thus introducing difficulties of convergence and doubts about the uniqueness of solution. Partial-equilibrium models also have several other problems. First, elasticity measures generally assume that the costs of converting from one good to another is small. (35) This is not the case when comparing, for example, an existing gas heating system to a geothermal energy direct heating system where retrofits and hook-ups to district heating unit could cost hundreds of dollars. Second, different investigators use different elasticity estimates thus leading to different market shares. Third, equation (1) ignores the actual interdependence of the GNP growth and energy prices, which could lead to significant error in estimated market shares. A typical example of the partial equilibrium model is the Energy Technology Assessment (ETA) lode1. The ETA model incorporates cross price elasticities for electric and non-electric energy. The demand side of the ETA model is based upon a hybrid of econometric and engineering process analysis. The supply side of ETA is handled through a conventional linear programming analysis. An intertemporal market equilibrium for the energy sector is applied through a reduced gradient non-linear optimization algorithm. 


\section{C.3.3 General Equilibrium Mode1s}

The general equilibrium models based on the energy-economy interaction concept allow for feedback from the energy sector to the balance of the economy and explicitly represent the GNP growth and energy prices as interdependent variables. Energy price increases may reduce the GNP sufficiently so as to exert additional downward pressure on energy demand. An example of such model is the ETA-MACRO model which is a merger between the ETA partial-equilibrium model and a macroeconomic growth model providing for substitution between capital, labor and energy inputs.

\section{3.4 Probabilistic Models}

All previously discussed ecometric models are deterministic, with future uncertainties of long term energy planning being handled through sensitivity analysis. To allow explicitly for future uncertainties it is necessary to use probabilistic models. Two different types of probabilistic models are avallable: the probabilistic general equilibrium model and the probabllity of least cost model.

(A) Probabilistic General Equilibrium Models. This model is based on Raifa decision tree analysis.(36) Using a tree diagram, the analyst graphs the problem as a series of dectsion and chance nodes unfolding sequentially over time. Thus, the decision-maker is allowed to define his set of feasible outcomes. However, the probabilistic general equilibrium model is difficult to implement because (1) it is necessary to restrict the set of possible outcomes and of 
feasible alternatives so as to reduce the problem to manageable dimensions, and (2) It is particularly difficult to avoid bias in the assessment of probabilities. A well known example of such a probabilistic general equilibrium is the SRC-Gulf model (also known as LEAP). LEAP is formulated to calculate the energy flow around an energy network, involving a set of end-use energy requirements and a set of available energy resources and energy conversion technologies, so as to minimize total cost subject to the demand and resource constraints in a target year. That is, the model assumes future demand for energy service as given and then determines the combination of energy resources and technologies to be used over time in order to meet those demands at least cost. Supplies and demands are balanced simultaneously at each node at each point in time over a 50-year planning horizon. Because of the high degree of regional and process deta11, the SRI-Gulf model has thousands of such nodes, and requires the solution of 100,000 simultaneous nonlinear equations. (34) This is done through a successive approximation algorfthm using decomposition techniques which may not converge to a unlque solution.

(B) Probability of Least Cost Model (PLC). The PLC model is basically a utflity decision model for selecting the appropriate technology for additional electric power generating capacity based on the expected benefit of a new technology over the least cost conventional technology. The idea is to use a distribution of engineering 
estimates of the levelized life cycle costs or figure of merit for each market competitor. The overlap of the two or more distributions will provide an estimate of the probability that one technology will be of higher worth and, hence, will capture a bigger market share than the other. The PLC model is very useful in capturing uncertainty about costs, but is nevertheless incapable of providing narket shares for new technologies that have no overlap in their respective busbar cost probability density function. Further, the PLC model fails to include other market non-cost factors and market time lags.

\section{C.3.5 Diffusion Models}

The diffusion model is the only simple model that is based on both price competitiveness and other non-price market factors. Based on empirical evidence(37) the diffusion model is an " $S$ " shaped growth curve which describes the growth of acceptance (by Individuals) of a new technology with perceived performance and economic risk.

\section{C.4 Comparative Analysis}

For comparative analysis, the main features of the aforementioned models are summarized in Table $c-1$. As shown in this table, these models differ in their basic assumptions and approach and will expectedly lead to different market share estimates. Also, all models, with the exception of diffusion models, do not fully account for non-price market factors such as environmental, perceived security of supply, cleanliness, ease of maintenance, and other premium attributes of the competing energy sources and technologies. 
TABLE C-1

COMPARISON OF MAIN FEATURES OF COMMON MARKET PENETRATION ESTIMATION METHODS

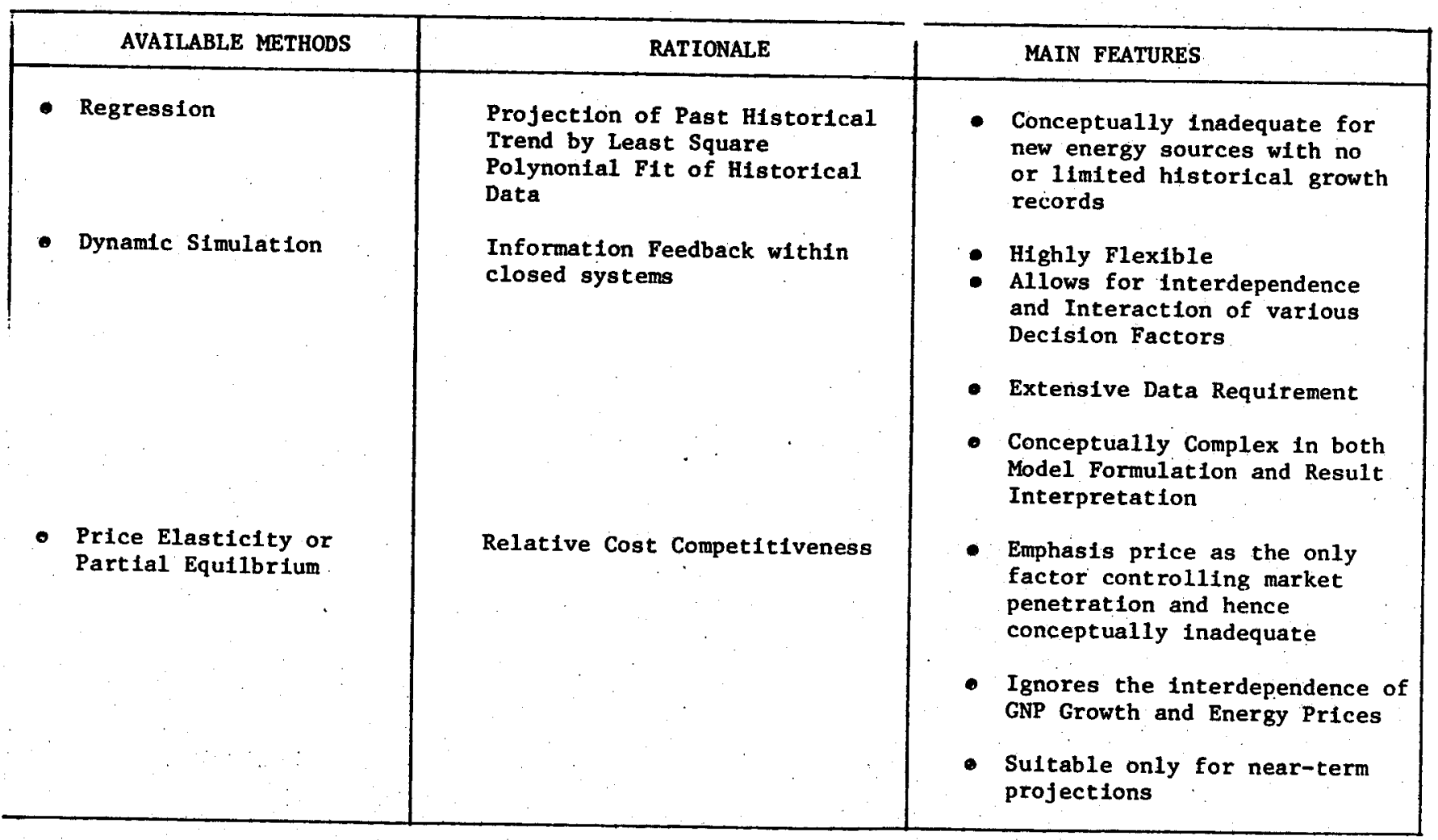


TABLE C-1 (Concluded)

\begin{tabular}{|c|c|c|}
\hline AVAILABILL MODELS & RATIONALE & MAIN FEATURES \\
\hline $\begin{array}{l}\text { - General Equilibrium Model } \\
\text { - Probabilistic Models } \\
\text { D Diffusion }\end{array}$ & $\begin{array}{l}\text { Market Share 1s Fixed by Interaction } \\
\text { of GNP and Energy Prices } \\
\text { Decision Tree Analysis } \\
\text { Natural Growth Function } \\
\text { (Pearl-Curve) }\end{array}$ & $\begin{array}{l}\text { - Tgnores Non-Price Market } \\
\text { factor and Hence Conceptually } \\
\text { Inadequate for new energy } \\
\text { - Assumes Equilibrium and } \\
\text { Hence is Inadequate for } \\
\text { short run Forecast } \\
\text { - Extensive Data Requirement } \\
\text { - Equilibrium Market Substi- } \\
\text { tution is f1xed by inter- } \\
\text { active Alborithom which } \\
\text { may not coverge } \\
\text { - Conceptually difficult } \\
\text { to Formulate } \\
\text { - Unless Restricted the } \\
\text { Decision Tree can grow } \\
\text { to Unmanageable Dimensions } \\
\text { - Bias in Assessment of } \\
\text { Probabilities } \\
\text { - Conceptually Simple } \\
\text { - Easy to implement } \\
\text { - Allows for both price and } \\
\text { non-price market factors } \\
\text { - Sultable for Multi- } \\
\text { Technology Comparison } \\
\text { - Deterministic } \\
\text { Model Key Parameters may } \\
\text { have to be determined } \\
\text { arbitrarily } \\
\text { - Most recommended for fore- } \\
\text { casting future market share } \\
\text { of new energy substitute }\end{array}$ \\
\hline
\end{tabular}


APPENDIX D

COLOCATED MARKET EXPANSION FACTOR IN 20 YEARS

FOR THE PACIFIC AND EASTERN REGIONS IN THE UNITED STATES 
TABLE D-1

COLOCATED MARKET EXPANSION FACTOR IN 20 YEARS FOR THE PACIFIC AND EASTERN REGIONS IN THE UNITED STATES*

\begin{tabular}{|c|c|c|c|c|c|c|}
\hline Region & $\begin{array}{l}\text { Opulance** } \\
\text { Factor } \\
\text { (K) }\end{array}$ & $\begin{array}{l}\text { Population Growth } \\
\text { Factor (1) } \\
\text { (P) }\end{array}$ & $\begin{array}{l}\text { Energy Demand } \\
\text { Factor (2) } \\
\text { (E) }\end{array}$ & $\begin{array}{l}\text { Land Apprecia- } \\
\text { tion Factor (3) } \\
\text { (L) }\end{array}$ & $\begin{array}{l}\text { New Resource } \\
\text { Discovery (4) } \\
\text { Factor }\end{array}$ & $\begin{array}{l}\text { Colocated Market } \\
\text { Expansion Factor } \\
(C M E)=K(P \star E \star R) / L\end{array}$ \\
\hline Pacific & 5 & 1.54 & 1.33 & 3.6 & 1.07 & 3.04 \\
\hline Eastern & 5 & 1.00 & 1.25 & 2.29 & 1.10 & 3.00 \\
\hline
\end{tabular}

* The colocated market potential at maturity date (1.e. 2005) for the RMB\&R is based on EG\&G field study for that region and hence no colocated market expansion factor was calculated for the RMB\&R.

** $\mathrm{K}$ is a proportionality constant that reflects opulancy and is taken as 5 based on $\mathrm{C}$. W. KIlmister for big cities (e.g., New York, Chicago, Paris and London).

*** Maturity date is the date at which the new technology becomes widely accepted. From foreign experlence in hydrothermal direct heat utilization the maturity perlod varies from 15 to 25 years after the penetration date $\left(T_{0}\right)$. Therefore, the maturfty date here 1 s taken as $\left.(1985+20)=2005\right)$.

(1) Based on Table D-1.

(2) Based on Reference (38).

(3) Personnel Communication with National Institute of Real Estate.

(4) Personnel Communication with USGS. 
TABLE D-2

REGIONAL

COLOCATED MARKET PENETRATION

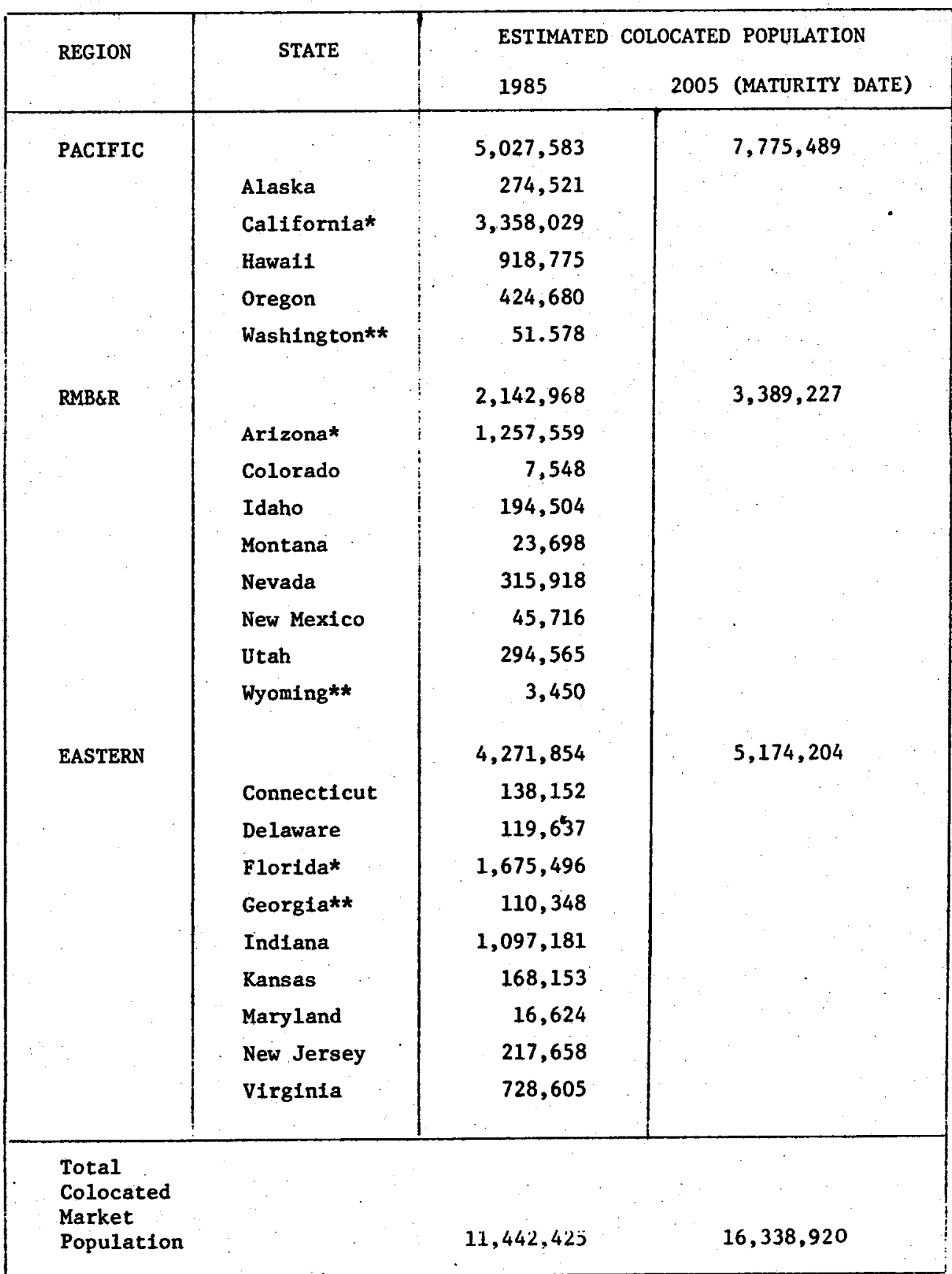

*Highest population in region. **Lowest population in region. 
APPENDIX E

ESTIMATE OF MARKET PENETRATION

RATE PARAMETER 


\section{APPENDIX E \\ ESTIIATE OF ILARKET PENETRATION \\ RATE PARAIETER}

One of the greatest uncertainties in the estimate of the market penetration rate lies in the selection of $\alpha$, the intrinsic growth rate parameter of the Blackman model.

$\alpha$ is related to the average propensity of a potential user to adopt the new technology within a given year. Because of the mathematical form of the Blackman equation, the specific values of do not lead to easy intuitive interpretation. It is easier to understand the growth of market shares by discussing another parameter, the takeover time, $\tau$, which is mathematically equivalent to but does not appear explicitly in Blackman's equation.

$\tau$ is defined here to be the number of years it takes the new technology to go from a market share of 10 percent to a market share of 90 percent. The derived relationship between $\alpha$ and $\tau$ is:

$$
\alpha=4.9344 / * \tau
$$

In various case studies $(39,40,41) \tau$ has been found to range from 5 to 80 years depending on largely uncharacterized features of the new technology and the situation in which it is being applied. In general, it appears to be the case that $\tau$ is relatively small, 5-15 years, when the new technology substitutes directly for an older process in situations that are under the explicit control of an individual firm. 
$\tau$ tends to be larger, on the order of 30-80 years, when the new technology requires substantial alterations in the industrial or societal infrastructure to allow 1 ts use. The T's associated with substitution of one energy form by another tend to fall in this range. Marchetti (41) has collected data on world energy market share growth that indicate a $\tau$ of about 70 years for the use of oil (substituting mainly for coal) and a $r$ of about 60 years for the use of natural gas (substituting for both coal and oil).

We have examined the market penetration rate for use of natural gas in the U.S. as a check on Marchetti's data. Working from data from Gas Facts (American Gas Association, 1979), it appears that in the period 1922 to 1970 , when the use of natural gas in the U.S. grew from 0.76 quad/year (market share $=3 \%$ ) to 22.0 quad/year (market share $=49 \%$, the equivalent $\tau$ was approximately 60 years.

We belleve that the natural gas market penetration case bears many resemblances to the geothermal hydrothermal direct heat case. Similarities between these two cases include:

- Plpelines are required to transport the bulk of the commodity between resource and user.

- The ultimate local distribution to the user depends, for the most part, on pipelines buried along existing streets.

- Efficient distribution and load leveling depends on connecting a number of users to a distribution system.

- The end user must alter a part, but not necessar1ly all, of his existing heat use system to use the new energy source. 
- Both energy systens are capital intensive, with the great bulk of the expense lying in the extraction subsystem (wells) and distribution subsystems (subsurface pipes).

- Most users are economically and technically incapable of drilling and operating their own wells.

- The bulk of the initial discoveries of resources are byproducts of searches for more valuable commodities: oll in the case of natural gas, and high temperature geothermal brines for electricity generation in the case of many low temperature hydrothermal resources.

There are also apparent dissimilarities between the natural gas

and the hydrothermal cases. These include:

- Natural gas can be transported economically for much greater distances. This allows the natural gas systems to be longer and more interconnected, resulting in greater economics of scale and greater interest on the part of large industrial firms and suppliers of capital.

- The waste products from natural gas use are disposed of in the atmosphere, while spend hydrothermal brines must be piped some distance before being disposed to surface waters or reinjected Into the earth. This imposes additional capital costs upon hydrothermal systems.

- There will probably be a greater proportion of hydrothermal cases where a single user or only a few users will be tied to one or a few geothermal wells by a short transportation and distribution systems. Most of the early adopters of geothermal direct use are connected in this manner. Nonetheless, we expect the largest share of eventual geothermal direct heat use to be managed by utility-like systems where large numbers of users are connected to a regulated supplier.

- In the case of natural gas, consumer acceptance may have been somewhat retarded by the percelved and real dangers of explosion associated with gas. This problem does not exist for hydrothermal energy systems.

On balance, we believe that the natural gas case is the most analogous to the geothermal direct use situation. We therefore have 
assumed $\tau$ to be 60 years $(\alpha=0.0732$ for the Blackman equation) for the geothermal case.

To estimate the effects of this assumption, the base case (no additional government buy) and Case 1 (additional government buy of 0.01 quad/year by 1985) were recalculated assuming either 45 years or 90 years. The results are shown in Table E-1, compared to the original results for the U.S. as a whole if $T$ is 60 years.

From Table E-1 it can be seen that:

(1) The impact of a change in the average market penetration rate (and hence in $T$ ) becomes more significant in the year 2000 and beyond.

(2). An initial government buy of 0.01 quads by 1985 seems to have stimulated an additional market share growth of 0.27 quads/year $(0.78-0.51)$. This growth in market share represents an increase of 53 percent over the base case market in 2020.

TABLE E-1

EFFECT OF VARIATION IN TAKEOVER TIME UPON HYDROTHERMAL DIRECT USE MARKET PENETRATION FOR U.S. (Quads/Year)

\begin{tabular}{|c|c|c|c|c|c|c|}
\hline & \multicolumn{3}{|c|}{ BASE CASE } & \multicolumn{3}{c|}{ CASE 1 } \\
\hline YEAR & $T=45$ & $T=60$ & $T=90$ & $T=45$ & $T=60$ & $T=90$ \\
\hline 1985 & 0.01 & 0.01 & 0.01 & 0.02 & 0.02 & 0.02 \\
1990 & 0.02 & 0.02 & 0.018 & 0.04 & 0.04 & 0.03 \\
2000 & 0.08 & 0.06 & 0.04 & 0.15 & 0.11 & 0.08 \\
2020 & 0.81 & 0.51 & 0.28 & 1.07 & 0.78 & 0.47 \\
\hline
\end{tabular}




\section{APPENDIX $\mathbf{F}$}

ESTIMATION OF COST EFFECTIVENESS OF

DIFFERENT LEVELS OF GOVERRMENT BUYS

TO STIMULATE COLOCATED HYDROTHERMAL MARKETS 
APPENDIX F

ESTIMATION OF COST EFFECTIVENESS OF

DIFFERENT LEVELS OF GOVERNMENT BUYS

TO STIMULATE COLOCATED HYDROTHERMAL MARKETS

In this appendix as well as in Appendix G, benefit/cost analysis provides the structure to evaluate the relative cost effectiveness of initial government buys IGB to stimulate future growth of both colocated and noncolocated hydrothermal direct heat utilization. A major problem in this analysis is the proper Identification of the cost Incurred by the government, and the benefits received by society. In this study the cost of the government initial buy is estimated as shown in Appendix $H$. The additional market share captured over the base case as a result of an Initial government buy represents the benefit. This incremental benefit over the base case is measured in terms of the cost of equivalent barrels of fuel oil saved on the basis of $\$ 30$ per barrel. The ratio of the total discounted incremental benefits to the total discounted cost is a measure of the cost-effectiveness of the varlous levels of the initial government buy. The detafled calculation is shown in Table F-1. A simflar calculation is shown In Appendix $G$ for the case of noncolocated markets. 
TABLE F-1

ESTIMATION OF COST EFFECTIVENESS OF VARTOUS LEVELS OF GOVERMMENT

SUPPORT (IGB) TO STIMULATE COLOCATED HYDROTHERMAL DIRECT HEAT MARKET SHARE GROWTH

\begin{tabular}{|c|c|c|c|c|c|c|c|c|c|c|}
\hline \multirow[b]{2}{*}{ Years } & \multicolumn{4}{|c|}{$\Delta C 1 *=\$ 0.184 \times 10^{9}($ Case $1 ;$ IGB $=0.01 Q)$} & \multicolumn{3}{|c|}{$\Delta C 2 *=\$ 0.736 \times 10^{9}$ (Case 2; IGB $\left.=0.04 Q\right)$} & \multicolumn{3}{|c|}{$\Delta C 3 *-\$ 1.7 \times 10^{9}$ (Case 3; IGB $\left.=0.09 Q\right)$} \\
\hline & $\begin{array}{c}Q / Y \mathbf{r} \text { of } \\
\text { Incremental } \\
\text { Market Share } \\
\text { Over Base } \\
\text { Case }\end{array}$ & $\begin{array}{l}\text { Equivalent } \\
\text { Pue1*** } \\
\text { Sav1ng8 10 } \\
\quad \$ 10^{9}\end{array}$ & $\begin{array}{c}\text { Discount } \\
\text { of } \\
\text { Savin }\end{array}$ & $\begin{array}{l}\text { Valuekt } \\
\text { sel } \\
\$ 10^{9}\end{array}$ & $\begin{array}{c}\text { Q/Yr of } \\
\text { Incremental } \\
\text { Market Share } \\
\text { Over Base } \\
\text { Case } \\
\end{array}$ & $\begin{array}{l}\text { Equivalent } \\
\text { Fue1 } \\
\text { Savings } \\
\$ 10^{9}\end{array}$ & $\begin{array}{c}\text { D1scounted Value } \\
\text { of Fuel } \\
\text { Savings } \$ 10^{9}\end{array}$ & $\begin{array}{c}\text { Q/Yr of } \\
\text { Incremental } \\
\text { Market Share } \\
\text { Over Base } \\
\text { Case } \\
\end{array}$ & $\begin{array}{c}\text { Equivalent } \\
\text { Fuel } \\
\text { Savings } \\
\$ 10^{9}\end{array}$ & \begin{tabular}{|c|} 
Discounted Value \\
of Fuel \\
Savings $\$ 10^{9}$
\end{tabular} \\
\hline 5 & 0.013 & 0.099 & $\begin{array}{l}\text { Discount } \\
\text { Factor } \\
0.6209\end{array}$ & 0.061 & 0.061 & 0.333 & 0.207 & 0.142 & 0.777 & 0.482 \\
\hline 10 & 0.031 & 0.169 & 0.3855 & 0.065 & 0.111 & 0.608 & 0.234 & 0.217 & 1.188 & 0.458 \\
\hline 15 & 0.056 & 0.307 & 0.2394 & 0.073 & 0.176 & 0.964 & 0.231 & 0.311 & 1.703 & 0.407 \\
\hline 20 & 0,086 & 0.470 & 0.1486 & 0.0698 & 0.264 & 1.445 & 0.215 & 0.431 & 2.359 & 0.350 \\
\hline 25 & 0.133 & 0.728 & 0.0923 & 0.0672 & $0.381^{\circ}$ & 2.085 & 0.192 & 0.573 & 3.137 & 0.289 \\
\hline 30 & 0.203 & 1.111 & 0.0573 & 0.063 & 0.521 & 2.852 & 0.163 & 0.736 & 4.029 & 0.231 \\
\hline 35 & 0.386 & 2.113 & 0.0356 & 0.0752 & 0.836 & 4.577 & 0.162 & 1.066 & 5.836 & 0.208 \\
\hline \multicolumn{3}{|c|}{$\begin{array}{l}\text { Total Incremental Bgnefits } \\
(\Delta B) \text { in } \$ 10^{2}\end{array}$} & & 0.474 & & & 1.406 & & & 2.426 \\
\hline \multicolumn{5}{|c|}{$\Delta B / \Delta C=0.414 \times 10^{9} / 0.184 \times 10^{9}=2.58$} & \multicolumn{3}{|c|}{$\Delta B / \Delta C=1.406 \times 10^{9} / 0.736 \times 10^{9}=1.91$} & \multicolumn{3}{|c|}{$\Delta B / \Delta C=2.426 \times 10^{9} / 1.7 \times 10^{9}=1.43$} \\
\hline
\end{tabular}

Case 1 is the most cost effective (1.e., has the highest $\Delta B / \Delta C$ ).

$\star \Delta C$ is the Incremental cost of Initial governmental buy, to stimulate the market share growth, calculated at $\$ 18.4 \times 10^{9}$ per quad (in 1980 do1lars).

** The discount rate 18 taken as 10 percent which 18 the mandated rate for federally supported projects other than those for flood control.

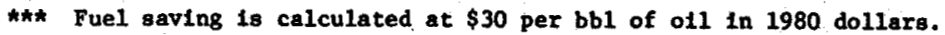


APPENDIX G

COMPARATIVE COST EFFECTIVENESS OF GOVERNMENT SUPPORT IN COLOCATED VERSUS NONCOLOCATED MARKETS 
APPENDIX G

COMPARATIVE COST EFFECTIVENESS OF GOVERMMENT

SUPPORT IN COLOCATED VERSUS NOHCOLOCATED MARKETS

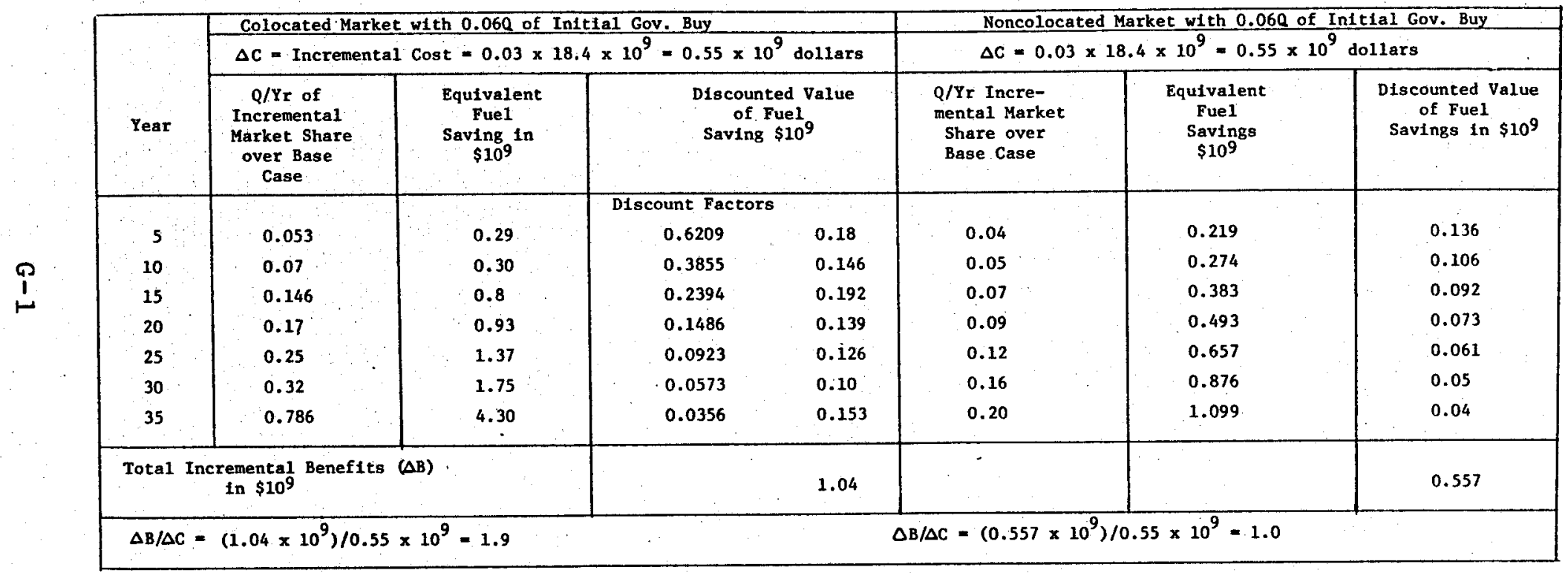




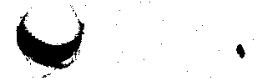

APPENDIX H ESTIMATED COST FOR AN INITIAL GOVERNMENT BUY OF 0.09 QUADS PER YEAR 
ESTIMATED COST FOR AN INITIAL GOVERNMENT BUY OF 0.09 QUADS PER YEAR

A 4,000 ft. deep well flowing at 500 gallon per minute of $100^{\circ} \mathrm{C}$ geothermal brine will support approximately $1.3 \times 10^{11} \mathrm{BTU} / \mathrm{Yr}$ (26), and will cost, complete with casing, 1.5 million dollars in 1978 dollars (i.e. $\$ 1.7 \times 10^{6}$ in 1980 dollars).

Installation of 0.09 quads per year will require building 180 units each with a typical capacity of 0.0005 quads per year over a period of five years (i.e. 36 units per year). Each unit will need 4 wells of the above mentioned type to support it.

Therefore, we need to drill and complete ( $4 \times 36$ or 144) successful wells per year to support 36 direct heat utilization plants. Assuming a drilling success ratio of 80 percent, the total cost of wells will amount to $\left(144 \times 1.7 \times 10^{6}\right)$ or $\$ 306 \times 10^{6}$ per year. 0.8

Based on reference (24) the estimated plant cost per quad of annual capacity is $\$ 1$ billion in 1978 dollars. Therefore the cost of 36 plants, each with a capacity of 0.0005 quads/per year, is $\$ 18$ million in 1978 dollars. Assuming an average inflation rate of 7 percent, the 36 plants would cost $\$ 21$ million in 1980 dollars. This means that the total annual investment required for both the wells and the plants is $\$ 327$ million and the total investment required over a five year period to install 0.09 quad/year of direct heat utilization is $\$ 1.66$ billion in 1980 dollars. 

1. K.W. Ford, D.L. Hartley, S.M. Berman et al. (edit). Efficient Use of Energy. AIP Conference Proceeding No. 25. (American Institute of Physics, N.Y., 1975).

2. U.S.G.S. - Circular 790.

3. Peterson, Eric A. "Possibilities for Direct Use of Geothermal Energy." ASHRAE Transactions 1979, Vol. 85, Part 1.

4. Neil, D.T., R.C. Schmitt. "Heat Pumps Coupled to Geothermal Resources Can Provide Economical Process Heat." Proceedings, the 4th Annual Heat Pump Technology Conference, Oklahoma State University, Stillwater, April 1979.

5. Blackman, W.A. "A Mathematical Model for Trend Forecasting." Technol. Forecast. Soc. Changes, Vol. 3, 1972, pp. 441-452.

6. Lenz, Ralph C., Jr., and H.W. Lanford. "The Substitution Phenomenan." Business Horizoris, February 1972.

7. Bloomster, C.H. "Resource Avallability Curves for Direct Application of Hydrothermal Resources Based on U.S.G.S. Circular 790." A Letter to Dr. Fred Abe1, DOE/DGE, February 16, 1979.

8. JPL Publication 79 - XX. Geothermal Direct Heat Use; Market Potential/Penetration Analysis for Federal Region IX (Arizona, California, Hawail, Nevada). October 1979.

9. EG\&G Idaho, Inc., Regional Hydrothermal Market Penetration s. Analysis, Rocky Mountain Basin and Range Region, October 1978.

10. The Johns Hopkins Univers1ty. Applied Physics Laboratory, Fact Sheets to Use of Geothermal Energy and Eastern United States, January 1979.

11. Weisbrad, Richard and William Barron. "Economic Evaluation of Low Temperature Geotherma1 Resources: Production Costs and Geographic Distribution of Potential Demand." (The Johns Hopkins University, The Center for Metropolitan Planning and Research, Baltimore, Maryland, 1979).

12. Karkheck, J., E. Beardsworth and J.R. Powe11. "Technical and Economic Aspects of Potential U.S. District Heating Systems." Eleventh Intersociety Energy Conversion Engineering Conference Proceedings, Vo1. II, September 1976. 
REFERENCES (Continued)

13. Reistad, G.H. Analysis of Potential Nonelectrical Applications and Geothernal Energy and Their Place in National Economy, (A Report by Lawrence Livermore Laboratory - UCRL, 5147, 1975.

14. U.S. Department of Commerce, Bureau of the Census, 1972 Census of Manufacturers, VoI. I Subject and Special Statistics, August 1976.

15. Klimister, C.W. "Population in Cities." The Mathematical Gazette, April 1975.

16. U.S. Department of Commerce, Bureau of the Census, County and City Data Book, 1977.

17. Linda1, B. "Industrial and Other Applications of Geothermal Energy." Geothermal Energy - Review of Research and Development (United Nations Education, Scientific and Cultural office, Paris, 1973).

18. Thomas, A.V. Cassel et al. Geothermal Investment and Policy Analysis with Evaluation of California and Utah Resources Areas. A Report Prepared Under Contract for U.S. Department of Energy, October 1979.

19. Fisher, J.C. and R.H. Pry. "A Simple Substitution Model of Technological Change." Technol. Forecast. Soc. Change, Vol. 3, 1971.

20. Floyd, A. "Trend Forecasting: A lethodology for Figure of Merit." First Annual Technology and Management Conference ( $\mathrm{J}$. Bright, Ed), Prentice-Hall, N.J., 1968.

21. Bright, J.R. A Brief Introduction to Technology Forecasting: Concepts and Exercises. The Pemaquid Press, Austin, Texas, 1974.

22. M. Sharif and G. Uddin. "A Procedure for Adopting Technologica1 Forecasting llodels." Technol. Forecast. Soc. Change, Vol. 7, 1976.

23. Progress Monitor - Geoheat Listing on Current Direct Heat Applications, April 7, 1980. 
24. Department of Energy, Division of Geothermal Energy. EG\&G Idaho, Inc., and University of Utah Research Institute Earth laboratory, Regional Hydrothermal Conmercialization Plan, July 1978.

25. Donald R. Pitts and Donald H. Clements. "The Future of Direct Utilization of Geothermal Energy," Direct Utilization of Geothermal Energy: A symposium, San Diego, Ca., 1978

26. National Research Council, Geothermal Resources and Technology in the United States, (1979).

27. Interagency Geothermal Coordinating Council, Geothermal Energy, Research, Development and Demonstration Program, Fourth Annual Report, (June 1980)

28. McDewitt, P.K. and C.R. Rao. The District Space Heating Potential of Low Temperature Hydrothermal Geothermal Resources in the Southwestern United States, (New Mexico State University Dept. of Economics, Albuquerque, New Mexico), 1978.

29. Facca, G. "The Structure and Behavior of Geothermal Fields." Geothermal Energy: Review of Research and Development (UNESCO, Paris, 1973).

30. Howard, J.H. (ed.). Present Status and Future Prospects for Non-electric Uses to Geothermal Resources. (UCRL, S1926) Dctober 1975.

31. Nahen, L.W. and F. Kreith. A Preliminary Feasibility Study of Utilizing Low Temperature Geothermal Sources in Colorado. (University of Colorado, Boulder, Colorado, 1976).

32. Cone, Bruce $W$. An Economic Analysis of Potential Uses of Geothermal Energy in Agriculture. (Pacific Northwest Laboratory, Battle Memorial Institute), 1978.

33. Hewett, L. A Survey of Available Market Penetration Methodologies Showing Utility in Addressing Solar Energy Market Penetration Problems. (The MITRE Corporation) WP-11831, 1976.

34. Forrester, J. Industrial Dynamics. (The M.I.T. Press), 1961.

35. Manne, Alan S. et al. "Energy Policy Modeling: A Survey. "Operations Research, Vol. 27, No. 7, January - February, 1979. 
36. Goodman, Allan C. Geothermal Energy Market Penetration: Deve1opment of a Model for the Residential Sector. (The Johns Hopkins University), 1979.

37. Rariffa, H. Decision Analysis: Introductory Lectures on Choices Under Uncertainty. (Addison Wesley, llenlo Park, CA), 1968.

38. Mansfield, E. "Technical Change and the Rate of Limitation." Economitrica, Vol. 29, No. 4, October 1961.

39. The Aerospace Corporation, Solar Thermal Dispensed Power Program: Total Energy Systems Projects, Vol. II Energy Use and Price Forecasts. (Final Technical Summary Report, Prepared for The Aerospace Corporation by Sherman H. Clark Associates, Menlo Park, Ca., 31 March 1978).

40. Marchetti, C. "Multicompetition and the Diffusion of New Technology in the Energy Systems," Meeting on R\&D, Management and Research Policy, International Institnoe fur Management und Verwaltung, Berlin, December 1978.

41. Harold A. Linstone, Deventra Sachol, ed., Technological Substitution: Forecasting Techniques and Applications (E1sevier, N.Y., 1976).

42. M. Nawaz Sharif and Chowdhury Kakir. "A Generalized Model for Forecasting Technological Substitution." Tech. Forecasting and Soc. Change, Vol. 18, No. 4, 1976. 

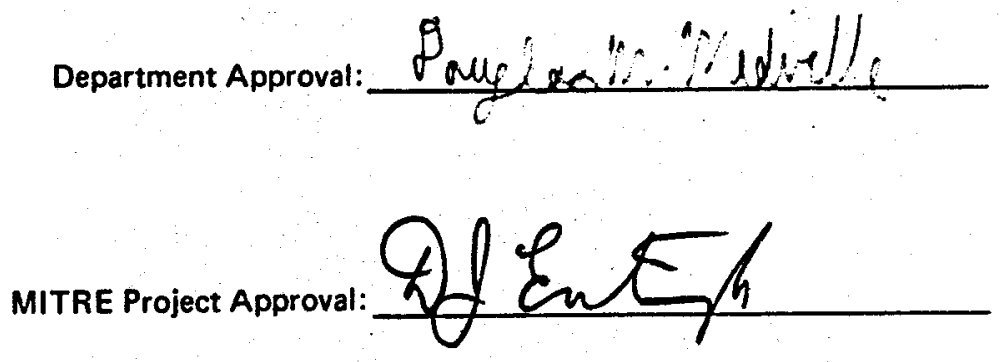